\title{
Non-Metal and Enzymatic Catalysts for Hydroperoxide Oxidation of Organic Compounds
}

\author{
Jacek Młochowski*, Wanda Peczyńska-Czoch, Magdalena Piętka-Ottlik and \\ Halina Wójtowicz-Młochowska
}

Faculty of Chemistry, Wroclaw University of Technology, Wroclaw 50-370, Poland

\begin{abstract}
Oxidation of different groups of organic compounds, with hydroperoxides catalyzed by non-heavy metal containing low-molecular-weight compounds and enzymes is reviewed. This article is concentrated mainly on the hydrogen peroxide and tert-butyl hydroperoxide, however other less common hydroperoxides are also mentioned. Since hydroperoxides themselves are inactive toward most of the organic substrates, in situ activation of the oxidant is necessary. For this purpose various activators have been applied in stoichiometric or catalytic amounts. The carboxylic acids, nitriles, amides and urea are representative for the first category. The organocatalysts such as $\alpha$-halo carbonyl compounds, ketones, imines, iminium salts, nitroxyl radicals and polyaminoacids, selenium compounds and enzymes are presented. They are involved in oxygen, and electron transfer processes whose mechanisms are briefly discussed, and their applications in laboratory and industrial synthesis are indicated.
\end{abstract}

Keywords: Oxidation, hydrogen peroxide, tert-butyl hydroperoxide, catalysts, enzymes.

\section{INTRODUCTION}

Oxidation reactions are basic processes widely applied in organic synthesis both in research and industry. Among the oxidants, the hydroperoxides have a prominent position. Among them, hydrogen peroxide (1) and $t$-butyl hydroperoxide (TBHP) (2) are commonly used [1-10]. Both of them are relatively stable, easy to store, commercially available, relatively cheap reagents of low molecular weight which can be used for both laboratory and industrial purposes. They contain relatively high amounts of active oxygen $\left(\mathrm{H}_{2} \mathrm{O}_{2}-\right.$ $47 \%$ and TBHP - $17.8 \%$ weight), and are environmentally friendly since water which is easy to recover from the reaction mixture, $t$-butanol, are the products of their reduction. Hydrogen peroxide is supplied mainly as a $30 \%$ aqueous solution and TBHP as a $70 \%$ aqueous solution or 5.0-6.0M solution in decane or nonane.

Although several other hydroperoxides are known, they are less common oxidation agents mainly because most of them are not commercially available, their stability is low and they are hazardous substances which can explode during preparation or storage. Nevertheless, some of them, presented in Scheme 1, have been employed in organic synthesis as the oxygen source. They are represented by cumyl hydroperoxide (3) [11], perhydrates 4 also called $\alpha$-hydroxy hydroperoxides derived from strongly electron-deficient aldehydes or ketones [12] (e.g. 2-hydroperoxyhexafluoro-2propanol $\left(4, \mathrm{R}^{1}=\mathrm{R}^{2}=\mathrm{CF}_{3}\right)$, 5-hydroperoxycarbonylphthalimide (5) [13], hydroperoxyflavines (6), related systems, and $\alpha$-azo hydroperoxides (e.g. 7) [14]. Concerned with the poor stability of hydroperoxyflavines and $\alpha$-azo

*Address correspondence to this author at the Faculty of Chemistry, Wroclaw University of Technology, Wroclaw 50-370, Poland; Tel: +48713202419; Fax: +48713284064; E-mail: mlochowskijacek@gmail.com hydroperoxides and their explosive nature a series of $\mathrm{N}$ substituted 3-hydroperoxyindolin-2-ones (8) were synthesized as stable alternatives and used as the reagents $[15,16]$. Their less stable simpler analogs - hydroperoxypyrrolidones were also obtained and investigated [17, 18]. Sugar hydroperoxides (e.g. 9) have also attracted some interest in recent years because they have a potentially good chance of applicability in stereoselective oxygen-transfer reactions since they are inherently chiral. They were synthesized and subsequently applied in the base-mediated asymmetric epoxidation of electron-deficient substrates without transition-metal catalysts [19-21].

The usual oxidation catalyst contains a transition metal which activates hydroperoxides for the oxyfunctionalization. The broad spectrum of applications of metal catalysts for hydrogen peroxide and TBHP oxidation have been reviewed elsewhere e.g. in [2-6, 22-25]. Such catalyst must withstand hostile oxidizing conditions, which may curtail the catalytic activity due to oxidative degradation of the metal complexes. Alternatively, one may perceive the use of organocatalysts the oxidatively resistant organic substances, which mediate catalytic homogenous oxidations without the need of metal complexes. The advantages of the non-metal catalysts include their availability, low cost and low toxicity, which confers huge direct benefits in the production of pharmaceuticals, animal health products, agrochemicals, fragrances and fine chemicals when compared with transition metal catalysts.

Until recently, the catalysts employed for oxidation of organic substrates fell almost exclusively into two general categories: transition metal salts and their oxoacid compounds or complexes and enzymes. More recently a third general approach to the catalytic oxidative transformation has emerged organocatalysis and numerous reactions have been noted. The most prominent catalysts 


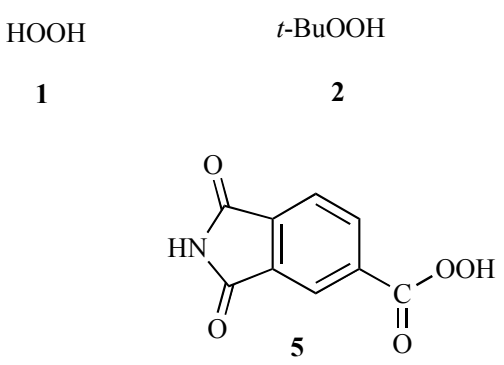

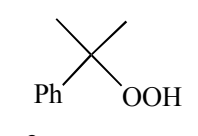

3<smiles>CCN1c2cc(C)c(C)cc2N(C)C2=NC(=O)NC(=O)C21OO</smiles>

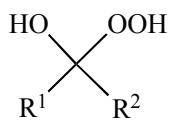

4

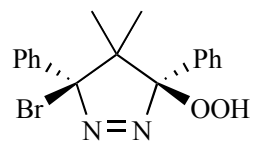

7

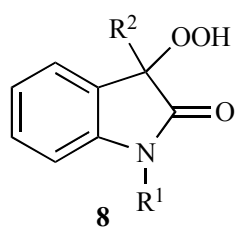

Scheme 1. Hydrogen peroxide and organic hydroperoxides.

have been some carboxylic acids, the perfluoro ketones, imines, polyaminoacids, nitrogen and selenium containing heterocyclic compounds and diaryldiselenides $[5,12,14,26$, 27]. The alternative group is biocatalysts - the enzymes. Although most of them contain metal atom in the active site, their advantages are high turnover number and high chemo-, and stereoselectivity. The enzymeloxygen source ratio is several orders lower than when classical catalyst is used. When they are used as oxidation catalysts, the reactions are environmentaly friendly and proceed in aqueous medium under very mild conditions [28-30].

The aim of this review is to highlight efforts made for application of different non transition metal-containing activators and catalysts or enzymes for hydroperoxide oxidation of different groups of organic compounds. The literature survey is up to 2009 . We would like to apologize to anyone who finds our description of her or his work inadequate or whose work has been omitted.

\section{HYDROPEROXIDE OXIDATION VIA ELECTRO- PHILIC OR NUCLEOPHILIC OXYGEN INTERMEDI- ATES}

\subsection{Hydroperoxides in Alkaline Media}

Hydrogen peroxide and TBHP themselves are slow oxidants in the absence of an activator due to the poor leaving tendency of the hydroxide or alkoxide ion and their use without an activator or catalyst is very limited [3-5].

It is well known that the oxygen-donation capacity of hydroperoxides (including peroxyacids) relates inversely to the $\mathrm{pK}_{\mathrm{a}}$ of the leaving group, i.e., on the ability of $\mathrm{RO}^{-}$to stabilize the negative charge, which is equivalent to its thermodynamic stability.

In alkaline medium, hydroperoxides act as nucleophiles, because formed peroxide anion $\mathrm{ROO}^{-}$can react with electron-deficient substrates. The nucleophilic addition by a Michael - type mechanism (illustrated in Scheme 2) involving an attack of hydroperoxide anion on the electrophilic carbon atom in $\alpha, \beta$-unsaturated carbonyl compound $\mathbf{1 0}$ is an example. The subsequent ring closure of the intermediate 11 gives the epoxide 12 [31]. Oxidation, in an inert solvent of a non-aromatic or non-enonic ethylenic bond or of a non-conjugated cyclic ketones in the presence of alkali or alkali metal salts or complex, resulted in epoxide or lactone [32].

Mildly basic conditions $\left(\mathrm{NaHCO}_{3}\right)$ have also been used to epoxide alkenes. When substrates are water insoluble, aqueous $\mathrm{MeCN}$ is a suitable medium [33]. A very similar system is useful for oxidative cleavage of organostannates containing a perfluoroalkyl group to furnish alcohols [34]. $\alpha$ Formylpyrroles yield 2-pyrrolinones [35]. Amines react with alkaline $\mathrm{H}_{2} \mathrm{O}_{2}$ and carbon disulfide to deliver isothiocyanates in $84-95 \%$ yield [36]. Epoxidations of enones with $\mathrm{H}_{2} \mathrm{O}_{2}$ can be catalyzed under mild conditions with a new strongly basic porous catalyst obtained by immobilization of the guanidine base (1,5,7-triazabicyclo[4.4.0]dec-5-ene) on silica support MCM-41 [37].

Under the mildly basic conditions aryl 1-imidazoyl sulfones and 1-(arenesulfonimidoyl)imidazoles are useful
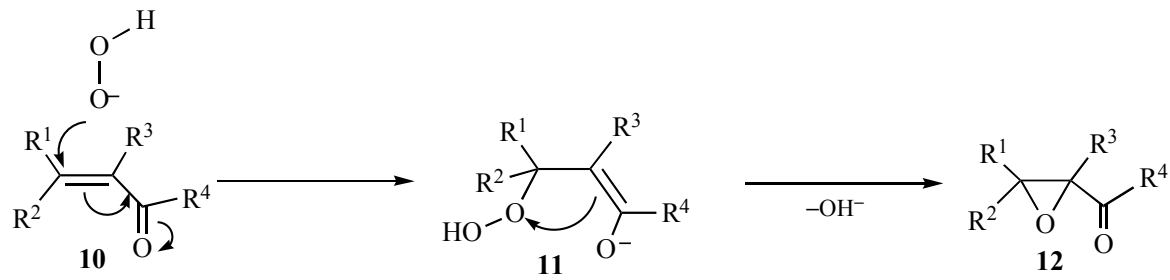

Scheme 2. Epoxidation of electrophilic olefine with alkaline hydrogen peroxide. 
chiral activators of $\mathrm{H}_{2} \mathrm{O}_{2}$ for diastereoselective epoxidation of olefins, allylic and homoallylic alcohols, and $\alpha, \beta-$ unsaturated ketones [38,39].

Alkaline hydrogen peroxide is also a convenient reagent for the hydrolysis of nitriles to amides. A number of aromatic and vinylic nitriles were converted under phasetransfer conditions into corresponding amides in high to excellent yields [40].

The reaction of $\mathrm{HOO}^{-}$ion with nitriles under controlled $\mathrm{pH}$ conditions $(\mathrm{pH} \approx 8)$ generated short-lived peroxyimidate anions 13 derived from imidoperoxoic acids 14 (Scheme 3) [41-44]. These reagents are specially useful for epoxidation when the substrate or oxidized product is sensitive to acidic conditions. Moreover, this oxidation has the advantage of being useful on both a large and small scale. For example (Z)-cyclooctene was oxidized in this way in $60 \%$ yield [45]. Although benzeneimidoperoxoic acid seems to be an excellent oxidant (Payne reaction), acetonitrile has some advantages over benzonitrile in terms of costs. In addition, it is often easier to remove acetamide rather than benzamide as a by-product [46]. Methaneimidoperoxoic acid, formed in situ from acetonitrile, and hydrogen peroxide oxidize sulfides to sulfoxides and sulfones in excellent yields, depending on the amount of the oxidant used [47]. When $\mathrm{N}, \mathrm{N}$-dimethylhydrazones $\mathbf{1 5}$ were oxidized with hydrogen peroxide in alkaline acetonitrile, depending on the substrate, nitrile $\mathbf{1 6}$ and/or amide $\mathbf{1 7}$ accompanied with carboxylic acid 18 and parent carbonyl compounds 19 were obtained [48].

The oxidation of pyridines using a combined oxidant of hydrogen peroxide and benzonitrile catalyzed by a basic hydrotalcite, $\mathrm{Mg}_{10} \mathrm{Al}_{2}(\mathrm{OH})_{24} \mathrm{CO}_{3}$ gave high yields of the corresponding pyridine $N$-oxides [49]. The hydroboration reaction, with subsequent oxidation by alkaline hydrogen peroxide, provides a convenient method for the cis-antiMarkovnikov hydration of alkenes from a less hindered site. The oxidation occurs with the total retention of configuration, placing the hydroxyl group in the position occupied by the boron atom in the initial organoborane. The reaction proceeds under mild conditions, with no rearrangements of the carbon skeleton [50].

Alkaline hydrogen peroxide is a mild and effective oxidant for the cleavage of $\alpha$-ketols and corresponding ketones, and carboxylic acids are produced. This reagent is inactive to 1,2diols, contrary to the case with periodic acid or lead(IV) acetate, and hence may cleave $\alpha$-ketols selectively in the presence of 1,2-dihydroxy group [51]. Oximes treated with alkaline hydrogen peroxide are converted in to the corresponding carbonyl compounds [52] and aromatic aldehydes or ketones undergo conversion to phenols (the
Dakin reaction) [53]. $\mathrm{N}$-Alkylquinolinium salts $\mathbf{2 0}$ are easily cleaved using alkaline hydrogen peroxide to give 2formylanilines 21 and 22 in 33-37\% yield (Scheme 4) [54].

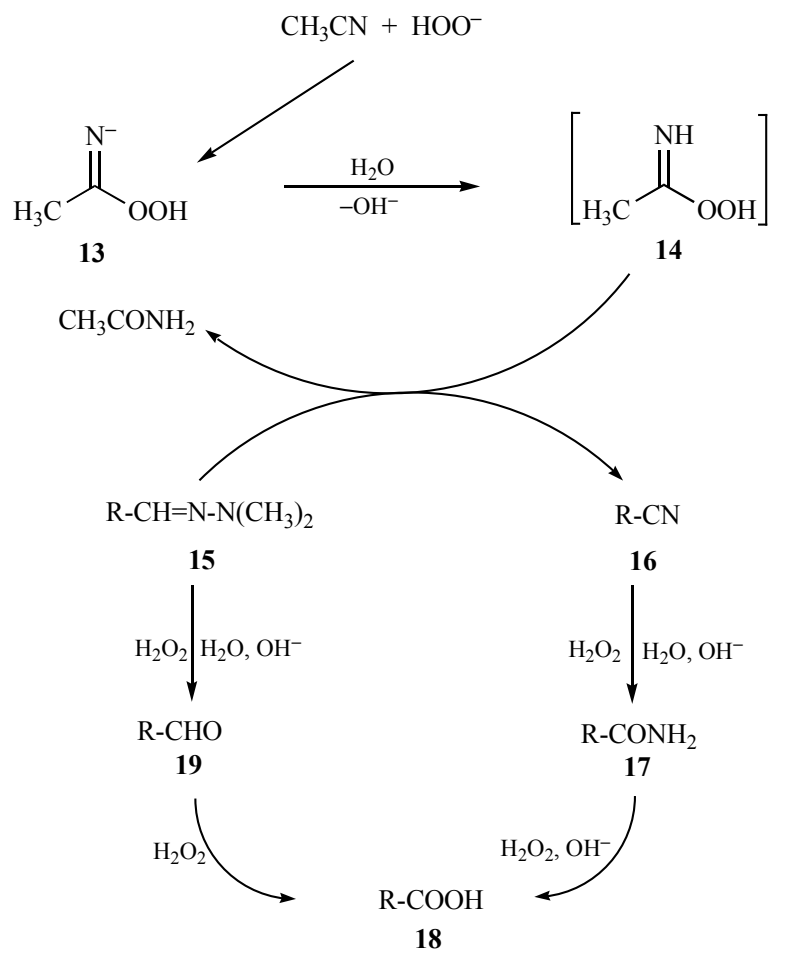

Scheme 3. Oxidation of $N, N$-dimethylhydrazones with alkaline hydrogen peroxide-acetonitrile.

In the bicarbonate-activated peroxide (BAP) system, the active oxidant formed from hydrogen peroxide and carbonate ion is a shortly living peroxymonocarbonate ion with $\left(t_{1 / 2}=5\right.$ min) and structure $\mathrm{HOOCO}_{2}$. The reagent was used for oxidation of sufides, cysteine and related thiols as well as for efficient epoxidation of water-soluble alkenes (e.g. methylvinyl ketone) while competitive diol formation is avoided [55-60].

TBHP under basic conditions can add, like to hydrogen peroxide, to a double bond that has an electron withdrawing group attached and $t$-butyl peroxides are produced. With acid chlorides in basic media, TBHP acts as a nucleophile, and with acid chlorides give appropriate $t$-butyl peroxy esters [61-64], while epoxides are transformed into $\beta$ hydroxydialkyl peroxides [65]. TBHP, and other organic hydroperoxides, in the presence of strong bases, react with aromatic nitro compound via vicarious nucleophilic substitution of hydrogen to form substituted $o$ - and $p$ nitrophenols [66-68].<smiles></smiles><smiles>C=CCC(=O)OCCO[Mg]</smiles><smiles></smiles>

Scheme 4. Oxidative conversion of alkylquinolinium salts into 2-formylanilines. 


\subsection{Hydroperoxides in Acidic Media}

Relatively strong carboxylic acids such as formic, succinic and trifluoroacetic react with hydrogen peroxide. Substitution of the hydroxyl group with the hydroperoxide group rapidly leads to an equilibrium concentration of the corresponding peroxycarboxylic acids $\mathrm{RC}(\mathrm{O}) \mathrm{OOH}$ (eg. peroxyacetic acid $\mathrm{R}=\mathrm{CH}_{3}$ ). Addition of strong mineral acid, in catalytic amount accelerates this process. For preparative purposes carboxylic acid can be used both in stoichiometric or catalytical amounts.

Peroxycarboxylic acids oxidize simple alkenes, alkenes carrying a variety of functional groups (such as ethers, alcohols, esters, ketones and amides), some aromatic compounds, furans and $\mathrm{N}$-azaheterocycles, sulfides and amines. Ketones and aldehydes undergo oxygen insertion reaction (Baeyer-Villiger oxidation) [69, 70]. Peroxyacetic acid was applied for $\mathrm{N}$-oxidation of tertiary amines and the pyridine-like heteroaromatic nitrogen atom [71]. The reaction proceeded in high temperature. Under less severe reaction conditions more reactive groups could be oxidized while $N$-oxidation does not occurs [72].

Phenothiazine sulfones and 4H-1,4-benzothiazine sulfones were prepared by oxidation of the corresponding benzothiazines and phenothiazines with $30 \%$ hydrogen peroxide in glacial acetic acid [73]. The same reagent was used for the oxidation of phenanthrene to diphenic acid [69]. The method for a large-scale production of 2-methyl-1,4naphthoquinone (menadione, vitamin K3) through the oxidation of 2-methylnaphthalene is based on using hydrogen peroxide in carboxylic acids or their anhydrides and a strong mineral acid as a catalyst for the formation of the peroxycarboxylic acid $[74,75]$.

Hydrogen peroxide coordinates the proton of protic acids ( $\mathrm{HF}, \mathrm{HCl}, \mathrm{HBr}$ ) and $\mathrm{HO}^{+}$cations are produced. The Lewis acids $\left(\mathrm{AlCl}_{3}, \mathrm{BF}_{3}, \mathrm{FSO}_{3} \mathrm{H} \cdot \mathrm{SO}_{2} \mathrm{ClF}, \mathrm{FSO}_{3} \mathrm{H} \cdot \mathrm{SbF}_{5} \cdot \mathrm{SO}_{2} \mathrm{ClF}\right)$ can catalyse oxidation reactions by forming acid-base adducts either with the substrate or with hydroperoxide, enhancing their reactivity and thereby acting as catalysts for the oxidation. These highly electrophilic species are bound to nucleophilic centers of substrate molecules resulting in hydroxylation. In this way, low to moderate yields of phenols can be obtained by the treatment of arenes having electron-donating substituents. Benzylic alcohols are oxidized to aldehydes and thioacetals or thioketals can be deprotected to parent carbonyl compounds. The BaeyerVilliger oxidation of ketones to esters was also accomplished [76-78]. In the latter reaction acylarenes were readily converted to phenols with $\mathrm{H}_{2} \mathrm{O}_{2}$-boric acid [79]. When secondary alcohols were oxidized to ketones with hydrogen peroxide in the presence of $20 \% \mathrm{HBr}$ as an acid catalyst no subsequent Bayer-Villiger oxidation to esters took place [80].

Peroxy groups may replace alcohols, ethers or sulfates directly or can be added to an alkene (with Markovnikov regioselectivity) by reacting an organic compound with TBHP in acetic acid, in the presence of sulfuric acid. The same oxidant reacts with ketones or aldehydes in the presence of strong acid catalyst (e.g. $\mathrm{HCl}$ ), to give a product with two $t$-BuOO groups in place of carbonyl group [3]. By an acid-catalyzed reaction with TBHP, acetal and enol ethers give the gem-bisperoxides [81]. The similar recation of acetals with hydrogen peroxide, catalyzed by boron trifluoride etherate and boron trifluoride-methanol at room temperature, yields gem-bishydroperoxides $\mathrm{R}_{2} \mathrm{C}(\mathrm{OOH})_{2}$ in various $9-95 \%$ yields [82]. Other gem-bishydroperoxides are formed when cyclic benzylic alcohols are treated with $50 \%$ $\mathrm{H}_{2} \mathrm{O}_{2}$ in the presence of sulfuric acid [83]. Furfuryl hydroperoxides 24 and 6-hydroperoxy-2H-pyran-3(6H)-one 25, which are valuable regenerable oxygen donors in enantioselective sulfoxidations, are readily prepared from the corresponding 2-furyl alcohols $\mathbf{2 3}$ in the reaction catalyzed with $p$-toluenesulfonic acid (PTSA) (Scheme 5) [84].

Esters are formed when aldehydes or acetals are oxidized in an alcoholic solvent with $\mathrm{H}_{2} \mathrm{O}_{2}$ and aqueous $\mathrm{HCl}$ [85]. 3Hydroperoxydioxolanes are synthesized from the corresponding 3-hydroxyderivatives using $\mathrm{H}_{2} \mathrm{O}_{2}$ with catalytic amount of $\mathrm{TsOH}$. These hydroxyperoxides are effective oxygen-transfer reagents to oxidation of amines and sulfides, and to epoxidation [86].

Unlike in conventional solvents, non-strained ketones such as cyclohexanone react smoothly with hydrogen peroxide in 1,1,1,3,3,3-hexafluoro-2-propanol 26 (HFIP) to give lactones. This reaction proceeds via an isolable spirobis-peroxide, which undergoes acid-catalyzed rearrangement of two equivalents of lactone [87]. Epoxidation of alkenes in HFIP is efficiently achieved with aqueous $50 \% \mathrm{H}_{2} \mathrm{O}_{2}$ and benzenearsonic acid $\left(\mathrm{PhAsO}_{3} \mathrm{H}_{2}\right)$ as catalyst. For BaeyerVilliger oxidation the more common $\mathrm{TsOH}$ is also useful. The role of catalyst is not clear. Although it has been postulated that benzenearsonic acid acts via active peroxyacid form most probably $\mathrm{TsOH}$ is a protic acid catalyst [88]. Nevertheless, it was also reported that in HFIP epoxidation, Baeyer-Villiger oxidation and selective oxidation of sulfides to sulfoxides proceed efficiently in the absence of catalyst (Scheme 6). In this reaction medium, the strong electron-withdrawing properties of fluorine along with the hydrogen bonding properties of the $\mathrm{O}-\mathrm{H}$, hydrogen atom lead to formation of an electrophically activated hydrogen peroxide intermediate 27. As expected, reactivity is increased as a function of fluorine substitution; (HFIP) is more active than 2,2,2-trifluroethanol (TFE). Alkene epoxidation is also promoted by polyfluoroalkanesulfonyl chloride [89-91].

A new economical and clean route for synthesis of 1,2diols is based on the dihydroxylation of alkenes with $30 \%$ $\mathrm{H}_{2} \mathrm{O}_{2}$ in the presence of resin supported sulfonic acid under metal free conditions without any organic solvent. The

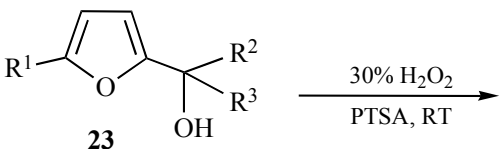

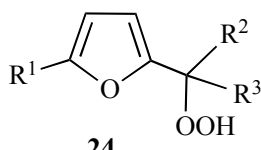

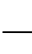

$\mathrm{H}_{2} \mathrm{O}$

PTSA

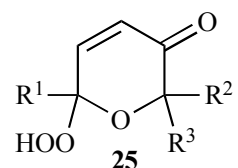

Scheme 5. Acid catalyzed hydrogen peroxide oxidation of 2-furyl alcohols. 


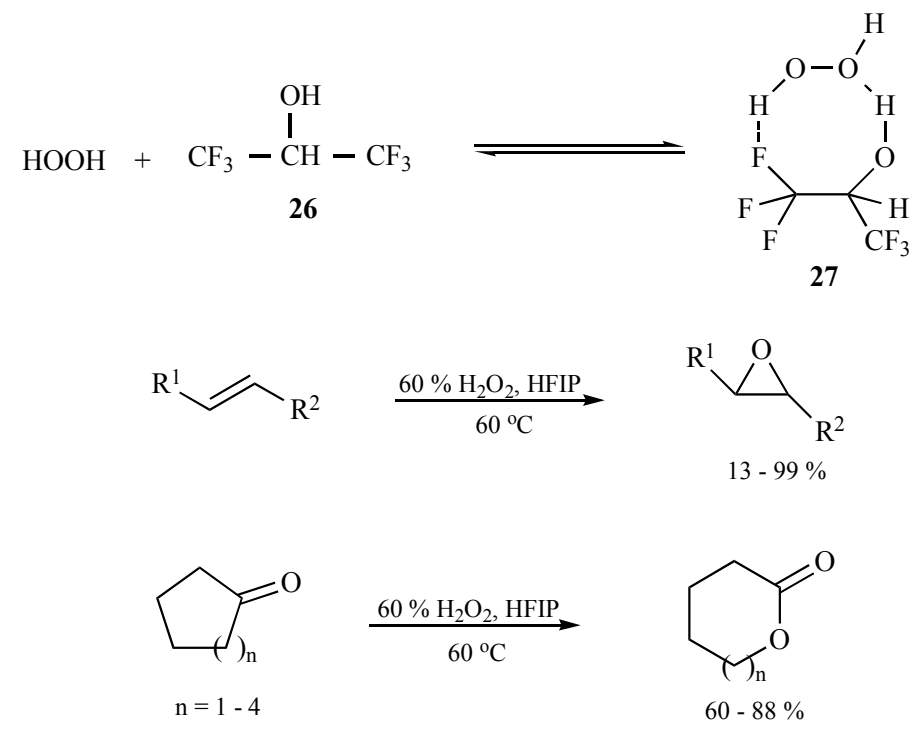

Scheme 6. Hydrogen peroxide epoxidation of alkenes and Bayer-Villiger oxidation of ketones in 1,1,1,3,3,3-hexafluoro-2-propanol (HFIP).

catalyst can be recycled easily and is effective for the last 10 cycles [92].

Fast oxidation of organic sulfides by hydrogen peroxide by in situ generated peroxynitrous acid, was reported. Under the optimized conditions $\mathrm{NaNO}_{2}$ acts as a catalyst in the form of $\mathrm{ONOOH}$, quickly carrying the oxygen from hydrogen peroxide to the sulfide [93].

\section{HYDROGEN PEROXIDE-UREA}

The hydrogen peroxide forms the adduct with urea $\mathrm{CO}\left(\mathrm{NH}_{2}\right)_{2} \cdot \mathrm{H}_{2} \mathrm{O}_{2}$ (UHP), also called percarbamide. It is a non-toxic, odorless crystalline solid, which has a high proportion of hydrogen peroxide (36 mass \%) with the active oxygen content of 17.02 mass \%. It is commonly used, commercially available reagent for safe oxidation of different organic substrates. Although, it is more active than hydrogen peroxide itself, in some reactions the catalysts had to be used [94].

In the last years, several reports appeared on use of UHP in oxidations of various organic substrates. Some of them concerned the conversion of amines into nitroalkanes, Baeyer-Villiger oxidation of ketones to lactones, oxidation of sulfides to sulfoxides or sulfones and conversion of pyridines to $\mathrm{N}$-oxides under heating in solid state [95-98]. In the presence of trifluoroacetic anhydride, it oxidizes electron-deficient pyridines to the $N$-oxides, being less hazardous than hot $\mathrm{H}_{2} \mathrm{O}_{2}-\mathrm{CH}_{3} \mathrm{COOH}$ and more effective than $\mathrm{H}_{2} \mathrm{O}_{2}-\mathrm{MeReO}_{3}$ [99]. This reagent was used, in the presence of maleic anhydride, as a mediator in a simple and convenient method for the oxidation in high yield of some thiols to the corresponding disulfides. Peroxymaleic acid formed in situ from the reaction of UHP with maleic acid anhydride has a key role in this oxidation [100].

The hydrogen peroxide-urea adduct oxidizes aromatic aldehydes to carboxylic acids at room temperature [101] and it was found to be an efficient reagent for the benzylic oxidation of various alkyl arenes under microvawe irradiation in solvent-free conditions [102]. This adduct has also been investigated in epoxidation of olefins, using various fluoroketones as catalysts. With reactive olefins, no catalyst was required. With monosubstituted olefins epoxides were obtained, in high yields, by using catalytic amounts (3-5\%) of perfluorodecan-2-one [103].

Eco-friendly laboratory procedures allow the oxidative iodination of various activated and deactivated arenes with UHP [104,105] and the same reagent was successfully used for the direct synthesis of hypervalent [bis(trifluoroacetoxy) iodo]arenes avoiding the use of hazardous reagents with the workup being only an aqueous extraction [105].

\section{HYDROPEROXIDES AS INTERMEDIATES}

\subsection{Perhydrates}

Perhydrates ( $\alpha$-hydroxy hydroperoxides ), are mainly obtained by the addition of hydrogen peroxide to an aldehyde or a ketone. Most of such perhydrates do not persist isolation and revert to the carbonyl precursor and hydrogen peroxide. Presumably, intramolecular hydrogen bonding is responsible for the persistence of the functionalized perhydrates [12]. That the perhydrate of hexafluoroacetone $\left(4, \mathrm{R}^{1}=\mathrm{R}^{2}=\mathrm{CF}_{3}\right)$ may be isolated as such is not overly surprising, when it is realized that the corresponding hydrate requires distillation from $\mathrm{P}_{2} \mathrm{O}_{5}$ to release the ketone [106].

The catalytic cycle for perhydrate-mediated oxygen transfer is shown in Scheme 7. The process is initiated with the ketone $\mathbf{2 8}$ and hydrogen peroxide by exchange of the hydroxy for the required hydroperoxy group to give the perhydrate oxidant $\mathbf{4}$ under catalytic conditions. Subsequently, the perhydrate transfers an oxygen atom to the substrate to afford the desired oxidation product and it is regenerated by the action of the started ketone or its hydrate.

The perhydrate $4\left(\mathrm{R}^{1}=\mathrm{R}^{2}=\mathrm{CF}_{3}\right)$, the strongly electrophilic oxidant, generated in situ by the treatment of hexafluoroacetone with hydrogen peroxide, efficiently oxidizes unactivated olefins to epoxides, ketones are converted to esters and aldehydes to carboxylic acids [106108]. Phenol, resorcinol, and anisole may be hydroxylated, 
but under more severe conditions, phenol and alkyl-activated and polynuclear arenes may be oxidized completely to the respective quinones $[109,110]$. Perhydrate $4\left(\mathrm{R}^{1}=\mathrm{R}^{2}=\mathrm{CF}_{3}\right)$ also efficiently transfers oxygen to heteroatom substrates such as sulfides, which may be selectively and quantitatively oxidized to the corresponding sulfoxides or sulfones by employing either 1 or 2 equiv of $\mathrm{H}_{2} \mathrm{O}_{2}$ as the oxygen source. Tertiary amines are oxidized to their $\mathrm{N}$-oxides in nearly quantitative yields; this oxidation is performed selectively in the presence of $\mathrm{C}=\mathrm{C}$ double bonds [111].

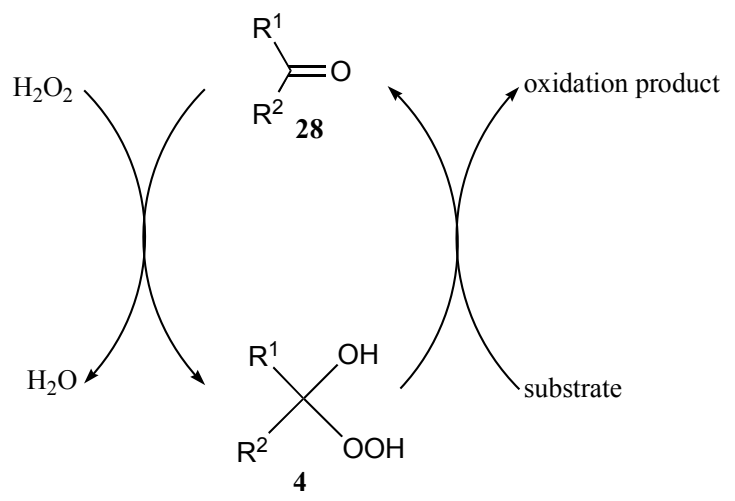

Scheme 7. The catalytic cycle for perhydrate-mediated oxygen transfer.

The high toxicity and volatility of hexafluoroacetone has prevented the wide use of this catalytic system. Using highmolecular-weight perfluoroketone (perfluoroheptadecan-9one) with less volatility, a selective and reusable catalyst for epoxidation with hydrogen peroxide made a suitable improvement [112].

Trichloroacetaldehyde and its hydrate as well as partially chlorinated acetone and chlorofluoroacetone have been employed as catalysts [113, 114]. Hexachloroacetone has been shown to catalyze the hydrogen peroxide epoxidation of a variety of $\mathrm{C}=\mathrm{C}$ bonds in steroidal compounds with a high $\pi$-facial selectivity [115-117]. Differently substituted in benzene ring trichloro-, trifluro- and perfluroacetophenones were also reported as catalysts for hydrogen peroxide oxidadion [118-120]. Trifluoroacetone was used as a catalyst for selective oxidation of organic sulfides to the corresponding sulfoxides, with $35 \%$ hydrogen peroxide in chloroform under very mild conditions [121].

A silica immobilized perfluoroacetophenone is an effective heterogeneous recyclable catalyst for the oxidation of different organic substrates using $60 \%$ aqueous hydrogen peroxide as oxygen donor. The oxidation of pyridine and derivatives to the corresponding $N$-oxides, showed that the catalyst was quite effective for this reaction. The yields were generally high for some representative substrates such as pyridine, 2- and 4-methylpyridine, quinoline, and 4methylquinoline; $\mathrm{N}$-oxides were the only products. Interestingly, 8-hydroxyquinoline was less reactive, presumably because of steric hinderence and the electronpoor 2,6-dichloropyridine was unreactive as expected. Aniline, alkyl-substituted aniline and halogen-substituted aniline derivatives all yielded the dimeric azoxy compounds as sole products in quantitative yields, while aniline with electron donating hydroxyl substitution or electron withdrawing nitro substitution yielded the corresponding nitro derivatives. The perfluoroketone-silicate also exhibited appreciable activity for epoxidation of alkenes although for less electrophilic substrates its activity was low [12].

\subsection{Imine Derived Hydroperoxysulfonyl Amides and Oxaziridines}

The reaction of imines with hydrogen peroxide or more often with monoperoxysulfate affords oxaziridines. These relatively weak electrophilic oxidants only manage to oxidize electron-rich substrates such as enolates, silyl enol ethers, sulfides, selenides, and amines; however, the epoxidation of alkenes has been achieved with activated oxaziridines produced from perfluorinated imines. Most of the oxidations by in situ generated oxaziridines, have been performed stoichiometrically, with the exception of sulfoxidations. When chiral imines are used as catalysts, optically active sulfoxides are obtained in good enantiomeric excess values. Imine-catalyzed oxidations are scarce and essentially limited to sulfoxidation. The catalyst reacts with the oxygen source, usually $\mathrm{KHSO}_{5}$ or $\mathrm{H}_{2} \mathrm{O}_{2}$, to afford the oxaziridine as the catalytic oxidant. The electrophilic oxygen atom of the oxaziridine is transferred to the electron-rich substrate, to give the oxygenated product with the release of the imine; thereby, the catalytic cycle has been completed [12].

The highly efficient asymmetric sulfoxidations mediated by some camphorsulfonylimines such as $\mathbf{2 9}$, using hydrogen peroxide as the oxidant have been suggested to proceed via intermediate $\alpha$-hydroperoxycamphorsulfonyl amides (30). However, some experimental data indicate oxaziridine $\mathbf{3 1}$ as an active oxidant (Scheme 8). Details of the results of these investigations have been sufficiently reviewed in the pertinent literature [122-127].

Several simple imines have also been tested as sulfoxidation catalysts with $\mathrm{H}_{2} \mathrm{O}_{2}$ as the oxygen source. The simple imine $\mathrm{N}$-benzylideneaniline gave poor yields of sulfoxides due to hydrolysis to its amine and carbonyl partner. The use of acetone oxime, cyclohexanone oxime derivatives and $N$-cyclohexylidene-benzenesulfonamide, gave moderate yields of sulfoxides. Among these, the cyclohexanone oxime showed the higher activity and was used under catalytic conditions. The cyclic sulfonylimine derived from saccharin, named 3-tert-butylbenzisothiazole1,1-dioxide, gave much higher yields of sulfoxide under catalytic conditions, but a long reaction time was necessary [128].

\subsection{Hydroperoxyflavines}

The reaction of flavine $32\left(\mathrm{R}^{1}, \mathrm{R}^{2}=\mathrm{Me}\right)$ and related heterocyclic systems with hydrogen peroxide (also with molecular oxygen) affords hydroperoxy derivatives. This reaction plays an important role in enzymatic oxidation. Moreover, the flavine hydroperoxide $33\left(\mathrm{R}^{1}, \mathrm{R}^{2}=\mathrm{Me}\right)$ and related hydroperoxides were used in synthetic practice as stoichiometric reagents [14]. Despite the growing interest in these peroxides organocatalytic oxidations of synthetic importance mediated by flavines were reported only in a few works.

Several sulfides oxidized with hydrogen peroxide with flavine perchlorate $\mathbf{3 2} \cdot \mathrm{HClO}_{4}\left(\mathrm{R}^{1}, \mathrm{R}^{2}=\mathrm{Me}\right)$ as catalyst, gave sulfoxides with excellent yields. For example, from 


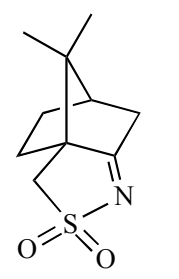

29

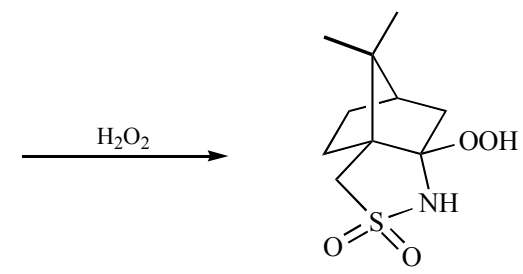

30

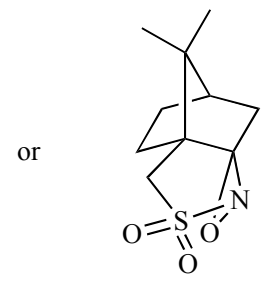

31

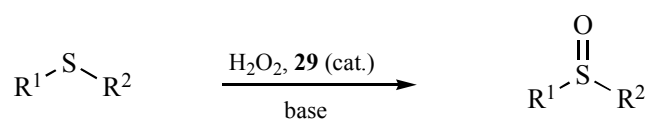

Scheme 8. Hydrogen peroxide oxidation of sulfides catalyzed by camphorsulfonylimines.

dibenzyl-, dibutyl-, and diphenylsulfides, sulfoxides were obtained in $\geq 96 \%$ yields with 1 equiv of $\mathrm{H}_{2} \mathrm{O}_{2}$ and $10 \mathrm{~mol} \%$ of catalyst. Dibenzylsulfoxide treated with 1 equiv of $\mathrm{H}_{2} \mathrm{O}_{2}$ and $10 \mathrm{~mol} \%$ of catalyst, gave dibenzylsulfone in $98 \%$ yield [129]. The biomimetic oxidation of nicotine with hydrogen peroxide in the presence of 5-ethylflavin mononucleotide perchlorate, gave the nicotine- $N$-oxide [130].

Chemoselective oxidation of a series of sulfides to their sulfoxides and oxidation of tertiary amines (but not heterocyclic pyridine-like systems) to amine oxides by $30 \%$ $\mathrm{H}_{2} \mathrm{O}_{2}$ using the neutral 1,5-dihydroalloxazine $\left(32 ; \mathrm{R}^{1}, \mathrm{R}^{2}=\mathrm{H}\right)$ as the catalyst, has been described. Under this catalytic system selective sulfoxidation of thioethers in the presence of many potentially reactive electron-rich functional groups was achieved, while further oxidation to sulfones did not occur even when a large excess of $\mathrm{H}_{2} \mathrm{O}_{2}$ was used over a prolonged reaction time [131-133].
Accordingly to the proposed sequence of reactions, presented in Scheme 9, the catalyst (for example alloxazine $32\left(\mathrm{R}^{1}, \mathrm{R}^{2}=\mathrm{H}\right)$ reacts with hydrogen peroxide for conversion to the active oxidant hydroperoxide $33\left(\mathrm{R}^{1}, \mathrm{R}^{2}=\mathrm{H}\right)$. The hydroperoxide reacts with the nucleophiles (sulfides or amines), to give the oxidation product and the intermediate 34, that is subsequently converted into salt $\mathbf{3 5}$ and finally oxidized to hydroperoxide 33.

By using the flavinium salt and $\mathrm{H}_{2} \mathrm{O}_{2}$ as the oxygen source different ketones were converted to the expected lactones in good yields under mild conditions. An interesting feature of this system is that under appropriate reaction conditions, the double bond and the alkoxy group are tolerated. Thus, the reaction is both chemo- and regioselective [14, 134].

In the presence of catalyst 36, 3-arylcyclobutanones 37 were converted in Baeyer-Villiger reaction to lactones 38 with up to $74 \%$ ee, using $30 \% \mathrm{H}_{2} \mathrm{O}_{2}$ as the oxygen source<smiles>[R]c1cc2c(cc1[R])N(CC)c1c(n(C)c(=O)n(C)c1=O)N2</smiles><smiles>[R]c1cc2nc3c(c(=O)n(C)c(=O)n3C)c(=O)[n+](CC)c2cc1[R]</smiles>

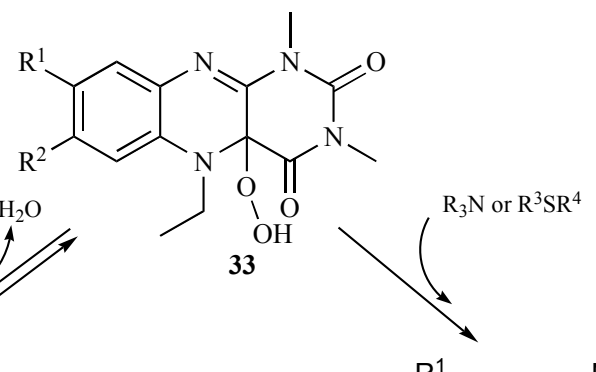<smiles>[R]c1cc2c(cc1[R])N(CC)C1(OCC)C(=O)N(C)C(=O)N(C)C1=N2</smiles><smiles>[R]C/C=C/N=CN(C)C=O</smiles><smiles>[Z]CN1c2cc([R4])c(C)cc2N=C2NC(=O)N(C)C(=O)C21O</smiles>

34

Scheme 9. The mechanism of hydrogen peroxide oxidation of sulfides and amines catalyzed by 1,5-dihydroalloxazine. 
<smiles>CCN1c2ccccc2N(C2N=C3C(=O)N(C)C(=O)N[C@@H]3[C@@H]3CCC[C@H]23)c2ccccc21</smiles>

36

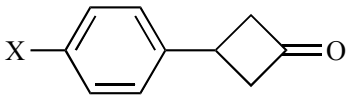

$37 \quad \mathrm{X}=\mathrm{H}, \mathrm{MeO}, \mathrm{F}$
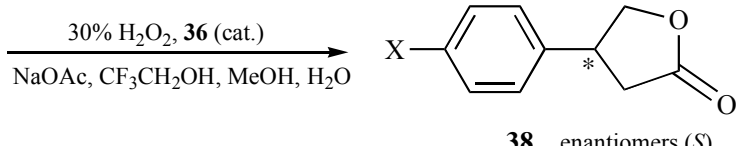

$61-78 \%$

Scheme 10. The stereoselective lactonization of cyclic ketones using $\mathrm{H}_{2} \mathrm{O}_{2} / \mathbf{3 6}$ system.

(Scheme 10). In this case, the flavinhydroperoxide formed in situ, is thought to play a dual role as the nucleophile and as the chiral catalyst responsible for asymmetric induction into the products $[14,135]$.

\section{AMINO ACIDS AND POLYAMINO ACIDS}

The common amino acids such as L-proline, L-leucine, L-phenylalanine and $N$-benzylproline are efficient catalysts for hydrogen peroxide oxidation of sulfides. The most efficient catalyst was L-proline. The conversion of substrate was almost quantitative and sulfoxide:sulfone ratio was 97:3. Unfortunately, a very low enantioselectivity ( $4.0 \%$ ee) was observed in the case of thioanisole. The experiments strongly suggest, that hydrogen bonding between the carboxylic group of L-proline and $\mathrm{H}_{2} \mathrm{O}_{2}$ plays a major role in this transformation. When the reactions were carried out with $t$ butyl hydrogen peroxide (TBHP), a mixture of sulfoxides and sulfones was formed [136].

Over a series of papers the group of Juliá and Colonna investigated the method for the catalyzed by poly-L-alanine (39) or poly-L-leucine (40) hydrogen peroxide oxidation of chalcones (41) and simple analogues to epoxides (42) under triphasic reaction conditions (Scheme 11). The catalyst may be readily separated from the reaction products, washed and reused. However, reuse of the catalyst frequently gave reduced enantioselectivity, a phenomenon ascribed to degradation of the catalyst under the strongly basic reaction conditions. A limitation of this methodology is the length of the reaction; even relatively reactive substrates such as chalcone and simple derivatives require $24 \mathrm{~h}$ for complete conversion. Less reactive substrates either generate products in low yield and enantiomeric excess or fail to form any epoxide. In particular, enolisable chalcones are poor substrates [137-143].

The biphasic procedure that reduces reaction times for chalcone to under 30 minutes, has been developed. The peroxide is delivered in the form of an anhydrous complex urea- $\mathrm{H}_{2} \mathrm{O}_{2}$, the inorganic base is replaced with a strong amidine base, 1,8-diazabicyclo[5.4.0] undec-7-ene (DBU) and the reaction is performed in an organic solvent such as THF. Under these conditions enolisable substrates, such as simple alkyl ketones, can be readily epoxidized [143,144]. These biphasic conditions constitute the most widely tested and reliable of the new class of polyamino acid catalysed<smiles>CNC(=O)C(C)NC(C)(C)C</smiles><smiles>[R]C=CC([R])=O</smiles><smiles>CO[N+](C)=O</smiles>

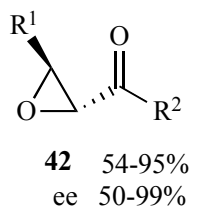

$\mathrm{R}^{1}, \mathrm{R}^{2}$ : aryl, heteroaryl, $\mathrm{PhCO}, t$-BuOH, $t$ - $\mathrm{BuO}_{2} \mathrm{C}, n-\mathrm{Bu}_{3} \mathrm{Sn}$<smiles>C/C(=C\C=C\C(=O)c1ccccc1)C(=O)c1ccccc1</smiles><smiles>C/C(=C\[C@H]1O[C@H]1C(=O)c1ccccc1)C(=O)c1ccccc1</smiles>

Scheme 11. Polyaminoacid catalyzed epoxidation. 
epoxidation systems. Examples reported by Roberts and coworkers typically use polyleucine, however it has recently been disclosed that poly-L-neopentylglycine can offer advantages of increased reaction rate and enantioselectivity [145]. An alternative procedure employs inexpensive sodium percarbonate $(\mathrm{NaPc})$ as both an oxidant and a base. Screening for a range of solvent systems for this oxidant revealed that organic-water mixtures are most effective; in particular DME-water gives rates and enantioselectivities comparable with the urea- $\mathrm{H}_{2} \mathrm{O}_{2} / \mathrm{THF} / \mathrm{DBU}$ system [146].

One further improvement, reported by Roberts and coworkers, is the introduction of a silica-supported polyamino acid catalyst. Polyleucine was stirred as a suspension in THF with a range of solid supports and the properties of the resultant adsorbed materials were investigated. It was found that silica provided the best combination of improved activity and ease of filtration/recycling. Generally the silica-adsorbed material is active enough to allow as little as $2.5 \mathrm{~mol} \%$ catalyst (based on 1 equivalent being a single polyamino acid chain) to be used without any reduction in enantioselectivity $[147,148]$. The polyleucine catalyzed epoxidation shows some interesting selectivity. For example, the diene $\mathbf{4 3}$ is selectively epoxidized on the disubstituted double bond to afford the mono-epoxide $\mathbf{4 4}$ in reasonable yield and good enantiomeric excess [149].

The epoxidation of 2-substituted naphthoquinones with $t$ $\mathrm{BuOOH}$, in an aqueous buffer solution containing a small amount (up to 5 molar\% equiv.) of bovine serum albumin (BSA), gives the corresponding epoxides with enantiomeric excess (ee) up to $100 \%$. The enantioselectivity is very sensitive to the addition of water, miscible or immiscible cosolvents and to the length of the alkyl chain in position 2 [150].

\section{CYCLODEXTRINS}

Asymmetric oxidation of sulfides to sulfoxides catalzsed by $\beta$-cyclodextrins was reported by Drabowicz and Mikolajczyk. The resulting sulfoxides had optical purities of $0.03-30.00 \%$ [151]. The procedure elaborated more recently allows the highly chemoselective formation of sulfoxides from sulfides and sulfones from sulfoxides [152].

The groups of Colonna [153-155] and Takahashi [156] have both reported on the modification of Weitz-Scheffer conditions by the addition of $\beta$-cyclodextrin. Under Colonna, $\mathrm{s}$ optimized conditions, the enantiomeric excesses recorded for the epoxidation of a range of naphthoquinones and chalcone derivatives were below $48 \%$; the highest enantiomeric excess observed by Takahashi and coworkers in the epoxidation of cinnamaldehyde was $2.5 \%$.

$\beta$-Cyclodextrin borate catalyses oxygenation of aryl substituted alkenes with TBHP to afford $\beta$-dioxyalcohols in good yields (63-86\%) [157]. It was shown that 2,2'ditlellurobis(2-deoxy- $\beta$-cyclodextrin), in the presence of structurally distinct hydroperoxides $\left(\mathrm{H}_{2} \mathrm{O}_{2}\right.$, TBHP, cumyl hydroperoxide), acts like the enzyme glutathione peroxidase in thiol oxidation [158].

A series of new $\alpha$-cyclodextrin derivatives were evaluated for their ability to affect amine and alcohol oxidations with hydrogen peroxide. Oxidation of aromatic amines gave corresponding nitrocompounds, or in some cases azo-, azoxy-, or other dimerization products. Oxidative cyclocondensation of 2-aminophenol results in 2aminophenoxazinon-2-one. The catalysis was found to follow enzyme kinetics, giving a rate increase $\left(\mathrm{k}_{\text {cat }} / \mathrm{k}_{\text {uncat }}\right)$ up to 1100 in the best case [159-161].

\section{SELENIUM AND TELLURIUM COMPOUNDS}

\subsection{Selenium(IV) and Tellurium(IV) Oxide}

The first publication on the use of selenium(IV) oxide $\left(\mathrm{SeO}_{2}\right)$ in oxidation reactions appeared in 1932 [162] and since then it has been applied as a versatile reagent for the synthesis of various types of organic compounds [163-167]. Due to its toxicity when taken orally, intense local irritation of skin and eyes, and the sometimes malodors volatile selenium-containing by-products are formed, $\mathrm{SeO}_{2}$ is used in modern synthesis only when it competes favourably well with other methods, provides unique reactivity or when used in catalytic amounts [4,167-171]. Contrary to selenium(IV) oxide, use of the tellurium(IV) oxide as the reagent, has been strongly limited [171]. The TBHP/SeO $\mathrm{Ser}_{2}$ or $\mathrm{H}_{2} \mathrm{O}_{2} / \mathrm{SeO}_{2}$ system is more convenient in use than $\mathrm{SeO}_{2}$ alone, particularly when it is used in catalytic amounts, very often in $5 \mathrm{~mol} \%$. Reaction conditions are much milder and as a result, yields are higher with less oxidation, dehydration, rearrangement of by-products and the problem of the removal of colloidal selenium is circumvented.

Like selenium(IV) oxide alone, the reagent $\mathrm{TBHP} / \mathrm{SeO}_{2}$ oxidizes alkenes, cycloalkenes and alkynes in the allylic position. Hydroxylation of cycloalkenes carrying alkyl substituents at the allylic position takes place preferentially on the ring $\alpha$-carbon atom. Oxidation of terminal alkenes results in $\mathrm{C}=\mathrm{C}$ bond migration and primary allyl alcohols formation. Terminal and non-terminal vinyl fluorides have been hydroxylated regioselectively in the allylic position adjacent to the fluorine bearing carbon [172,173]. $\mathrm{TBHP} / \mathrm{SeO}_{2}$ was used in the allylic hydroxylation of isolated double bonds in straight-chain hydrocarbons, e.g. monounsaturated fatty acids, esters and alcohols. Either allylic position was hydroxylated or both positions reacted, to give dihydroxy isomers. Yields of monohydroxy compounds in which the $\mathrm{OH}$ group was between the double bond and $\mathrm{C}(1)$ were usually higher than those in which the $\mathrm{OH}$ group was between the double bond and the methyl terminus [174-176]. When an $\alpha$-methylene group is oxidized, the reaction proceeds under mild reaction conditions [177-179].

Unlike alkenes, alkynes show a strong tendency to $\alpha, \alpha^{\prime}-$ dihydroxylation upon reaction with $\mathrm{TBHP} / \mathrm{SeO}_{2}$. The oxidation of different acetylenes allowed assignment of the reactivity sequence $\mathrm{CH}_{2}=\mathrm{CH}>\mathrm{CH}_{3}$. Alkynes bearing one methylene and one methine substituent afforded the enynone as the major product. When internal alkynes e.g. 45 were treated with $\mathrm{TBHP} / \mathrm{SeO}_{2}$ in addition to the expected products 46 and 47 , substantial amount of dioxygenated products 48 and 49 were also found (Scheme 12). Considering stereochemical aspects, an interesting difference between $\mathrm{SeO}_{2}$ oxidations of alkenes and alkynes is worth pointing out. In the case of alkenes, the allylic selenic acid intermediate $\mathbf{5 0}$ can in principle give rise to allylic alcohol by a [2,3]-sigmatropic shift to either face of the olefinic bond. This is a consequence of free rotation about $\mathrm{C}(1)$ to 


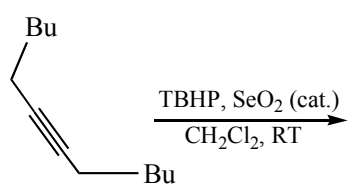

45

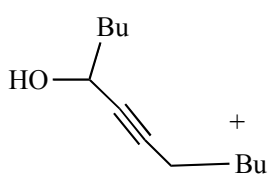

$4621 \%$

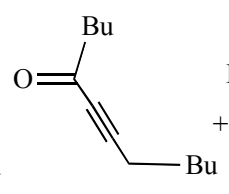

$47 \quad 7 \%$

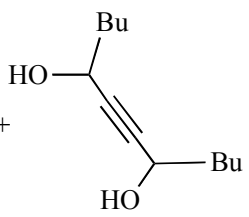

$48 \quad 42 \%$

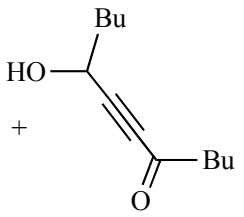

$492 \%$

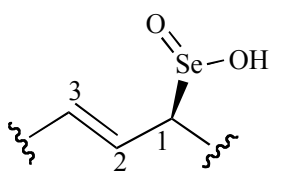

50

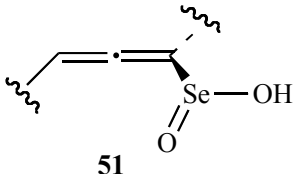

51

Scheme 12. Oxidation of alkyne with $\mathrm{TBHP} / \mathrm{SeO}_{2}$.

$\mathrm{C}(2)$ bond in 50. However, in the case of alkynes, the putative allenic seleninic intermediate $\mathbf{5 1}$ arising from an ene reaction of $\mathrm{SeO}_{2}$ with the alkyne, has a fixed geometry and only one [2,3]-transition state is feasible. Thus, in the case of acetylenes, the stereochemistry of the oxidation product should be determined only by the stereochemistry of the initial ene reaction, which produces the allenic seleninic acid 51 [179].

The TBHP/SeO$/ 2$ has been used to convert alkenes to their corresponding $\alpha, \beta$-unsaturated ketones [180] or aldehydes [181-183]. It was also found to be a highly selective for the oxidation of allylic methyl groups to trans- $\alpha, \beta$-unsaturated aldehydes [184] and it was applied for the synthesis of 1,2,3triones from 1,3-diketones [185]. The urea-hydrogen peroxide, in the presence of catalytic quantities of $\mathrm{SeO}_{2}$ under microwave irradiation has successfully led to the allylic oxidation of alkenes while keeping the other chemical functionalities intact [186]. The TBHP/SeO ${ }_{2}$ reagent allowed the oxidation of activated methyl groups of $\mathrm{N}$-heterocyclic compounds under milder conditions than $\mathrm{SeO}_{2}$ alone without the formation of the over-oxidized carboxylic acids [187]. Claisen rearrangement based on vinyl fluorides took place when 2-fluoroalkenes were treated with $\mathrm{TBHP} / \mathrm{SeO}_{2}$ [188].

A number of alkenes were trans dihydroxylated with $30 \%$ aqueous hydrogen peroxide in the presence of $20 \mathrm{~mol} \%$ of $\mathrm{SeO}_{2}$ at room temperature. The isolated yields of the diols were in a range 55-88\%. Cyclic, acyclic, terminal and internal alkenes were smoothly converted to their corresponding diols and no $\alpha$-hydroxylation or $\alpha$ oxygenation to aldehydes or ketones was observed. It was found, that aliphatic alkenes exhibited better results than their aromatic analogues and the sterically hindered double bonds exhibited poor yield compared with less hindered one. When arylidenemalononitriles were used as substrates, they produced the corresponding carbonyls due to the presence of the two electron-withdrawing groups on one terminal of the olefins. The peroxyselenic(IV) acid is responsible for the epoxidation of alkenes, which in the presence of water and selenic(IV) acid forms the corresponding diols 52 (Scheme 13) $[189]$.

A synthetic method for some aryl pyridines involved $\mathrm{H}_{2} \mathrm{O}_{2} / \mathrm{SeO}_{2}$ dihydroxylation and methoxyhydroxylation of 4aryl-1,2,3,6-tetrahydropyridines [190]. Selenium(IV) oxide that mediated dihydroperoxidation of 3-aryl-1,4,5,6tetrahydropyridine, was also examined [191].

Long chain alkenes and unsaturated acid esters oxidized with $\mathrm{H}_{2} \mathrm{O}_{2} / \mathrm{SeO}_{2}$ at ambient temperature gave, depending on the reaction time, vicinal diols, selenite esters and epoxides. For methyl oleate after a short reaction time $(4 \mathrm{~h})$ the epoxide was produced, while the time was prolonged for 24 $\mathrm{h}$ ester, accompanied with diol, was a major product. It supported the hypothesis that the product sequence is epoxides $\rightarrow$ selenite esters $\rightarrow$ vicinal diols [192].

Ring transformations using $\mathrm{H}_{2} \mathrm{O}_{2} / \mathrm{SeO}_{2}$ resulted in the ring contraction of cycloalkanones to norcycloalkane carboxylic acids [193,194], and related rearrangements in acyclic ketones [193-197] as well as 3-ketosteroids $[198,199]$. Moreover, it was observed that ketal 53 was rapidly converted, in high yield, into the $\varepsilon$-enollactone $\mathbf{5 4}$. A simple explanation for the formation of $\mathbf{5 4}$ involves acidcatalyzed hydrolysis of the ketal protecting group, followed by a Baeyer-Villiger type oxidation of intermediate ketone

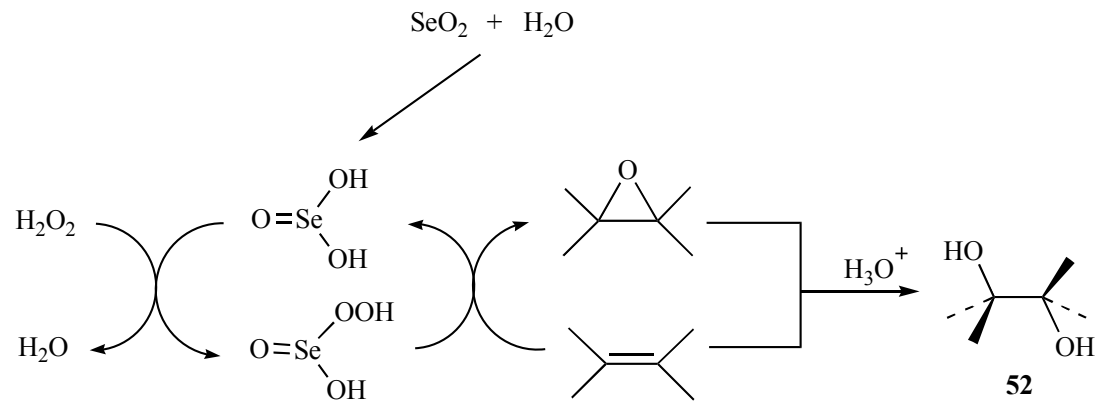

Scheme 13. Hydrogen peroxide trans-dihydroxylation of alkenes catalyzed by $\mathrm{SeO}_{2}$. 


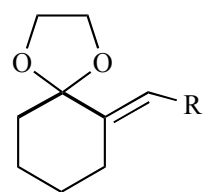

53

$\mathrm{R}=2$-furyl
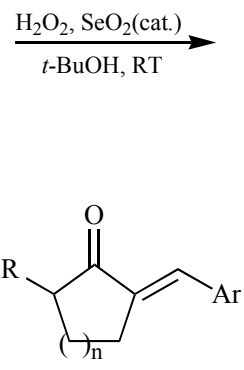

55

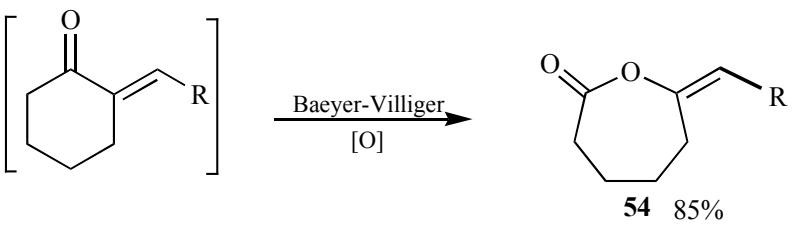

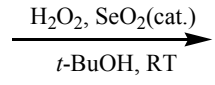

$\mathrm{n}=1-3 ; \mathrm{R}=\mathrm{H}, \mathrm{Me} ; \mathrm{Ar}=2$-furyl, phenyl, 4-methoxyphenyl<smiles>[R]C1C(=O)O/C(=C/[125I])CC1[As]</smiles>

$60-92 \%$

Scheme 14. Lactonization of cycloalkanones with $\mathrm{H}_{2} \mathrm{O}_{2} / \mathrm{SeO}_{2}$.

53. The reaction extended on the other 2-alkylidenecycloalkanones 55 yielded corresponding enollactones 56 [200] (Scheme 14).

Oxidative cleavage of ene-lactams can be performed efficiently by $\mathrm{SeO}_{2}$ catalyzed oxidation with $\mathrm{H}_{2} \mathrm{O}_{2}$ to give the corresponding ketoimides. The reaction provides convenient methods for the preparation of macrocyclic ketoimides and construction of $N$-fused azabicyclic ring systems such as indolizidine and cephalotaxine skeletons [201].

The Baeyer-Villiger reaction using $\mathrm{H}_{2} \mathrm{O}_{2} / \mathrm{SeO}_{2}$ for various benzaldehydes possessing hydroxy or methoxy substituents mainly in ortho and para position, and/or a furan ring, afforded phenols rapidly in good yield or mixtures of the phenols and carboxylic acids. On the other hand, meta-substituted benzaldehydes or benzaldehydes carrying less effective electron donating groups, electrondeficient heteroaromatic and aliphatic aldehydes were oxidized to the corresponding carboxylic acids [200, 202, 203].

$\mathrm{N}$-Oxidation of secondary amines with $\mathrm{H}_{2} \mathrm{O}_{2} / \mathrm{SeO}_{2}$ is a convenient way of synthesizing nitrones [204-206]. Differently ring substituted anilines were oxidized to nitroso compounds or azoxybenzenes using hydrogen peroxide in the presence of catalytic amounts of selenium(IV) oxide. As it has been shown for methyl 4-aminobenzoate the result strongly depends on the solvent. Treating this compound with $\mathrm{H}_{2} \mathrm{O}_{2} / \mathrm{SeO}_{2}$ in methanol at room temperature, furnishes the azoxyarene exclusively. The same oxidation in aprotic, nonpolar dichloromethane, gives nitrosoarene as a major product in $80 \%$ yield $[207,208]$.

Despite using of tellurium(IV) oxide as a stoichiometric oxidant it was applied in small molar ratio as catalyst while $\mathrm{H}_{2} \mathrm{O}_{2}$ or TBHP were the reoxidants $[209,210]$. The $\mathrm{H}_{2} \mathrm{O}_{2} / \mathrm{TeO}_{2}$ system was used for the selective oxidation of sulfides to the corresponding sulfoxides. Reaction occurs at room temperature and is highly chemoselective. Neither over-oxidation of the formed sulfoxide to sulfone occurs, nor are double bonds or other functional groups such as hydroxyl or carbonyl group affected even in the presence of one equivalent of $\mathrm{TeO}_{2}$. An initially observed disadvantage of the method, which is a long reaction time, was circumvented by the addition of a small amount of concentrated hydrochloric acid [211].
Oxidation of cyclohexanone with $\mathrm{TeO}_{2} / \mathrm{H}_{2} \mathrm{O}_{2}$ under reflux afforded 1-hydroxy-1'-hydroperoxydicyclohexyl peroxide in $42 \%$ yield [194] whereas oxidation with $\mathrm{SeO}_{2} / \mathrm{H}_{2} \mathrm{O}_{2}$ resulted in a ring contraction and cyclopentanecarboxylic acid was produced. $\mathrm{TeO}_{2} / \mathrm{H}_{2} \mathrm{O}_{2}$ reagent was also applied for oxidative conversion of $N, N$-dimethylhydrazones derived from aliphatic and heteroaromatic aldehydes into nitriles, although the more efficient catalyst was phosphomolybdic acid [212].

\subsection{Organoselenium and Organotellurium Compounds}

For hydrogen peroxide oxidation, selenoxides $\mathrm{R}_{2} \mathrm{SeO}$ and selenides $\mathrm{R}_{2} \mathrm{Se}$ have been used as the catalysts since the selenoxides are generated in situ from selenides and returned to the reaction cycle. 2-Carboxyphenyl phenyl selenide was successfully used as a catalyst for oxidation of sulfides into sulfoxides and/or sulfones [213]. 3,5-Di(trifluoromethyl) phenyl benzyl selenoxide is an efficient catalyst for the epoxidation of various olefinic substrates and the BaeyerVilliger oxidation of aldehydes and ketones [214]. Another oxygen-transfer, easy to regenerate, catalyst 2,4-bis(perfluorooctyl)phenyl butyl selenide was used for epoxidation of alkenes by $60 \%$ hydrogen peroxide in fluorinated solvents. Oxidation of aldehydes and ketones under mono-, bi-, or triphasic conditions with 3,5-bis(perfluorooctyl) phenyl butyl selenide gave the carboxylic acids or carboxyesters, respectively. The active intermediates were corresponding bis(perfluorooctyl)benzeneseleninic acids $[215,216]$.

Epoxidation in combination with a subsequent ringopening reaction leading to dihydroxylated products was developed recently. The alkene is epoxidized by peroxyselenic(IV) acid generated in situ by oxidation of diphenyl diselenide with hydrogen peroxide and the epoxide is opened by an $\mathrm{S}_{\mathrm{N}} 2$-type reaction. The stereocontrol in these reactions depends on the steric and electronic properties of the substrate [217].

Allyl selenides are good catalysts for the oxidation of benzyl thioalcohol with TBHP. 3-Hydroxypropyl allyl selenide (57) proved to be exceptional in this reaction. It was found, that this selenide is a procatalyst which undergoes a series of rapid oxidation and sigmatropic [2,3]-rearrangement steps to form a cyclic seleninate ester (58), the true catalyst for hydroperoxide oxidation (Scheme 15) [218]. The ester (58), aromatic cyclic seleninate esters and spirodioxyselenuranes also exhibit glutathione peroxidase mimic activity as catalysts $[219,220]$. 


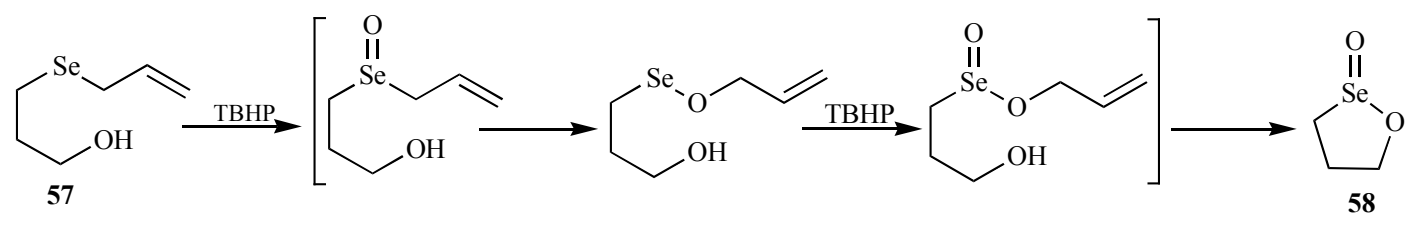

Scheme 15. TBHP oxidation of hydroxypropyl allyl selenide (57) into seleninate ester (58).

Dendrimeric polyphenyl selenide can catalyse the oxidation of bromide with hydrogen peroxide for subsequent reaction with alkenes [221]. A dendrimer with twelve $\mathrm{PhSe}$ groups showed an autocatalytic effect which resulted in the turnover of numbers of above $6 \cdot 10^{4}$. The reaction is initiated by the bromonium cation generated in the uncatalyzed background reaction [222]. The impressive catalyst for the bromination of arenes and for bromolactonization is (4hydroxymethyl) phenyl selenoxide. The catalyst is easily separated from the reaction mixture by filtration and the recovered catalyst can be reused without loss of activity [223].

Dimethyl ditelluride and diphenyl ditelluride, which may be regarded as precursors for tellurinic acids, assuming that $\mathrm{H}_{2} \mathrm{O}_{2}$ acts upon them as it does upon diselenides also, were found to be inactive in this reaction. It was assumed that when tellurinic acids were treated with hydroperoxides, even in aqueous medium, they formed anhydrides instead of peroxytellurinic acids [224]. The exception is cross-linked to polystyrene-tellurinic acid used as a catalyst for selective hydrogen peroxide epoxidation of olefins. In the presence of this catalyst, cyclohexene treated with $\mathrm{H}_{2} \mathrm{O}_{2}$ in $t-\mathrm{BuOH}$ at $60^{\circ} \mathrm{C}$ for $24 \mathrm{~h}$ quantitatively yielded the epoxide [225]. Despite of lack of success in epoxidation of alkenes catalyzed by ditellurides, diaryl ditellurides, have been found to be a thiol peroxidase like catalysts for hydrogen peroxide oxidation of thiols to the corresponding disulfides [226].

In the last two decades different, easily accessible seleninic acids, or more frequently their precursors diselenides RSeSeR, have been used as catalysts for the oxidation of different organic compounds with hydrogen peroxide, TBHP and other oxygen donors $[165,168,227$ 230].

Peroxybenzeneseleninic acid $\mathrm{PhSe}(\mathrm{O}) \mathrm{OOH}$, generated from diphenyl diselenide and hydrogen peroxide, was applied for the oxidation of primary aromatic amines to aromatic nitroso compounds, which can be used in a one-pot hetero Diels-Alder reaction with conjugated dienes to form oxazines as well as for preparation of azoxyarenes [208,231]. An improved protocol for selective oxidation of activated alcohols with TBHP, was devised resulting in significantly decreased catalyst loading $(<1 \mathrm{~mol} \%)$ [231].

2-Nitro- and 2,4-dinitrobenzeneseleninic acids 2$\mathrm{NO}_{2} \mathrm{C}_{6} \mathrm{H}_{4} \mathrm{Se}(\mathrm{O}) \mathrm{OH}(\mathbf{5 9})$ and 2,4- $\left(\mathrm{NO}_{2}\right)_{2} \mathrm{C}_{6} \mathrm{H}_{3} \mathrm{Se}(\mathrm{O}) \mathrm{OH}(\mathbf{6 0})$ and related diselenides, have been applied as catalysts for hydrogen peroxide and TBHP oxidation of different groups of organic compounds [232-234]. Oxidation of aldehydes and aryl methyl ketones $\mathbf{6 1}(\mathrm{R}=\mathrm{Me})$ into phenol formates or acetates 62, which in one-pot procedures are subsequently hydrolyzed to phenols $\mathbf{6 3}$, is a useful way of synthesizing phenols with electron-donating substituents or polycondensed ring systems [235].

In a similar reaction, $\alpha, \beta$-unsaturated aldehydes 64 give vinyl formates $\mathbf{6 5}$, accompanied by the products of their subsequent transformations (Scheme 16) [236]. Recently, Ichikawa and coworkers described bis(2-phenyltrifluoromethanesulfonate) diselenide $\left(2-\mathrm{TfOC}_{6} \mathrm{H}_{4} \mathrm{Se}\right)_{2}$ as a catalyst for the Baeyer-Villiger oxidation. Reaction with hydrogen peroxide generates the peracid, which reacts with cyclic ketones to yield the corresponding lactones in high yields [237].

The proposed mechanism of the oxidation of organic substrate in the presence of areneseleninic acid $\mathbf{6 6}$ or its precursor the diaryl diselenide $\mathbf{6 7}$, is presented in Scheme 17. Both of them are oxidized in situ with hydrogen peroxide or TBHP into areneperoxyseleninic acid $\mathbf{6 8}$, the active oxygen donor. Peroxybenzeneseleninic acid and its 2-nitroand 2,4-dinitro analogues were obtained by hydrogen peroxide oxidation of the corresponding diaryl diselenides and were fully characterized [238, 239].

Diselenides 69-79 used more recently as catalysts for oxidation of different groups of organic substrates are presented in Scheme 17. They are easily available in the reaction of alkyl, aryl, and heteroaryl halides with dilithium
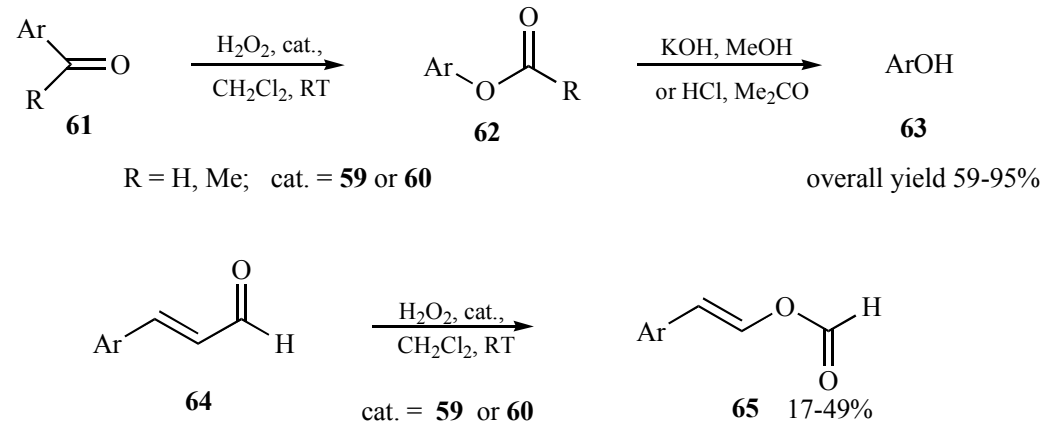

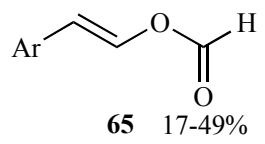

Scheme 16. Hydrogen peroxide oxidation of aromatic aldehydes and ketones, and $\alpha, \beta$-unsaturated aldehydes catalyzed by seleninic acids or diselenides. 


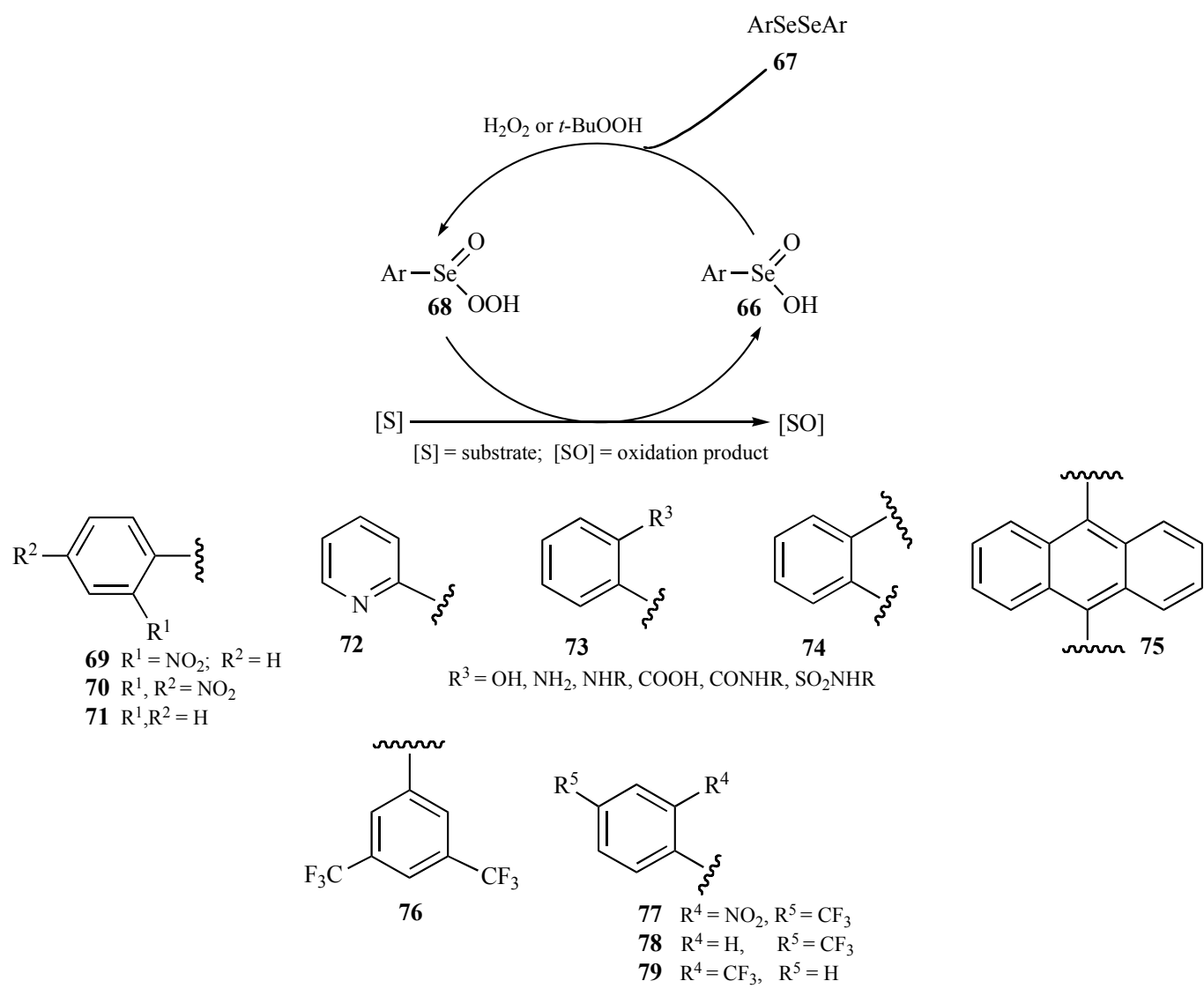

Scheme 17. The mechanism of hydroperoxide oxidation of organic substrate catalyzed by diaryl deselenide or areneselenenic acid.

diselenide formed in situ from elemental lithium and selenium in aprotic media [240-242].

It has been observed, that the effectiveness of selenium catalysts strongly depends on the substrate used. While ortho-substituted diphenyl diselenides are the best catalysts for hydrogen peroxide oxidation of sulfides into sulfoxides and ketazines into their parent ketones [243, 244], the poly(bis-1,2-phenylene) diselenide (74) was selected for preparative oxidation of various aromatic aldazines, aldoximes, and conversion of tosylhydrazones into arenecarboxylic acids [245].

In the presence of poly(bis-9,10-anthracenylene) diselenide (75) a broad spectrum of aliphatic, unsaturated and aromatic nitriles was obtained, in excellent preparative yields, by oxidation of the corresponding $N, N$ dimethylhydrazones [48]. It was the catalyst of choice for oxidation of cycloalkanones $\mathbf{8 0}$ to cycloalkanecarboxylic acids 81. The results of more detailed studies on the chemoand stereoselectivity of this reaction support the mechanism, presented for cyclohexanone (82) in Scheme 18. Most probably, the reaction involves addition of two bulky arylselenium cations in both $\alpha$-positions of the ketone, the elimination of diaryl diselenide from adduct $\mathbf{8 3}$ and finally the Favorski-like rearrangement of intermediate $\mathbf{8 4}$ to the acid 85 [246].

Although preparative yields of the cycloalkanecarboxylic acids did not exceed $60 \%$, they were substantially higher than those obtained when selenium(IV) oxide was the catalyst. Since the cycloalkanones are cheap and easily available substrates, the elaborated method is suitable for the synthesis of acids 81, particularly those having five-, sixand seven-membered rings.

The bis[2-nitro-4-(trifluoromethyl)phenyl] diselenide (77) was found to be an efficient catalyst for hydrogen peroxide oxidative degradation of electron-rich benzene ring in the phenol or its ortho substituted derivatives 86, 88 and 90. Depending on the substrate used, muconic acid (87), muconolactones 89 or 1,4-benzoquinones 91 were produced in satisfactory to good yields. Similar ring-degradation took place when substituted naphthalenes were oxidized. Cinnamic acid or benzofurane derivatives were the final products [241,242,247] (Scheme 19).

Recently it was reported that bis[3,5-bis(trifluoromethyl) phenyl] diselenide (76) has been significantly more active than other previously described selenium catalysts for epoxidation and Baeyer-Villiger oxidation of carbonyl compounds with hydrogen peroxide [248,249].

Areneseleninic acids and selenoxides can be used as catalysts for the oxidation of bromide, with hydrogen peroxide, to hypobromite and bromine in a two-phase reaction mixture. Among various areneseleninic acids tested as catalysts, the most effective were benzeneseleninic acid and 4-methoxybenzeneseleninic acid. Generated in situ $\mathrm{Br}_{2}$ and $\mathrm{NaOBr}$ bring on the cyclization of unsaturated enolic acids, such as for example, 4-pentenoic acid (92) or related unsaturated alcohols, give the lactone 93, accompanied with a small amount of dibromo acid 94. Similarly, the 


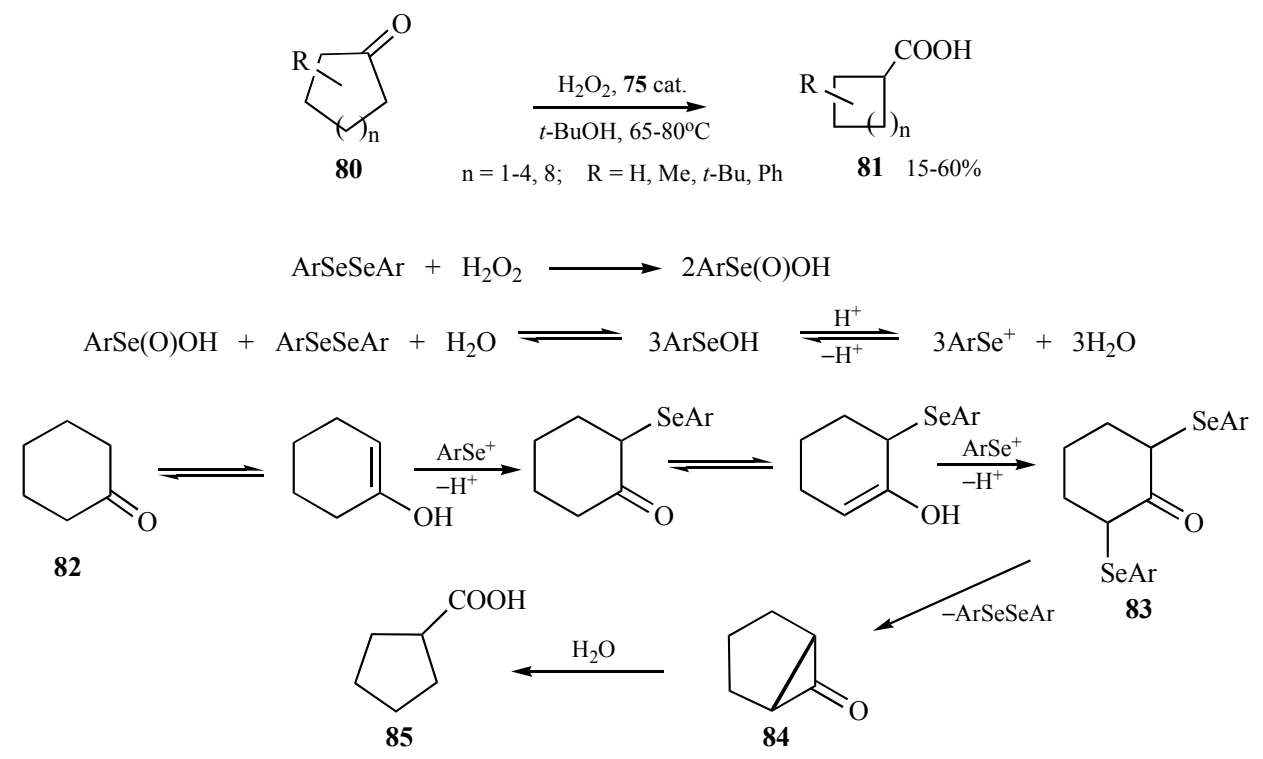

Scheme 18. Oxidative conversion of cycloalkanones into cycloalkanecarboxylic acids catalyzed by poly(bis-9,10-anthracenylene) diselenide (75).<smiles>[R]c1ccccc1O</smiles>

86<smiles>[R]c1cccc(O)c1</smiles>

88<smiles>[R]c1cccc([R])c1O</smiles>

90

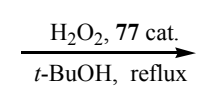

$\mathrm{R}^{1}=\mathrm{H}, \mathrm{OH}, \mathrm{OMe}, \mathrm{CHO}$

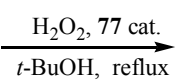

$\mathrm{R}^{2}=2$-alkyl, 4-alkyl

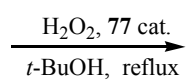

$\mathrm{R}^{3}=\mathrm{Me}, t-\mathrm{Bu}$<smiles>O=C(O)/C=C\C=C(C(=O)O)C(=O)O</smiles>

$87 \quad 38-50 \%$<smiles>[R]C1=CC(CO)OC1=O</smiles><smiles>[R]C1=CC(=O)C=C([R])C1=O</smiles>

$91 \quad 74-83 \%$

Scheme 19. Oxidation of the benzene ring of phenols with $\mathrm{H}_{2} \mathrm{O}_{2}$ / bis[(2-nitro-4-trifluoromethyl)phenyl] diselenide (77).

electrophilic bromination of activated aromatic rings can be performed with high yields (Scheme 20) [250,251].

Other works showed the evidence that well known glutathione peroxidase mimic the ebselen (95), related selenenamides and diselenides could catalyze the hydroperoxide oxidation of various organic compounds. The catalyst 95 was used in $5 \mathrm{~mol} \%$, and diselenide 96 in 2.5 mol\% while the stoichiometric oxidant was $30 \%$ hydrogen peroxide or $80 \%$ TBHP and results are presented in Scheme 21 [27,228,229,241,252-254]. It was postulated, that all these reactions have ionic character and that active intermediate is hydroperoxyselenurane 97 [255].

The sulfides 98 are exclusively oxidized into sulfoxides 99 [243]. Aromatic aldoximes 100 oxidized in methanol give carboxymethyl esters 101 [256]. Nitriles 102 are produced from $N, N$-dimethylhydrazones $\mathbf{1 0 3}$ by oxidation with hydrogen peroxide [238,243] or from benzylamines $\mathbf{1 0 4}$ oxidized with TBHP [257]. Hydrogen peroxide oxidation of ketazines 105 gives the parent ketones 106 [243]. 1,2,3,4-
Tetrahydroisoquinoline (107) is dehydrogenated to isoquinoline (108) which undergoes subsequent oxidation into the $N$-oxide 109 [258]. Cyclooctene (110) treated with TBHP gives epoxide 111, accompanied with trace amounts of 3-hydroxycyclooctene, resulting from $\alpha$-hydroxylation [259], while oxidation catalyzed by selenium(IV) oxide obtains 3-hydroxycyclooctene as a major product and epoxidation is not observed [171,259]. Oxidation of aromatic aldehydes 112, having electron-donating substituents, with TBHP in the presence of ebselen, led almost exclusively to the acids 113, thus avoiding the Baeyer-Villiger rearrangement [255], contrary to mentioned earlier, oxidation with hydrogen peroxide in the presence of selenium(IV) oxide, where mixtures of arenecarboxylic acids and phenols or even phenols as the sole products, were produced [203].

Despite the ionic reactions presented above, some other reactions can proceed via a free-radical mechanism. Catalyzed by ebselen, TBHP oxidation of alkylarenes 114 to alkyl aryl ketones 115 [257], anthracene (116) to 


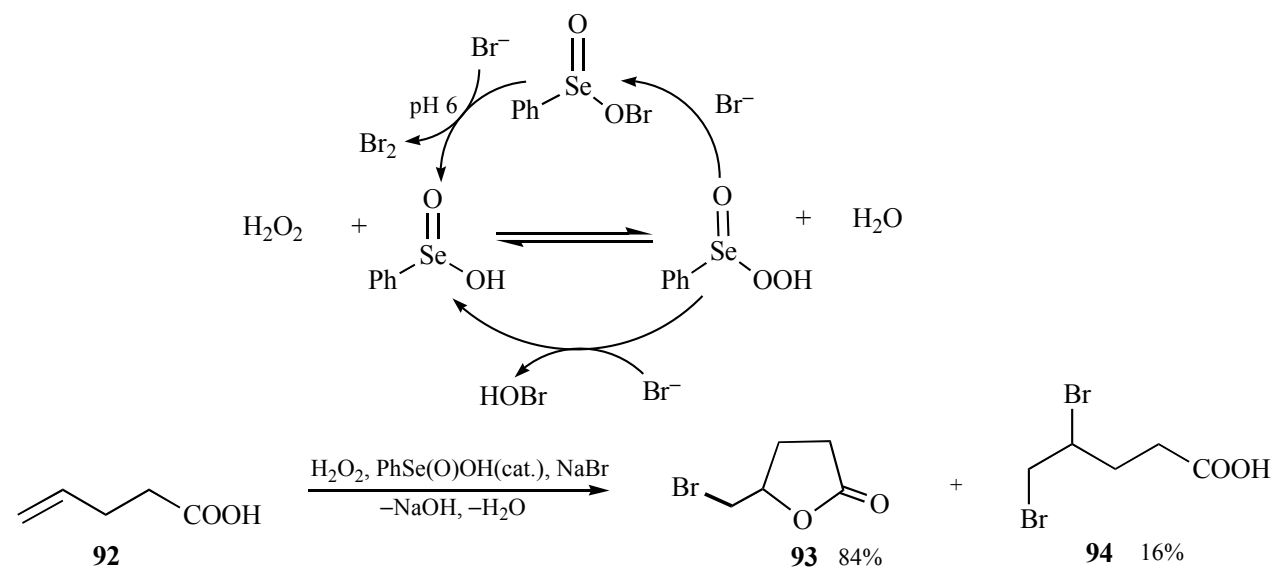

Scheme 20. Bromolactonization of an enolic acid via benzeneseleninic acid catalyzed oxidation of $\mathrm{NaBr}_{\text {with }} \mathrm{H}_{2} \mathrm{O}_{2}$.<smiles>O=c1c2ccccc2[nH]n1-c1ccccc1</smiles>

95<smiles>O=C(Nc1ccccc1)c1ccccc1Cl</smiles>

96

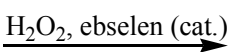

$\mathrm{MeOH}, 20^{\circ} \mathrm{C}$

\begin{tabular}{|c|c|c|c|c|}
\hline $\mathrm{ArCH}=\mathrm{NMe}_{2}$ & $\frac{\mathrm{H}_{2} \mathrm{O}_{2} \text {, ebselen (cat.) }}{\mathrm{MeOH}, 20^{\circ} \mathrm{C}}$ & & $\underset{t-\mathrm{BuOH} \text {, reflux }}{\mathrm{TBHP} \text {, ebselen (cat). }}$ & $\mathrm{ArCH}_{2} \mathrm{NH}_{2}$ \\
\hline 103 & $92-98 \%$ & & $62-70 \%$ & \\
\hline
\end{tabular}

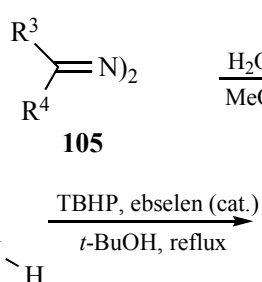

107
$\frac{\mathrm{H}_{2} \mathrm{O}_{2} \text {, ebselen (cat.) }}{\mathrm{MeOH}, 20^{\circ} \mathrm{C} \text { or } 65^{\circ} \mathrm{C}}$

$\mathrm{R}_{\mathrm{R}^{4}}^{3}=\mathrm{O}$

$106 \quad 62-98 \%$

$10858 \%$<smiles>c1ccc2ccccc2c1</smiles><smiles>[O][Si]1(O)c2ccccc2C(=O)N1c1ccccc1</smiles>

97
$\mathrm{ArCOOMe}$

$101 \quad 62-82 \%$<smiles>[R]S([R])=O</smiles>

$99 \quad 92-95 \%$

$+$<smiles>[O-][n+]1ccc2ccccc2c1</smiles>

$10919 \%$<smiles>C1=CCCCCCC1</smiles>

110<smiles>[3H]C=O</smiles>
$t$-BuOH, reflux

$\stackrel{\text { TBHP, ebselen (cat.) }}{\longrightarrow}$ $t$ - $\mathrm{BuOH}$, reflux

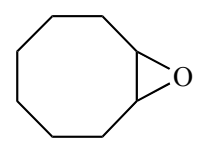

$11160 \%$<smiles>[14CH3]C(=O)O</smiles>

Scheme 21. Oxidation of ionic character catalyzed by ebselen.

anthraquinone (117) [260], 1,4-dimethoxyarenes to 1,4quinones (e.g., 2-methyl-1,4-dimethoxynaphthalene (118) to menaquinone (119) [261] and oxidative coupling of 2aminophenols (e.g., 120 to phenoxazinones 121) [262] gave results similar to those with the one-electron oxidants $\mathrm{Ce}(\mathrm{IV}), \mathrm{Ag}(\mathrm{II})$, or $\mathrm{Mn}(\mathrm{III})$ (Scheme 22).
Moreover, oxidation of ketazine (122), derived from 2acetylpyridine, gave a mixture of ketone $\mathbf{1 2 3}$ and condensed triazole 124 [257]. The same result was found when cerium ammonium nitrate was used as the reagent. This suggests, that the reaction proceeds via cation-radicals. Both of the postulated mechanisms, ionic and free-radical, were discussed in greater detail in a review article [27]. 
<smiles>[R]Cc1ccccc1[R]</smiles>

114<smiles>c1ccc2cc3ccccc3cc2c1</smiles>

116<smiles>COc1cc(C)c(OC)c2ccccc12</smiles>

118<smiles>Nc1ccccc1O</smiles>

120

$$
\underset{t \text { - } \mathrm{BuOH}, \text { reflux }}{\stackrel{\text { TBHP, ebselen (cat.) }}{\longrightarrow}}
$$

$\underset{\text { TBHP, ebselen (cat.) }}{\stackrel{\text { MeCN, reflux }}{\longrightarrow}}$

$\mathrm{MeCN}$, reflux

$\stackrel{\text { TBHP, ebselen (cat.) }}{\longrightarrow}$

$t$-BuOH, reflux<smiles>[R]C(=O)c1ccccc1[R4]</smiles><smiles>O=C1c2ccccc2C(=O)c2ccccc21</smiles>

$117 \quad 41 \%$<smiles>CC1=CC(=O)c2ccccc2C1=O</smiles>

$11961 \%$<smiles>Nc1cc2nc3ccccc3oc-2cc1=O</smiles>

$12186 \%$<smiles>CC(=N)c1ccccn1</smiles>

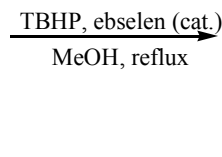<smiles>CC(=O)c1ccccn1</smiles><smiles>Cc1nnn2ccccc12</smiles>

Scheme 22. Catalyzed by ebselen oxidations of free-radical character.

A few benzisoselenazol-3(2H)-ones 125-128 and openchain selenenamide 129 were covalently immobilized to the solid support, either silica or polymer (Scheme 23) $[260,263,264]$. They exhibited appreciable catalytic activity similar to the activity of ebselen, and could be easily recovered by filtration, and reused. The most prospective oxygen-transfer recoverable catalyst is benzisoselenazolone covalently bound to a silica support $\mathbf{1 2 5}$ named HALICAT. It has been applied to hydrogen peroxide oxidation of sulfides and TBHP oxidation of the aromatic aldehydes to acids and alkylarenes to alkyl aryl ketones [263].

It should be noted that ebselen (95) is a stable, non toxic compound. It can be obtained easily from anthranilic acid via bis(2-carboxyphenyl) diselenide and aniline. The method has a more general value because, by using various amines and other compounds with primary amino groups, different benzisoselenazol-3(2H)-ones and 2-substituted diphenyl

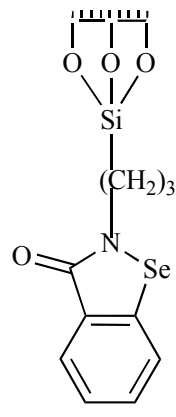

125<smiles>[Y]C(CC)c1ccc(-n2[se]c3ccccc3c2=O)cc1</smiles>

126<smiles>CCC(C)C(=O)NCCn1[se]c2ccccc2c1=O</smiles>

127<smiles>[Y]C(CC)c1ccc(CNc2ccccc2-n2[se]c3ccccc3c2=O)cc1</smiles>

128

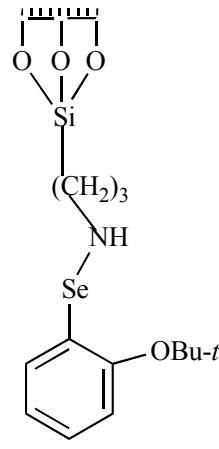

129

Scheme 23. Benzisoselenazol-3(2H)-ones and selenenamide covalently immobilized on the solid supports. 


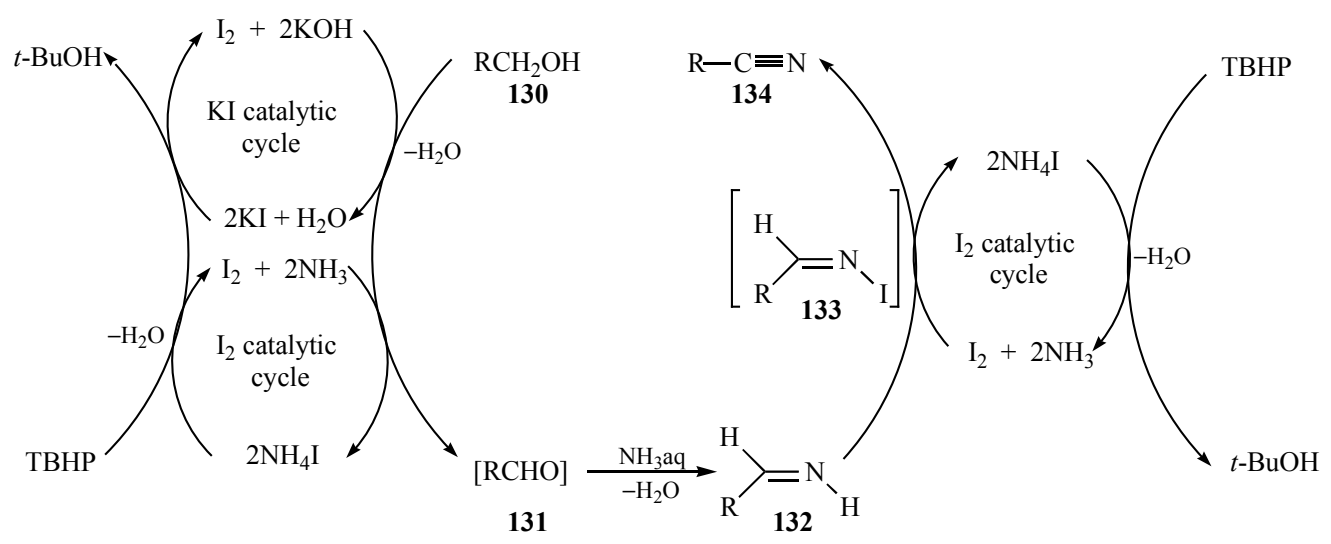

Scheme 24. Oxidative transformations of alcohols, aldehydes and amines using $\mathrm{KI} / \mathrm{I}_{2}-\mathrm{TBHP}$ system.

diselenides, also these bounded to solid support, can be obtained in high yields [244,253,254,265,266].

\section{OTHER CATALYSTS}

Recently, the use of catalytic amount of KI or molecular iodine for the facile oxidative amidation of aldehydes and alcohols to form amides using TBHP as an external oxidant has been reported [267]. The same reagent and catalysts were used for direct oxidative conversion of alcohols, aldehydes and primary amines to the nitriles. Aromatic primary amines were oxidized to the corresponding nitro compounds. The present catalytic system works well for both electron-rich and electron-poor substrates [268, 269].

Based on the obtained results, the plausible mechanism, as shown in Scheme 24, was proposed. In the case of alcohol 130 an aldehyde 131 could be an intermediate, which could be achieved by using either $\mathrm{KI}$ or $\mathrm{I}_{2}$ as a catalyst. Aldehyde 131 thus formed reacts with ammonia to form an imine $\mathbf{1 3 2}$. Imine further reacts with iodine to form $N$-iodo aldimine 133, finally transformed into nitrile 134 by $\beta$-elimination of HI with ammonia. In case of direct conversion of primary amines to nitrile, a similar mechanism via imine and $N$-iodo aldimine was expected. It has been proposed earlier that under alkaline conditions, iodine is involved in multiple equilibriums, in which hypoiodous acid is one of the possible intermediates [268]. Similar intermediate was also proposed under acidic conditions with $\mathrm{NaI}$ and $\mathrm{H}_{2} \mathrm{O}_{2}$ for the $\alpha$ iodination of ketones [270].

Silica gel has been found to mediate the efficient $t$-butyl hydroperoxide oxidation of sulfides to sulfoxides $(80-88 \%$ yield), and sulfoxides to sulfones (93\% yield). These studies afforded insights into the mechanism of surface-mediated processes. It was found that oxidation of sulfides or sulfoxides by TBHP/silica gel occurs at least predominantly via nucleophilic attack by the substrate molecule on the hydroperoxide, which is activated by being bound to isolated silanol sites on the silica gel surface [271].

Under aqueous/biphasic organic conditions aqueous hydrogen peroxide oxidizes aldehydes to carboxylic acids without affecting olefinic or alcoholic function. The phasetransfer catalyst is $\left[\mathrm{CH}_{3}\left(n-\mathrm{C}_{8} \mathrm{H}_{17}\right)_{3}\right] \mathrm{HSO}_{4}\left(\mathrm{QHSO}_{4}\right)$ and the reaction is catalyzed simply by acid [272 ].

2,2,6,6-Tetramethylpiperidine-1-oxyl (TEMPO) was used as a catalyst for selective hydrogen peroxide oxidation of benzylic alcohols to the corresponding aldehydes. Using TEMPO/ $/ \mathrm{HBr} / \mathrm{H}_{2} \mathrm{O}_{2}$ system and ionic liquid [bmim]PF6 at room temperature the aldehydes were obtained in $72-92 \%$ yield. The catalyst was simple to recover and reuse [273].

\section{ENZYMES}

Enzymes are proteins that catalyze a lot of biological reactions in vivo. They are large molecules with unique stereostructures, therefore they can be highly selective for certain types of substrates and reactions. As versatile catalysts they act also in vitro with natural and man-made organic compounds. They can be selective for substrates and stereoselective in reactions they catalyze, their selectivity can range from very narrow to very broad.

The active sites of enzymes are chiral, and enzymes are well suited as catalysts for reactions generating specific, mostly the enantiomerically pure intermediates and products. Therefore they are being increasingly used in pharmaceutical industry, agrochemistry, analytical chemistry and polymer science to create novel attractive materials [28].

In broader terms, enzymes play an important part of the spectrum of catalysts available to synthetic chemists. Biocatalytic procedures (including immobilization of enzymes on various supports, application of organic solvents, methods of coenzymes regeneration) may offer practical routes to chemoenzymatic synthesis as a challenging alternative to classical synthetic methods [29].

The demand of novel highly active enzymes stimulates their search in pro- and eukcaryotic world. Particularly, various methods of screening microorganisms or plants for enzymatic activities provide new approaches to the discovery of useful biocatalysts and work out their production on the large scale. The generation of novel tailor-made proteins, mainly due to molecular engineering techniques also creates the fascinating opportunity of providing new catalysts with specific activities [30, 274-278].

An unique group of biocatalysts, belonging to the oxidoreductase class of enzymes, are peroxidases performing oxidation of selected organic compounds using hydroxyperoxides $[279,280]$. Due to their catalytical versatility and stability, peroxidases are of particular interest as potential biocatalysts for industrial oxidation processes. Some commercialy available ones have received extensive attention in the last decades as biocatalysts for organic 
synthesis, chemiluminescent assays, radiochemistry, immunochemistry and for construction of biosensors used in analytical diagnostics and bioremediation of pollutants [281].

Peroxidases are widely distributed in nature, found in all domains of life: microorganisms, plants and animals. They perform a variety of biological functions, such as the synthesis of macromolecules and the detoxification of hydrogen peroxide, accepting a broad range of substrates [282]. Traditionally, their names are derived from their sources or from their substrates, but based on their structure of active center, peroxidases are classified into three groups: heme peroxidases, vanadium peroxidases and non-metal peroxidases. From the first group, horseradish peroxidase (HRP), lactoperoxidase (LPO), soybean peroxidase (SBP) and several fungal peroxidases like lignin (LiP), manganese (MnP) and haloperoxidase (CPO) are mostly used as biocatalysts [283-286]. Vanadium peroxidases (VPBO), enzymes belonging to the second group, possessing a single bound vanadate ion in the inactive centre occurig in seeweeds were found to be attractive novel catalysts [287,288]. Representatives of the third group: glutathione peroxidases (GPx), enzymes containing selenocysteine in active site also have gained attention [289].

There are several novel peroxidases under study, produced mainly by basidiomycetous wood rotting fungi. They show unique catalytic properties potentially very challenging in several biotechnological processes [290,291].

Peroxidases are versatile enzymes, they catalyze a variety of reactions depending on the conditions and kind of oxidizing agent (hydroxyperoxide or atmospheric oxygen), electron transfer, disproportionation, halogenation, sulfoxidation, epoxidation, demethylation, dehydrogenation, hydroxylation, $\alpha$-oxidation. In the presence of hydroperoxides biooxidation of aromatic compounds, heteroatomatic compounds, epoxidation, sulfoxidation and halogenation occurs [280]. Therefore these biocatalysts can be used as a tool in asymmetric synthesis. The transformation of a broad range of substrates performed by peroxidases leads to valuable compounds for the synthesis of biologically active molecules. The small-scale applications of peroxidases in the area of synthetic organic chemistry, especially when regio- and enantioselective oxidations are sought, are both numerous and appealing, and have been summarized in many reviews [279,280,292-295]. Oxidative coupling of phenols and aromatic amines is promising for the synthesis of complex molecules with high biological activities, conductive polymers, resin manufacture and removal of pollutants. Halogenation reactions make it possible to obtain radiolabeled compounds or halohydrins used in organic synthesis. The highly selective epoxidation and sulfoxidation of a variety of substrates to yield useful chiral synthons are particularly important.

Useful peroxidase catalysed reactions, when hydrogen peroxide (or other hydroperoxide) is an oxygen source can be divided on three groups: (1) oxidative dehydrogenation, (2) oxidative halogenation, (3) oxygen transfer reactions: (Scheme 25)

\subsection{Oxidative Dehydrogenation}

A variety of peroxidases effecitvely catalyze oxidation of phenols 135 to generate phenoxy radicals which react with each other to form in non-enzymatic way dimeric and polymeric products 136 (Scheme 26) [296,297].

Peroxidases may be useful for the removal of phenolic contaminants from water, wastewater [298] and used for the synthesis of phenolic polymers in industry as an alternative method to harmful phenol-formaldehyde procedures [299, 300]. Syringaldehyde (137), one of the major derivatives of lignin, was copolymerized with bisphenol A (138) to a polymer 139 harboring an active aldehyde group in the backbone using fungal peroxidase CiP (Coprinus cinnereus) (Scheme 27) [301].

The oxidative coupling of phenols catalyzed by peroxidases is a very attractive method for preparing various phenolic dimers showing biological activity. Using HRP as a biocatalyst $(E)$-stilbene-3,4-diol (140) (resveratrol analogue) was oxidized to dimeric product, novel phytoalexin (141) (Scheme 28) [302]. Two monomeric Vinca alkaloids, catharantine and vindoline were oxidized under similar conditions to the heterodimeric product vinblastine which is an antitumor agent [303].

Enzymatic oxidative polymerization of phenols and its derivatives using peroxidases has several advantages over conventional harsh chemical methods. Phenolic monomers having various substituents are polymerized to give a new

$$
\begin{gathered}
2 \mathrm{AH}+\mathrm{H}_{2} \mathrm{O}_{2} \longrightarrow \mathrm{A}-\mathrm{A}+2 \mathrm{H}_{2} \mathrm{O} \\
\mathrm{AH}+\mathrm{H}_{2} \mathrm{O}_{2}+\mathrm{H}^{+}+\mathrm{X}^{-} \longrightarrow \text { AX } \\
\mathrm{A}+\mathrm{H}_{2} \mathrm{O}_{2} \longrightarrow 2 \mathrm{H}_{2} \mathrm{O} \\
\mathrm{AO}+\mathrm{AH}=\text { substrate; } \mathrm{X}=\mathrm{Cl}, \mathrm{Br}, \mathrm{I}
\end{gathered}
$$

Scheme 25. Hydroperoxide oxidations catalyzed by peroxidase.<smiles>COc1ccccc1O</smiles>

135

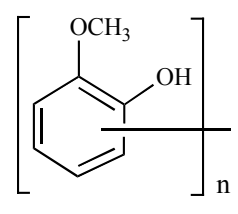

136

Scheme 26. HRP catalyzed oxidation of phenols. 
<smiles>COc1cc(C=O)cc(OC)c1O</smiles>

137<smiles>CC(C)(c1ccc(O)cc1)c1ccc(O)cc1</smiles>

138

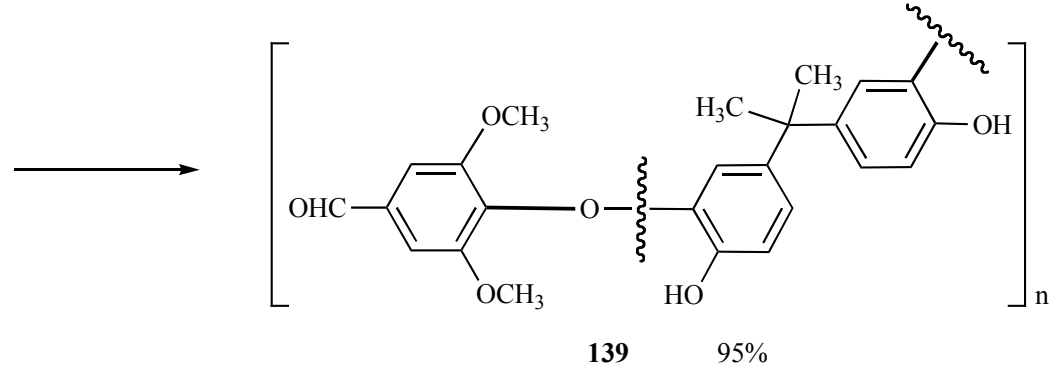

Scheme 27. Copolymerization of syringaldehyde and bisphenol A by fungal (Coprinus cinnereus) peroxidase.<smiles>Oc1ccc(/C=C/c2ccccc2)cc1O</smiles>

140

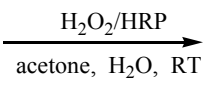

acetone, $\mathrm{H}_{2} \mathrm{O}, \mathrm{RT}$<smiles>Oc1ccc([C@H]2Oc3cc(/C=C/c4ccccc4)ccc3O[C@H]2c2ccccc2)cc1O</smiles>

Scheme 28. HRP catalyzed oxidative cyclocondensation of $(E)$-stilbene-3,4-diol.

class of functional polyaromatics, the structure and solubility of which can be controlled by changing the reaction conditions.

Using hydrogen peroxide in the presence of HRP, aniline $(\mathbf{1 4 2}, \mathrm{R}=\mathrm{H})$ and its derivatives polymerize to polyanilines 143 , one of the most investigated conducting polymers for the electronic industry (Scheme 29) [304].

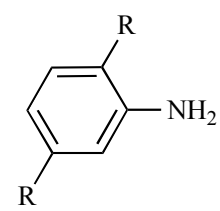

142

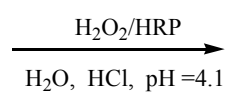

$\mathrm{R}=\mathrm{H}, \mathrm{OMe}$

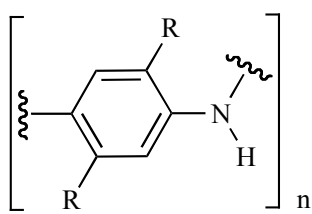

143
Scheme 29. Biocatalytic synthesis of polyanilines.

Oxidative coupling of $o$-aminophenols 144 with hydrogen peroxide in the presence of HRP lead to aminophenoxazinones $\mathbf{1 4 5}$ (Scheme 30) [305]. Phenoxazinones are widely distributed in nature as insect pigments, fungal metabolites and antitumor antibiotics [306, 307]. Synthetic analogues are used as fluorescent dyes in analytical chemistry [308].

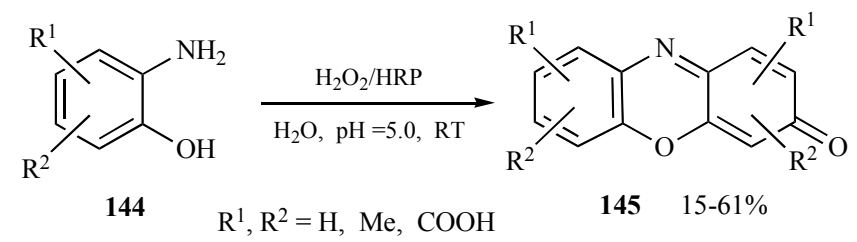

Scheme 30. Oxidative cyclocondensation of aminophenols to aminophenoxazinones.
Particularly interesting are the reactions of $O$ dealkylation catalyzed by peroxidases involved in nature in lignin biodegradation processes [309]. In preparative organic chemistry, $O$ - as well as $N$-dealkylation reactions require severe conditions while, due to biocatalytic procedures, removal of alkyl groups can be easily performed as it is shown for $O$-demethylation of 9-methoxyellipticine $\mathbf{1 4 6}$ [310] and conversion of $\mathrm{N}, \mathrm{N}$-dimethylanilines 147 into $\mathrm{N}$ monomethylanilines 148 (Scheme 31) [311].

In spite of synthetic chemistry, peroxidase-catalyzed polymerization as well as $O$ - and $N$-demethylation, have been exploited for the treatment of industrial wastewater polluted with polyphenols and phenylenediamines, removal of lignins degradation products accumulated in wood decomposition procedures for bio-fuel production and degradation of azo dyes used in textile industry [312,313].

Peroxidases are able to catalyse formation of chromogenic products, e.g 150 from amine 149 and phenol as shown in Scheme 32 [314]. These reactions have been utilized in several immunoassay procedures, chemiluminescence and construction of biosensors [307,314,315].

\subsection{Oxidative Halogenation}

Several peroxidases, named haloperoxidases, isolated from various sources catalyze oxidation of chloride, bromide and iodide by hydrogen peroxide. They are divided into three groups. In the first group there are enzymes without prosthetic group, mainly found in bacteria. The second group comprises heme-dependent peroxidases derived from different sources. In this group the most well known is lactoperoxidase (LPO) isolated from milk and haloperoxidase (CPO) found in marine fungus Caldariomyces fumago. 
<smiles>COc1ccc2[nH]c3c(C)c4ccncc4c(C)c3c2c1</smiles><smiles>[R]c1ccc(N(C)C)cc1</smiles>

147
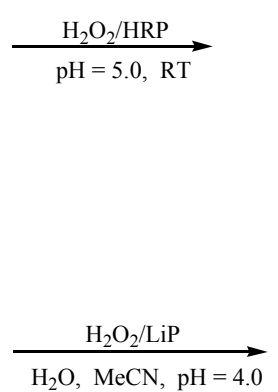

$\mathrm{R}=\mathrm{Br}, \mathrm{CF}_{3}, \mathrm{CN}, \mathrm{NO}_{2}$<smiles>Cc1c2c(c(C)c3ccncc13)C1=CC(=O)C=CC1=N2</smiles><smiles>[R]c1ccc(NC)cc1</smiles>

$148 \quad 16-62 \%$

Scheme 31. Enzymatic $O$ - and $N$-demethylation.<smiles>Cc1c(N)c(=O)n(-c2ccccc2)n1C</smiles><smiles>Cc1c(N=C2C=CC(=O)C=C2)c(=O)n(-c2ccccc2)n1C</smiles>

Scheme 32. Formation of chromogenic product derived from 4-aminoantipyrine by peroxidases (HRP, LPO) used in analytical metodology.

Third group includes vanadium-containing peroxidases (VPOs) produced by several species of alga and marine fungi. According to the oxidized halogen haloperoxidases are classified as chloro, iodo- and bromo-peroxidases. A common substrate to evaluate enzymatic activity of all haloperoxidases is monochlorodimedone $\mathbf{1 5 1}$ oxidized to 2,2-dihalogeno-1,3-diketone 152 (Scheme 33) [293].

Haloperoxidases can be used as biocatalysts for the preparation of halohydrins from alkenes [293, 316]. Both enantiomers 154 and $\mathbf{1 5 5}$ are obtained from propene 153, which can be subsequently converted chemically or with halohydrin epoxidases to chiral 2-methyloxirane $\mathbf{1 5 6}$ (Scheme 34) [292].

Haloperoxidases, mainly bovine milk lactoperoxidase (LPO) are commonly used to produce radiolabelled compounds and for radioiodination of proteins and nucleic acids [317,318] Halogenation reactions facilitate to obtain several novel intermediates for the synthesis of biologically valuable compounds such as 2-deoxy-2-halo-sugars. For example, when using unprotected glycal 157 as substrate and chloroperoxidase as catalyst, single haloisomers 158-160 were obtained (Scheme 35) [319].

\subsection{Oxygen Transfer Reactions}

In asymmetric synthesis of natural products optically active epoxides are important building blocks. Among the peroxidases so far tested, only chloroperoxidase from Caldariomyces fumago (CPO) in the absence of chlorine ions catalyzes useful oxygen transfer reactions, i.e. asymmetric epoxidation of olefins and sulfoxidation. This versatile enzyme was used to oxidize several olefins: aliphatic and aromatic (styrene and its ring-substituted derivatives). Results reported from various laboratories $[280,292,293,320]$ indicate that $\mathrm{CPO}$ catalyzes oxidation of olefins, using both $\mathrm{H}_{2} \mathrm{O}_{2}$ and TBHP as oxygen donors, affording the corresponding epoxides mostly in good enantiomeric excesses values. The examples presented in Scheme 36 illustrate this type of reaction. The selectivity of bioconversion depends on the structure of the substrate used. In general cis- substituted olefins were epoxidized with good yields and excellent enantiomeric excess, whereas transcompounds were poorly accepted.<smiles>CC1(C)CC(=O)C(Cl)=C(Cl)C1</smiles>

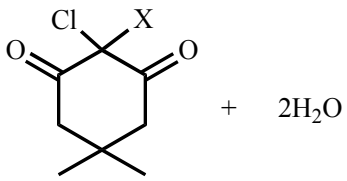

152

Scheme 33. Oxidative halogenation of monochlorodimedone catalyzed by haloperoxidases. 

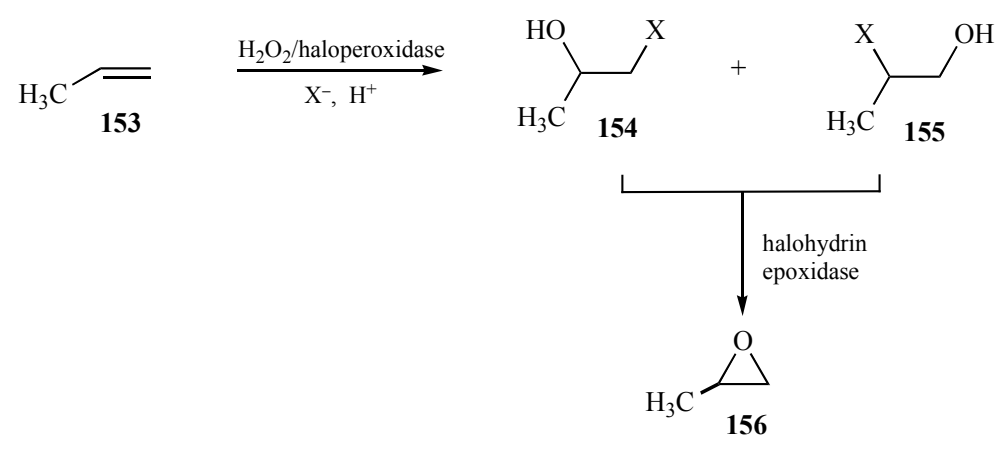

Scheme 34. Formation of halohydrins catalyzed by haloperoxidases.
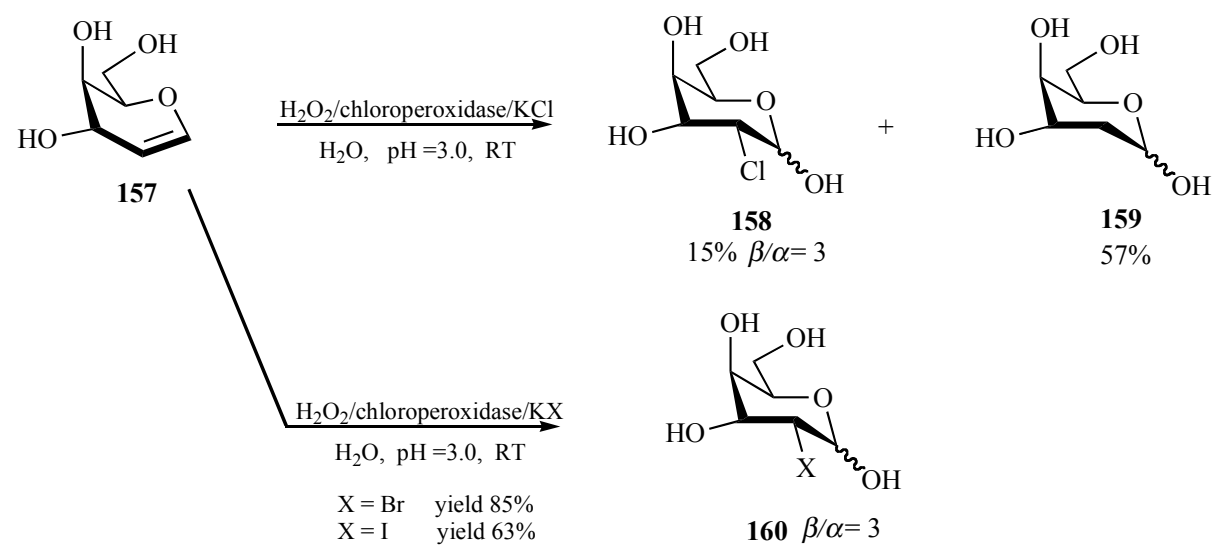

Scheme 35. Biohalogenations of glycals.

A number of heme and vanadium peroxidases were tested to catalyze enantioselective sulfoxidation. The highest yields were observed when chloroperoxidase from Caldariomyces fumago (CPO) was a catalyst. The dialkyl and alkyl aryl sulfides 163 were oxidized to sulfoxides 164 in excellent yields and high $(S)$-enantiomers dominated $[280,293,321]$. The examples are presented in Scheme 37 [280]. Some conformationally restricted sulfides (dihydrobenzenotiophenes) were also accepted by CPO but in such case $(R)$-isomers prevailed. The variations in products formation were dependent on substrate structures [322].

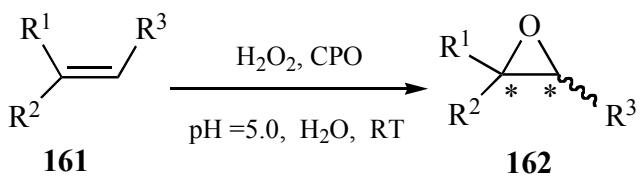

$$
\begin{array}{ll}
\mathrm{R}^{1}, \mathrm{R}^{2}=\mathrm{H} ; \mathrm{R}^{3}=\mathrm{Ph} & \text { yield } 89 \%, \text { ee } 49 \% \\
\mathrm{R}^{1}=\mathrm{H} ; \mathrm{R}^{2}=\mathrm{Me} ; \mathrm{R}^{3}=\mathrm{Ph} & \text { yield } 67 \%, \text { ee } 96 \% \\
\mathrm{R}^{1}=\mathrm{H} ; \mathrm{R}^{2}=\mathrm{Et} ; \mathrm{R}^{3}=n-\mathrm{Bu} & \text { yield } 20 \%, \text { ee } 95 \%
\end{array}
$$

Scheme 36. Epoxidation of olefins catalyzed by CPO.

Peroxidases catalyzing a variety of reactions are readily inactivated by their substrate, particularly hydrogen peroxide , when concentration of $\mathrm{H}_{2} \mathrm{O}_{2}$ is high, above $25 \mathrm{mM}$. Such inactivation of hemoprotein is described as "suicide inactivation" [323]. This problem can be solved by using a very low and controlled hydrogen peroxide supplementation, nessesary just for the maintenance of an effective oxidation level. This can be achieved using a direct pulsated addition,

electrogeneration in situ [324] or an enzymatic formation of hydrogen peroxide [325].

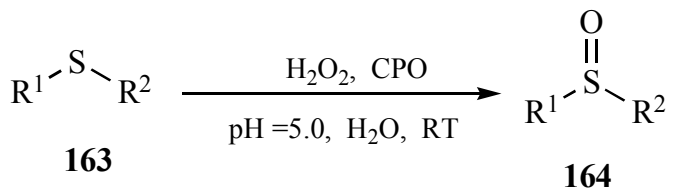

$$
\begin{array}{ll}
\mathrm{R}^{1}=\mathrm{Ph} ; \mathrm{R}^{2}=\mathrm{Me} & \text { yield } 90 \%, \text { ee } 99 \% \\
\mathrm{R}^{1}=\mathrm{PhCH}_{2} ; \mathrm{R}^{2}=\mathrm{Me} & \text { yield } 100 \%, \text { ee } 90 \% \\
\mathrm{R}^{1}=t-\mathrm{Bu} ; \mathrm{R}^{2}=\mathrm{Me} & \text { conversion } 80 \%, \text { ee } 85 \% \\
\mathrm{R}^{1}=\mathrm{CH}_{2}=\mathrm{CH} ; \mathrm{R}^{2}=\mathrm{Me} & \text { conversion }>98 \%, \text { ee }>98 \%
\end{array}
$$

Scheme 37. Enzymatic oxidation sulfides to sulfoxides.

\section{CONCLUSIONS AND OUTLOOK}

In this work an attempt has been made to summarize the progress in the exploitation of the non-metal-containing catalysts and enzymes for hydroperoxide, mainly hydrogen peroxide and tert-butyl hydroperoxide, oxidation. Among catalysts have been perhydrates, hydroperoxysulfonylhalides, oxazilidines, hydroperoxyflavines, aminoacids and polyaminoacids, cyclodextrins as well as selenium and tellurium compounds (oxides and organoselenium, and organotellurium compounds). Other hydroperoxide activators such as bases, acids and urea have also been presented. The described oxidant/catalyst systems are ecologically friendly reagents, convenient for modern organic synthesis and have been used for oxidative transformations of various groups of organic compounds. The most important reactions have been allylic hydroxylation, $\alpha$-oxygenation of alkenes and enolizable ketones, epoxydation of alkenes, oxidation of 
methyl groups in arenes and heteroarenes, 1,2-hydroxylation of alkenes, dehydrogenation and oxidative $\mathrm{C}-\mathrm{O}$ and $\mathrm{C}-\mathrm{C}$ cleavage, oxidative ring closure and ring transformation, heteroatom $N$ - and $S$-oxidation, Baeyer-Villiger conversion of ketenes into lactones and other. The mechanisms and stereochemistry of some important reactions have been discussed and their scope and limitations have been indicated. Where possible, links have been made to enzymatic oxygenations where hydroperoxides are oxygen sources. Although an effort has been made to include all relevant literature, authors do not claim completeness. However, this review can serve as a valuable critical overview of the area, and it is hoped that the contribution helps in encouraging further research in this field.

\section{ABBREVIATIONS}

\begin{tabular}{|c|c|c|}
\hline BAP & $=$ & Bicarbonate-activated peroxide \\
\hline BSA & $=$ & Bovine serum albumin \\
\hline $\mathrm{CPO}$ & $=$ & Chloroperoxidase \\
\hline DBU & $=$ & 1,8-Diazabicyclo[5.4.0]undec-7-ene \\
\hline HFIP & $=$ & 1,1,1,3,3,3-Hexafluoro-2-propanol \\
\hline HRP & $=$ & Horseradish peroxidase \\
\hline LiP & $=$ & Lignin peroxidase \\
\hline LPO & $=$ & Lactoperoxidase \\
\hline $\mathrm{MnP}$ & $=$ & Manganese peroxidase \\
\hline PTSA $=$ & $=$ & $p$-toluenesulfonic acid \\
\hline SBP & $=$ & Soybeen peroxidase \\
\hline $\mathrm{TBHP}=$ & $=$ & $t$-Butyl hydroperoxide \\
\hline TEMPO= & $=$ & 2,2,6,6-Tetramethylpiperidine-1-oxyl \\
\hline TFE & $=$ & 2,2,2-Trifluroethanol \\
\hline THF & $=$ & Tetrahydrofurane \\
\hline UHP & $=$ & $\begin{array}{l}\text { Percarbamide, hydrogen peroxide and urea } \\
\text { adduct, } \mathrm{CO}\left(\mathrm{NH}_{2}\right)_{2} \cdot \mathrm{H}_{2} \mathrm{O}_{2}\end{array}$ \\
\hline $\mathrm{VPO}$ & $=$ & Vanadium-containing peroxidase \\
\hline
\end{tabular}

\section{REFERENCES}

[1] Sheldon, R.A. Homogenous and heterogenous catalytic oxidations with peroxide reagents. Top. Curr. Chem., 1993, 164, 21-43.

[2] Rao, A.S.; Mohan, H.R. In Encyclopedia of Reagents for Organic Synthesis; Paquette, L.A., Ed.; Wiley\&Sons: Chichester, 1995; Vol. 4, pp. 2731-2735.

[3] Jones, A.K.; Wilson, T.E. In Encyclopedia of Reagents for Organic Synthesis; Paquette, L.A., Ed.; Wiley\&Sons: Chichester, 1995; Vol. 2, pp. 880-888.

[4] Berkessel, A.; Voglt, N. In The chemistry of peroxides; Rappoport, Z. Ed.; Wiley\&Sons: Chichester, 1996; Vol. 2, Part 1, pp. 307-595.

[5] Goor, G.; Glenneberg, J.; Jacobi, S. In Ullmans Encyclopedia of Industrial Chemistry; 6th ed.; Wiley-VCH; Weinheim, 2003; Vol. 17, pp. 253-305.

[6] Franz, G.; Sheldon, R.A. In Ullmans Encyclopedia of Industrial Chemistry; 6th ed.; Wiley-VCH; Weinheim, 2003; Vol. 24, pp. 487-544.

[7] Chen, M.S.; White, M.C. A predictably selective aliphatic C-H oxidation reactions for complex molecule synthesis. Science, 2007, 318, $783-787$.

[8] Sanderson, W.F. Cleaner industrial processes using hydrogen peroxide. Pure Appl. Chem., 2000, 72, 1289-1304.
[9] ten Brink, G.-J.; Arends, I.W.C.E.; Sheldon, R.A. The BayerVilliger Reaction: New developments toward greener procedures. Chem. Rev., 2004, 104, 4105-4124.

[10] Woodward, S.S.; Finn, M.G.; Sharpless, K.B. Mechanism of asymmetric epoxidation. 1. Kinetics. J. Am. Chem. Soc., 1991, 113, 106-113.

[11] Rossiter, B.E. In Encyclopedia of Reagents for Organic Synthesis; Paquette, L.A. Ed.; Wiley\&Sons: Chichester, 1995; Vol. 2, pp. $1407-1408$.

[12] Adam, W.; Saha-Moller, C.R.; Ganeshpure, P.A. Synthetic applications of nonmetal catalysts for homogenous oxidations. Chem. Rev., 2001, 101, 3499-3548.

[13] James A.P.; Sankey, M.; Johnstone, R.A.A.; McCarron, W.; Trenbirth, B. 5-Hydroxperoxycarbonyl-phthalimide: a new reagent for epoxidation. Chem. Commun., 1998, 429-430.

[14] Gelalcha, F.G. Heterocyclic hydroperoxides in selective oxidations. Chem. Rev., 2007, 107, 3338-3361.

[15] Rebek, J. Jr.; McCready, R. Olefin epoxidation with $a$-substituted hydroperoxides. J. Am. Chem. Soc., 1980, 102, 5602-5605.

[16] Nishio, T. Synthesis of 3-hydroperoxyindolin-2-ones and oxidation of sulphides to sulphoxides by 3-hydroperoxyindolin-2-ones. $J$. Chem. Soc. Perkin Trans. 1, 1991, 1717-1720.

[17] Drago, R.S.; Riley, R. Oxidation of $N$-alkylamides to novel hydroperoxides by dioxygen. J. Am. Chem. Soc., 1990, 112, 215218.

[18] Patton, D.E.; Drago, R.S. Regenerable $N$-alkylamide hydroperoxide for catalytic substrate oxidation. J. Chem. Soc. Perkin Trans. 1, 1993, 1611-1616.

[19] Hamann, H.J.; Hoft, E.; Liebsher, J. In Peroxide Chemistry, Mechanistic and Preparative Aspects of Oxygen Transfer; Adam, W., Ed.; Wiley-VCH, 2000; pp. 381-405.

[20] Dwyer, C.L.; Gill, C.D.; Ichihara, O.; Taylor, R.J.K. The enantioselective epoxidation of quinones using sugar hydroperoxides. Synlett, 2000, 704-706.

[21] Bundu, A.; Berry, N.G.; Gill, C.D.; Dwyer, C.L.; Stachulski, A.V.; Taylor, R.J.K.; Whittall, J. The design and synthesis of novel anomeric hydroperoxides: influence of the carbohydrate residue in the enantioselective epoxidation of quinones. Tetrahedron Asymmetry, 2005, 16, 283-293.

[22] Ho, T.L. Fiesers' reagents for organic synthesis, Wiley\&Sons: Hoboken, New Jersey, 1988-2008; Vol. 13, p. 145; Vol. 14, p. 177; Vol. 15, p. 294; Vol. 17, pp. 146-148; Vol. 18, pp. 184, 185; Vol. 19 , pp. 51-53, 166, 167; Vol. 20, pp. 61,62, 188; Vol. 21, pp. 76, 217, 218; Vol. 22, pp. 226, 227; Vol. 23, p. 204; Vol. 24, pp. 209210 .

[23] McNamara, C.A.; Dixon, M.J.; Bradley, M. Recoverable catalysts and reagents using recyclable polystyrene-based supports. Chem. Rev., 2002, 102, 3275-3300.

[24] Kaczorowska, K.; Kolarska, Z.; Mitka, K; Kowalski, P. Oxidation of sulfides to sufoxides. Part 2: oxidation by hydrogen peroxide. Tetrahedron, 2005, 61, 8315-8327.

[25] Piera, J.; Backvall, J.-E. Catalytic oxidation of organic substrates by molecular oxygen and hydrogen peroxide by multistep elektron transfer - A biomimetic approach. Angew. Chem. Int. Ed., 2008, 47, 3506-3523.

[26] Berkessel, A.; Groger, H. Asymmetric Organocatalysis; Wiley$\mathrm{VCH}$; Weinheim, 2005.

[27] Młochowski, J.; Kloc, K.; Lisiak, R.; Potaczek, P.; Wójtowicz, H. Developments in the chemistry of selenaheterocyclic compounds of practical importance in synthesis and medicinal biology. Arkivoc, 2007, vi, 14-46.

[28] Adam, W.; Lazarus, M.; Saha-Moller, C.R; Weichold, O.; Hoch, U.; Haring, D.; Schreier, P. In Biotransformations; Haber, F., Ed.; Springer-Verlag: Berlin-Heidelberg-New York, 2000; Vol. 63, p. 73.

[29] van der Velde, T.; van Rantwijk, F.; Sheldon, R.A. Improving the catalytic performance of peroxidases in organic synthesis. Trends Biotechnol., 2001, 19, 73-80.

[30] Colonna, S.; Caggero, N. Richelmi, C.; Pasta, P. In Enzymes in Action, Zwanenburg, B.; Mikołajczyk, M.; Kiełbasiński, P. Eds; Nato Science Series, Kluwer Academic Publishers: Dortrecht, 2000; Vol 33, p. 133-160.

[31] Zwanenburg, B.; ter Wiel, J. $a, b$-epoxysulfones by epoxidation of $a, b$-unsaturated sulfones. Tetrahedron Lett., 1970, 11, 935-936. 
[32] Mimount, H. Process for the preparation of lactones or epoxides. PCT Int. Appl. WO 2004078738, 2004; Chem. Abstr., 2004, 141, 227479.

[33] Yao, H.; Richardson, D.E. Epoxidation of Alkenes with Bicarbonate-Activated Hydrogen Peroxide. J. Am. Chem. Soc., 2000, 122, 3220-3221

[34] Falck, J.R.; Lai, J-Y.; Ramana, D.V.; Lee, S.-G. Synthesis of alcohols via mild oxidation of perfluoroethylstannates. Tetrahedron Lett., 1999, 40, 2715-2716.

[35] Pichou-Santander, C.; Scott, A.I. Preparation of pyrrolin-2-ones and 4,5-dihydropyrrin-1-ones by oxidation of $a$-formylpyrroles and $a$-formyldipyrromethanes with hydrogen peroxide. Tetrahedron Lett., 2000, 41, 2825-2829.

[36] Li, G.; Fajima, H.; Ohtani, F. An improved procedure for the preparation of isothiocyanates from primary amines by using hydrogen peroxide as the dehydrosulfurization reagent. J. Org. Chem., 1997, 62, 4539-4540.

[37] Subba Rao, Y.V.; De Vos, D.E.; Jacobs, P.A. 1,5,7Triazabicyclo[4.4.0]dec-5-ene Immobilized in MCM-41: A Strongly basic porous catalyst. Angew. Chem., Int. Ed., 1997, 36, 2661-2663.

[38] Kluge, R.; Schulz, M.; Liebsch, S. Diastereoselective epoxidation of olefins by organosulfonic peracids, II. Tetrahedron, 1996, 52, 2957-2976.

[39] Kluge, R.; Hocke, H.; Schulz, M. Activation of hydrogen peroxide for asymmetric epoxidation by chiral arenesulfonimidoylimidazoles. Tetrahedron Asymmetry, 1997, 8, 2513-2516.

[40] Olach, G.A.; Arvanaghi, M.; Vankar, Y.D.; Prakash G.K.S. Synthetic methods and reactions; 89. Improved transformation of nitro compounds into carbonyl compounds by hydrogen peroxide /potassium carbonate. Synthesis, 1980, 662-663.

[41] Bach, R.D. In Encyclopedia of Reagents for Organic Synthesis; Paquette, L.A. Ed.; Wiley\&Sons: Chichester, 1995; Vol. 6, pp. 3944-3945.

[42] Gillit, N.D.; Domingos, J.; Bunton, C.A. Oxidation of thioanisole by hydrogen peroxide: activation by nitriles. J. Phys. Org. Chem., 2003, 16, 603-607.

[43] Bachmann, C.; Gesson, J.-P.; Renoux, B.; Tranoy, I. A Hydrogenbonded model for the syn epoxidation of cyclic allylic ethers under Payne conditions. Tetrahedron Lett., 1998, 39, 379-382.

[44] Vacque, D.; Dupuy, N.; Sombret, B.; Huvenne, J.P.; Legrant, P. In situ characterization of peroxybenzimidic acid by FT-raman and ATR/FTIR spectroscopy. J. Mol. Struct., 1996, 384,165-171.

[45] Bach, R.D.; Knight, J.W. Epoxidation of olefins by hydrogen peroxide-acetonitrile: cis-cyclooctene oxide. Org. Synth., Coll. Vol., 1990, 7, 126-128.

[46] Pandiarajan, K. In Synthetic reagents; Pizey, J.S. Ed.; HorwoodWiley: New York, 1985; p. 60.

[47] Bulman Page, P.C.; Graham, A.E.; Bethel, D.; Park, B.K. A simple convenient method for the oxidation of sulphides. Synth. Commun., 1993, 23, 1507-1514.

[48] Giurg, M.; Młochowski, J.; Ambrożak, A. hydrogen peroxide oxidation of $\mathrm{N}, \mathrm{N}$-dimethylhydrazones promoted by selenium compounds, titanosilicalites or acetonitrile. Polish. J. Chem., 2002, 76, 1713-1720.

[49] Yamaguchi, K.; Mizugaki, T.; Ebitani, K.; Kanada, K. Heterogenous $\mathrm{N}$-oxidation of pyridines Rusing a combined oxidant of hydrogen peroxide and nitriles catalysed by basic hydrotalcites. New J. Chem., 1999, 23, 799-802.

[50] Brown, H.C.; Snyder, C.; Subba Rao, B.C.; Zweifel, G. Organoboranes for synthesis: Oxidation of organoboranes with alkaline hydrogen peroxide as a convenient route for the cishydratation of alkenes via hydroboration. Tetrahedron, 1986, 42, 5505-5510.

[51] Ogata, Y.; Sawaki, Y.; Shiroyama, M. Oxidative cleavage of $a$ ketols and related ketones with alkaline hydrogen peroxide. J. Org. Chem., 1977, 42, 4061-4066.

[52] Ho, T-L. Ketone regeneration from oximes with alkaline hydrogen peroxide. Synth. Commun., 1980, 10, 465-468.

[53] Hocking, M.B. Dakin oxidation of $o$-Hydroxyacetophenone and some benzophenones: rate enhancement and mechanistic aspects. Can. J. Chem., 1973, 51, 2384-2392.

[54] Apple, I.A.; Meth-Cohn, O. 2-Aminobenzaldehydes from quinolinium salts and alkaline hydrogen peroxide. Arkivoc, 2002, $v i, 4-14$.
[55] Richardson, D.E.; Yao, H.; Frank, K.M.; Bennett, D. Equilibria, kinetics and mechanism in the bicarbonate activation of hydrogen peroxide: oxidation of sulfides by peroxymonocarbonate. J. Am. Chem. Soc., 2000, 122, 1729-1739.

[56] Flaganan, J.; Jones, D.P.; Griffith, W.P.; Skapski, A.C.; West, A.P. On the existence of peroxycarbonates in aqueous solution. J. Chem. Soc., Chem. Commun., 1986, 20-21.

[57] Adam, A.; Mehta, M. $\mathrm{KH}\left(\mathrm{O}_{2}\right) \mathrm{CO}_{2} \mathrm{H}_{2} \mathrm{O}_{2}$ - An oxygen-rich salt of monoperoxocarbonic acid. Angew. Chem., Int. Ed., 1998, 37, 13871388.

[58] Fakhraian, H.; Valizadeh, F. Activation of hydrogen peroxide via bicarbonate, sulfate, phosphate and urea in the oxidation of methyl phenyl sulfide. J. Mol. Catal. A: Chem., 2010,333, 69-72.

[59] Vakhitova, L.N.; Zhil'tsova, S.V.; Skrypka, A.V.; Razumova, N.G.; Taran, N.A.; Savelova, V.A.; Popov, A.F. Micellar catalytic effects in the oxidation of methyl phenyl sulfide with hydrogen peroxide and the peroxocarbonate anion. Theor. Exp. Chem., 2006, 42, 287-294.

[60] Regino, C.A.S.; Richardson, D.E. Bicarbonate-catalysed hydrogen peroxide oxidation of cysteine and related thiols. Inorg. Chim. Acta, 2007, 360, 3971-3977.

[61] Schulz, M.; Berlin, P. Isomeric peroxy esters of sugar carboxylic acids. Angew. Chem., Int. Ed., 1967, 6, 950-951.

[62] Klein, R.J.; Milas, N.A. Organic peroxides. XL. Reaction of symand unsym-phthaloiyl chloride with tert-butyl hydroperoxide. $J$. Org. Chem., 1971, 36, 2900-2902.

[63] Baj, S.; Chrobok, A. The synthesis of organic peresters via the phase-transfer catalysis. Polish J. Chem., 1999, 73, 1185-1189.

[64] Rindich, N.O.; Lyavinets, O.S. Acylation of tert-butyl hydroperoxide by benzoyl chloride in media with high basicity. Ukr. Khim. Zh., 2009, 75, 123-127.

[65] Kropp, H.; Ball, M.; Schroeder, H.; Witke, G. Organische peroxide - X: Basenkatalizierte addition von hydroperoxiden an oxirane. Tetrahedron, 1974, 30, 2943-2948.

[66] Mattersteig, G.; Pritzkow, W.; Voerckel, V. The reaction of organic hydroperoxides with aromatic nitro compounds: First examples of a Vicarious Nucleophilic Hydroxylation. J. Prakt. Chem., 1990, 332 569-572.

[67] Brose, T.; Holzscheiter, F.; Mattersteig, G.; Pritzkow, W.; Voerckel, V. Vicarious nucleophilic hydroxylation of aromatic nitro compounds with organic hydroperoxides. J. Prakt. Chem./Chem. Ztg., 1992, 334, 497-504.

[68] Makosza, M.; Sienkiewicz, K. Hydroxylation of nitroarenes with alkylhydroperoxide anions via vicarious nucleophilic substitution of hydrogen. J. Org. Chem., 1998, 63, 4199-4208.

[69] Rao, A.S.; Mohan, H.R. In Encyclopedia of Reagents for Organic Synthesis; Paquette, L.A. Ed.; Wiley\&Sons: Chichester, 1995; Vol. 6, pp. 3933-3939.

[70] Caster, A.C.; Rao, A.S.; Mohan, H.R. In Encyclopedia of Reagents for Organic Synthesis; Paquette, L.A. Ed.; Wiley\&Sons: Chichester, 1995; Vol. 6, pp. 5167-5172.

[71] Youssif, S. Recent trends in the chemistry of pyridine $N$-oxides. Arkivoc, 2001, $i, 242-268$.

[72] Dodd, R.H.; Le Hyaric, M. The oxidation of aromatic aldehydes to carboxylic acids using hydrogen peroxide in formic acid. Synthesis, 1993, 295-297.

[73] Kumar, G.; Gupta, V.; Gautam, D.; Gupta, R. Synthesis of sulfones of 4H-1,4-benzothiazines and phenothiazines. Phosphorus Sulfur Silicon Relat. Elem., 2004, 179, 1941-1948.

[74] Tiwari, K.K.; Bit, K.C.; Thakur, S.K.; Mishra, K.K.; Rao, S.R. PCT Int. Appl. WO 200456739, 2004; Chem. Abstr., 2004, 141 88923

[75] Thiel, W.; Sun, Y.; Schubert, A.; Bohle, A. PCT Int. Appl. WO 2005123644, 2005; Chem. Abstr., 2007, 144, 69665.

[76] Olach, G.A.; Fung, A.P.; Keumi, T. Oxyfunctionalization of hydrocarbons. 11. Hydroxylation of benzene and alkylbenzenes with hydrogen peroxide in hydrogen fluoride/boron trifluoride. $J$. Org. Chem., 1981, 46, 4305-4306.

[77] Dakka J.; Sasson, Y. Hydrobromic acid catalyzed oxidation of benzyl alcohol by hydrogen peroxide. Bull. Soc. Chim. France, 1988, 756

[78] Olach, G.A.; Narang, S.C.; Salem, G.F. Synthetic methods and reactions; 78. Cleavage of ethanediyl $s, s$-acetals with hydrochloric acid/hydrogen peroxide. Synthesis, 1980, 657 .

[79] Roy, A.; Reddy, K.R.; Mohanta, P.K.; Ila, H.; Jungjappat, H Hydrogen peroxide/boric acid: an efficient system for oxidation of 
aromatic aldehydes and ketones to phenols. Synth. Commun., 1999, 29, 3781-3791.

[80] Sharma, V.B.; Jain, S.L; Sain, B. A new and efficient transition metal-free oxidation of secondary alcohols to ketones using aqueous $\mathrm{HBr}$ and $\mathrm{H}_{2} \mathrm{O}_{2}$. Synlett, 2005, 173-175.

[81] Terent'ev, A.O.; Kutkin, A.V.; Troitzky, N.A.; Ogibin, Y.N.; Nikishin, G.I. Synthesis of geminal bisperoxides by acid-catalyzed reaction of acetals and enol ethers with tert-butylhydroperoxide. Synthesis, 2005, 2215-2219.

[82] Terent'sev, A.O.; Kutkin, A.V.; Platonov, M.M.; Ogibin, Y.N.; Nikishin, G.I. A new method for the synthesis of bishydroperoxides based on a reaction of ketals with hydrogen peroxide catalyzed by boron trifluoride complexes. Tetrahedron Lett., 2003, 44, 73597363.

[83] Hamann, H.-J.; Liebscher, J. Primary geminal bishydroperoxides by hydroperoxide rearrangement. Synlett, 2001, 2001, 96-98.

[84] Massa, A.; Palombi, L.; Scettri, A. A convenient approach to renevable hydroperoxides. Tetrahedron Lett., 2001, 42, 4577-4579.

[85] Takeda, T.; Watanabe, H.; Kitahara, T. Direct oxidation of acetals and aldehydes to esters. Synlett, 1997, 1997, 1149-1150.

[86] Baumstark, A.; Chen, Y.-X.; Rodriguez, A. Synthesis and oxygenatom transfer reactions of 3-hydroperoxy-3,4,4,5,5pentasubstituted-1,2-dioxolanes. J. Heteroatom. Chem., 1996, 33, 1399-1402.

[87] Berkessel, A.; Andreae, M.R.M.; Schmickler, H.; Lex, J. BaeyerVilliger oxidation with hydrogen peroxide in fluorinated alcohols: Lactone formation by a nonclassical mechanism. Angew. Chem., Int. Ed., 2002, 41, 4481-4484.

[88] Berkessel, A; Andreae, M.R.M. Efficient catalytic methods for the Baeyer-Villiger oxidation and epoxidation with hydrogen peroxide. Tetrahedron Lett., 2001, 42, 2293-2295.

[89] Neimann, K.; Neumann, R. Electrophilic activation of hydrogen peroxide: selective oxidation reactions in perfluorinated alcohol solvents. Org. Lett., 2000, 2, 2861-2863.

[90] Ravikumar, K.S.; Begue, J.-P.; Bonnet-Delpon, D. A selective conversion of sulfide to sulfoxide in hexafluoro-2-propanol. Tetrahedron Lett., 1998, 39, 3141-3144.

[91] Yan, Z.; Tian, W.; Caster, A.C.; Rao, A.S.; Mohan, H.R. In Encyclopedia of Reagents for Organic Synthesis; Paquette, L.A., Ed.; Wiley\&Sons: Chichester, 1995; Vol. 6, pp. 5167-5172.

[92] Usui, Y.; Sato, K.; Tanaka, M. Catalytic dihydroxylation of olefins with hydrogen peroxide: an organic-solvent and metal-free system. Angew. Chem., Int. Ed., 2003, 42, 5623-5625.

[93] Vayssie, S.; Elias, H. Fast oxidation of organic sulfides by hydrogen peroxide by in situ generated peroxynitrous acid. Angew. Chem., Int. Ed., 1998, 37, 2088-2090.

[94] Haeney, H. In Encyclopedia of Reagents for Organic Synthesis, Paquette, L.A. Ed.; Wiley\&Sons: Chichester, 1995; Vol. 4, pp. 2742-2743.

[95] Ballini, R.; Marcantoni, E.; Petrini, M. Synthesis of functionalized nitroalkanes by oxidation of oximes with urea-hydrogen peroxide complex and trifluoroacetic anhydride. Tetrahedron Lett., 1992, 33, 4835-4838.

[96] Astudillo, L.; Galindo, A.; Gonzales, A.G.; Mansilla, H. A very simple oxidation of olefins and ketones with UHP-Maleic anhydride. Heterocycles, 1993, 36, 1075-1080.

[97] Balicki, R. A Mild and efficient procedure for the oxidation of organic sulfides to sulfones by use of urea-hydrogen peroxide/trifluoroacetic anhydride system. Synth. Commun., 1999, 29, 2235-2339.

[98] Varma, R.S.; Naicker, K.P. The urea-hydrogen peroxide complex: solid-state oxidative protocols for hydroxylated aldehydes and ketones (Dakin Reaction), nitriles, sulfides and nitrogen heterocycles. Org. Lett., 1999, 1, 189-192.

[99] Caron, S.; Do, N.M.; Sieser, J.E. A practical, efficient and rapid method for the oxidation of electron deficient pyridines using trifluoroacetic anhydride and hydrogen peroxide-urea complex. Tetrahedron Lett., 2000, 41, 2299-2302.

[100] Karami, B.; Montazerozohori, M.; Habibi, M.H. Urea-Hydrogen Peroxide (UHP) oxidation of thiols to corresponding disulfides promoted by maleic anhydride as mediator. Molecules, 2005, 10, 1358-1363.

[101] Balicki, R. A mild and convenient procedure for the oxidation of aromatic aldehydes to carboxylic acids using urea-hydrogen peroxide in formic acid. Synth. Commun., 2001, 31, 2195-2198.
[102] Paul, S.; Nanda, P.; Gupta, R. Solvent-free benzylic oxidations using urea-hydrogen peroxide complex (uhp) under microvawe irradiation. Synlett, 2004, 531-532.

[103] Legros, J.; Crousse, B.; Bonnet-Delpon, D.; Begue, J.-P. UreaHydrogen peroxide/hexafluoro-2-propanol: an efficient system for a catalytic epoxidation reactions without a metal. Eur. J. Org. Chem., 2002, 3290-3293.

[104] Luliński, P.; Kryska, A.; Sosnowski, M.; Skulski, L. Eco-Friendly oxidative iodination of various arenes with urea-hydrogen peroxide adduct (UHP) as the oxidant. Synthesis, 2004, 441-445.

[105] Page, T.K.; Wirth, T. Simple direct synthesis of [bis(trifluoroacetoxy)iodo]arenes. Synthesis, 2006, 3153-3155.

[106] Ganeshpure, P.A.; Adam, W. a-Hydroxy hydroperoxiodes (perhydrates) as oxygen transfer agents in organic synthesis. Synthesis, 1996, 179-188.

[107] Chambers, R.D.; Clark, M. Hexafluoroacetone-hydrogen peroxide, a new peroxyacid. Tetrahedron Lett., 1970, 11, 2741-2742.

[108] Ganem, B.; Heggs, R.P.; Biloski, A.J.; Schwartz, D.R. A new oxidation of aldehydes to carboxylic acids. Tetrahedron Lett., 1980, 21, 685-688.

[109] Kojo, S.; Fukunishi, K. Hydroxylation of benzenes involving the $\mathrm{NIH}$ shift utylizing electronic model compound for monooxygenases. Chem. Lett., 1983, 1707-1710.

[110] Adam, W.; Ganeshpure, P.A. Oxidation of arenes to para-quinones with hydrogen peroxide catalyzed by hexafluoroacetone hydrate. Synthesis, 1993, 280-282.

[111] Ganem, B.; Biloski, A.J.; Heggs, R.P. A biomimetic heteroatom oxidation. Tetrahedron Lett., 1980, 21, 689-690.

[112] van Vliet, M.C.A.; Arends I.W.C.E.; Sheldon, R.A. Pentafluoroheptadecan-9-one: a selective and reusable catalyst for epoxidation with hydrogen peroxide. Chem. Commun., 1999, 263264.

[113] Kasch, H. A novel highly effective and stereoselective epoxidation of allylic and homoallylic alcohols using chloral hydrate and hydrogen peroxide. Tetrahedron Lett., 1996, 37, 8350.

[114] Stark, C.J. Epoxidation of olefins by hydrogen peroxide in the presence of tetrachloroacetone. Tetrahedron Lett., 1981, 22, 20892092.

[115] Mais, D.E.; Chen, L.-Z.; Wagoner, M.A.; Hayes, J.S.; Wang, M.W. Synthesis and characterization of tritium-labelled RU486. J. Label. Compd. Radiopharm., 1995, 36, 1199-1203.

[116] Ottow, E.; Beier, S.; Elger, W.; Henderson, D.A.; Neef, G.; Wiechert, R. Synthesis of ENT-17(prop-1-ynyl-17b-hydroxy-11b(4-(N,N-dimethylamino)-phenyl)-4,9-estradien-3-one, the antipode of RU-38486. Steroids, 1984, 44, 519-530.

[117] Scholz, S.; Hofmeister, H.; Neef, G.; Ottow, E.; Scheidges, C.; Wiechert, R. Synthese von 14,17-überbrückten $11 b$-Arylsteroiden. Liebigs Ann. Chem., 1989, 151-158.

[118] Nickisch, K.; Arnold, H.; Rohde, R. European patent appl. 298,020, 1989; Chem. Abstr., 1989, 111, 39670.

[119] Cleve, A.; Fritzemeier, K.H.; Heinrich, N.; Klar, U.; MuellerFahrnow, A.; Neef, G.; Ottow, E.; Schwede, W. 18b-Aryl steroids in the androstene series. The role of the $11 b$-region in steroid progesterone receptor interaction. Tetrahedron, 1996, 52, 15291542.

[120] Cleve, A.; Neef, G.; Ottow, E.; Scholz, S.; Schwede, W. Synthesis of $14 b-H$ antiprogestins. Tetrahedron, 1995, 51, 5563-5572.

[121] Lupattelli, P.; Ruzziconi, R.; Scafato, P.; Degl'Innocenti, A.; Paolbelli, A.B.; Beli, A. 1,1,1-Trifluoroacetone as an efficient catalyst for the hydrogen promoted selective oxidation of sulfides to sulfoxides. Synth. Commun., 1997, 27, 441-446.

[122] Neimann, K.; Neumann, R. A new non-metal heterogenous catalyst for the activation of hydrogen peroxide: a perfluorinated ketone attached to silica for oxidation of aromatic amines and alkenes. Chem. Commun., 2001, 487-488.

[123] Bethell, D.; Bulman Page, P.C.; Vahedi, H. Catalytic asymmetric oxidation of sulfides to sulfoxides mediated by chiral 3-substituted1,2-benzisothiazole 1,1-dioxides. J. Org. Chem., 2000, 65, 67566760 .

[124] Bulman Page, P.C.; Heer, J.P.; Bethell, D.; Lund, B. A Asymmetric sulfur oxidation mediated by camphorsulfonylimines. Phosphorus Sulphur Silicon Relat. Elem., 1999, 153-154, 247-258.

[125] Bulman Page, P.C.; Heer, J.P.; Bethell, D.; Collington, E.W.; Andrews, D.M. Asymmetric sulfoxidation using [(3,3-Dimethoxycamphoryl)sulfonyl]oxaziridine. Tetrahedron Asymmetry, 1995, 6 , 2911-2914. 
[126] Bulman Page, P.C.; Heer, J.P.; Bethell, D.; Collington, E.W.; Andrews, D.M. Highly enantioselective catalytic asymmetric oxidation of sulfides using hydrogen peroxide. Synlett, 1995, 773775 .

[127] Bulman Page, P.C.; Heer, J.P.; Bethell, D.; Collington, E.W.; Andrews, D.M. A new system for catalytic asymmetric oxidation of sulfides using a hydrogen peroxide based reagent. Tetrahedron Lett., 1994, 35, 9629-9632.

[128] Bulman Page, P.C.; Bethell, D.; Stocks, P.A.; Heer, J.P.; Graham, A.E.; Vahedi, H.; Healy, M.; Collington, E.W.; Andrews, D.M. Sulfur oxidation mediated by imine derivatives. Synlett, 1997, 1355-1358.

[129] Murahashi, S-I.; Oda, T.; Masui, Y. Flavin-catalyzed oxidation of amines and sulfur compounds with hydrogen peroxide $\mathrm{J}$. Am. Chem. Soc., 1989, 111, 5002-5003.

[130] Chaudhary, S.; Awasthi, A.; Chauhan, S.M.S. Biomimetic oxidation of nicotine with hydrogen peroxide and 5-ethylflavin mononucleotide perchlorate. Indian. J. Chem., Sect. B, 1998, 37B, 294-297.

[131] Minidis, A.B.E.; Bäckvall, J.-E. Mild and efficient flavin-catalyzed $\mathrm{H}_{2} \mathrm{O}_{2}$ oxidations. Chem. Eur. J., 2001, 7, 297-302.

[132] Lindén, A.A.; Krüger, L.; Bäckvall, J.-E. Highly selective sulfoxidation of allylic and vinylic sulfides by hydrogen peroxide using flavin as catalyst. J. Org. Chem., 2003, 68, 5890-5896.

[133] Bergstad, K.; Bäckvall, J.-E. Mild and efficient flavin-catalyzed $\mathrm{H}_{2} \mathrm{O}_{2}$ Oxidation of tertiary amines to amine $N$-Oxides. J. Org. Chem., 1998, 63, 6650-6655.

[134] Mazzini, C.; Lebreton, J.; Furstoss, R. Flavin-catalyzed baeyervilliger reaction of ketones: oxidation of cyclobutanones to $g$ lactones using hydrogen peroxide. J. Org. Chem., 1996, 61, 8-9.

[135] Murahashi, S.-I.; Ono, S.; Imada, S.Y. Asymmetric baeyer-villiger reaction with hydrogen peroxide catalyzed by a novel planar-chiral bisflavin. Angew. Chem., Int. Ed., 2002, 41, 2366-2368.

[136] Reddy, K.R.; Rajasekhar, C.V.; Ravindra, A.R. L-Proline $\mathrm{H}_{2} \mathrm{O}_{2}$ : A new chemoselective approach for oxidation of sulfides to sulfoxides. Synth. Commun., 2006, 36, 3761-3766.

[137] Juliá, S.; Masana, J.; Vega, J.C. "Synthetic Enzymes". Highly stereoselective epoxydation of chalkone in a triphasic toluenewater-poly[(s)-alanine] system. Angew. Chem., Int. Ed., 1980, 19, 929-931

[138] Juliá, S.; Guixer, J.; Masana, J.; Rocas, J.; Colonna, S.; Annuziata, R.; Molinari, H. Synthetic Enzymes. Part 2. Catalytic asymmetric epoxidation by means of polyamino acids in a triphase system. $J$. Chem. Soc., Perkin Trans. 1, 1982, 1317-1324.

[139] Colonna, S.; Molinari, H.; Banfi, S.; Juliá, S.; Masana, J.; Alvarez, A. Synthetic Enzymes- 4: Highly enantioselective epoxidation by means of polyamino acids in a triphase system: influence of structural variations within the catalyst. Tetrahedron, 1983, 39, 1635-1641.

[140] Banfi, S.; Colonna, S.; Molinari, H.; Juliá, S.; Guixer, J. Asymmetric epoxidation of electron-poor olefins- V: Influence on stereoselectivity of the structure of poly- $a$-amino acids used as catalysts. Tetrahedron, 1984, 40, 5207-5211.

[141] Porter, M.J.; Skidmore, J. Asymmetric epoxidation of electrondeficient olefins. Chem. Commun., 2000, 1215-1225.

[142] Kroutil, W.; Lasterra-Sánchez, M.E.; Maddrell, S.J.; Mayon, P.; Morgan, P.; Roberts, S.M.; Thornton, S.R.; Todd, C.J.; Tüter, M. Development of the Julia asymmetric epoxidation reaction. Part 2. Application of the oxidation to alkyl enones, enediones and unsaturated keto esters. J. Chem. Soc., Perkin Trans. 1, 1996, 2837 2844.

[143] Adger, B.M.; Barkley, J.V.; Bergeron, S.; Cappi, M.W.; Flowerdew, B.E.; Jackson, M.P.; McCague, R.; Nugent, T.C.; Roberts, S.M. Improved procedure for Julia-Colonna asymmetric epoxidation of $a, b$-unsaturated ketones: total synthesis of diltiazem and Taxol side-chain. J. Chem. Soc., Perkin Trans. 1, 1997, 35013508 .

[144] Bentley, P.A.; Bergeron, S.; Cappi, M.W.; Hibbs, D.E.; Hursthouse, M.B.; Nugent, T.C.; Pulido, R.; Roberts, S.M.; Wu, L.E. Asymmetric epoxidation of enones employing polymeric $a$ amino acids in non-aqueous media. Chem. Commun., 1997, 739740 .

[145] Dhanda, A.; Drauz, K.-H.; Geller, T.P.; Roberts, S.M. PaaSiCats: Novel polyamino acid catalyst. Chirality, 2000, 12, 313-317.

[146] Allen, J.V.; Drauz, K.-H.; Flood, R.W.; Roberts, S.M.; Skidmore, J. Polyamino acid catalysed asymmetric epoxidation: Sodium percarbonate as a source of base and oxidant. Tetrahedron Lett., 1999, 40, 5417-5420.

[147] Geller, T.; Roberts, S.M. A new procedure for the Julia-Colonna stereoselective epoxidation reaction under non-aqueous conditions: the development of a catalyst comprising polyamino acid on silica. J. Chem. Soc., Perkin Trans. 1, 1999, 1397-1398.

[148] Carde, L.; Davies, H; Geller, T.; Roberts, S.M. PaaSiCats Powerful catalysts for asymmetric epoxidation of enones. Novel syntheses of $\alpha$-arylopropanoic acids including $(S)$-fenoprofen. Tetrahedron Lett., 1999, 40, 5421-5424.

[149] Allen J.V.; Cappi, M.W.; Cary, P.D.; Roberts, S.M.; Williamson N.M.; Wu, L.E. Stereoselective epoxidation of electron-poor dienes using poly(L-leucine). J. Chem. Soc., Perkin Trans. 1, 1997, $3297-$ 3298.

[150] Colonna, S.; Gaggero, N.; Manfredil, A., Spadoni, M.; Casella, L.; Carrea, G.; Pasta, P. Asymmetric Weiz-Scheffer epoxidation promoted by bovine serum albumin: Part III. Highly stereoselective synthesis of optically active epoxynaphthoquinones. Tetrahedron, 1988, 44, 5169-5178.

[151] Drabowicz, J.; Mikołajczyk, M. Asymmetric oxidation of sulfides to sulfoxides catalyzed by b-Cyclodextrin. Phosphorus Sulfur Silicon Relat. Elem., 1984, 21, 245-248.

[152] Ji, H.-B.; Hu, X-F.; Shi, D-P.; Li, Z. Controllable oxidation of sulfides to sulfoxides and sulfones with aqueous hydrogen peroxide in the presence of $b$-cyclodextrin. Russian J. Org. Chem., 2006, 42, 959-961.

[153] Banfi, S.; Colonna,S.; Julia, S. Asymmetric catalytic epoxidation by means of cyclodextrins. Synth. Commun., 1983, 13, 1049-1052.

[154] Colonna, S.; Banfi, S.; Papagni, A. Catalytic asymmetric epoxidation in the presence of cyclodextrins. Gazz. Chim. Ital., 1985, 115, 81-83.

[155] Colonna, S.; Manfredi, A.; Annunziata, R.; Gaggero, N.; Casella, L. Biomimetic asymmetric synthesis. Enantioselective WeizScheffer epoxidation of vitamin $\mathrm{K}_{3}$ and analogs in the presence of cyclodextrins. J. Org. Chem., 1990, 55, 5862-5866.

[156] Hu, Y.; Harada, A.; Takahashi, S. Cyclodextrin $\mathrm{H}_{2} \mathrm{O}_{2}$ : A new system for asymmetric epoxidation. Synth. Commun., 1988, 18, 1607-1610.

[157] Bhat, S.; Chandrasekaran, S. Oxygenation of alkenes with $t$-BuOH catalysed by cyclodextrin borate. Tetrahedron Lett., 1996, 37 3581-3584.

[158] Dong, Z.-Y.; Huang, X.; Mao, S.-Z.; Liang, K.; Liu, J.-Q.; Luo, G.M.; Shen, J.-C. Cyclodextrin-derived mimic of glutathione peroxidase exhibiting enzymatic specificity and high catalytic efficiency. Chem. Eur. J., 2006, 12, 3575-3579.

[159] Marinescu, L.; Molbach, M.; Rousseau, C.; Bols, M. Supramolecular oxidation of anilines using hydrogen peroxide as stoichiometric oxidant. J. Am. Chem. Soc., 2005, 127, 1757817579.

[160] Lopez, O.L.; Marinescu, L.; Bols, M. New cup-shaped acyclodextrin derivatives and a study on their catalytic properties in oxidation reactions. Tetrahedron, 2007, 63, 8872-8880.

[161] Hauch, F.T.; Bierre, J.; Bols, M. Cyclodextrin aldehydes are oxidase mimics. ChemBioChem., 2009, 10, 2494-2503.

[162] Riley, H.L.; Morley J.F.; Friend, N.A.C. Selenium dioxide, a new oxidizing agent. Part I. Its reaction with aldehydes and ketones. $J$ Chem. Soc., 1932, 1875-1883.

[163] Maity, A.C. Selenium Dioxide $\left(\mathrm{SeO}_{2}\right)$ - A versatile reagent Synlett, 2008, 465-466.

[164] Paulmier, C. Selenium Reagents and Intermediates in Organic Synthesis, Pergamon Press: Oxford, 1986.

[165] Back, T.G. In The Chemistry of Organic Selenium and Tellurium Compounds; Patai, S.; Rapoport, Z., Eds.; Wiley \& Sons: Chichester, 1987; Vol. 2, Chap. 3, pp. 91-213.

[166] Hoekstra, W.J. Selenium(IV) oxide In e-EROS Encyclopedia of Reagents for Organic Synthesis, Wiley\&Sons, 2010.

[167] McNally, J. Selenium(IV) oxide - tert-Butylhydroperoxide In eEROS Encyclopedia of Reagents for Organic Synthesis, Wiley\&Sons, 2010.

[168] Młochowski, J.; Said, S.B. Catalyzed hydrogen peroxide oxidation of organic compounds. Polish. J. Chem., 1997, 71, 149-169.

[169] Smith, C.W.; Holm, R.T. Reactions of Hydrogen Peroxide. I. A novel use of selenium dioxide as catalyst for oxidation of acrolein to acrylic acid. J. Org. Chem., 1957, 22, 746-748. 
[170] Gebhardt, C.; Priewisch, B.; Ivran, E.; Rueck-Braun, K. Oxidation of anilines with hydrogen peroxide and selenium dioxide as catalyst. Synthesis, 2008, 1889-1894.

[171] Ogawa, A. Selenium and Tellurium in Organic Synthesis In Main Group Metals in Organic Synthesis; Yamamoto, Y.; Oshima, K.. Eds.; Wiley-VCH Verlag: Weinheim, 2004; Vol. 2, pp. 813-866.

[172] Sharpless, K.B.; Umbreit, M.A. Allylic oxidation of olefins by catalytic and stoichiometric selenium dioxide with tert-butyl hydroperoxide. J. Am. Chem. Soc., 1977, 99, 5526-5528.

[173] Ernet, T.; Haufe, G. Allylic hydroxylation of vinyl fluorides. Synthesis, 1997, 953-956.

[174] Knothe, G.; Bagby, M.O.; Weisleder, D.; Peterson, R.E. Allylic mono- and dihydroxylation of isolated double bonds with selenium dioxide - tert-butyl hydroperoxide. J. Chem. Soc., Perkin Trans 2, 1994, 1661-1670.

[175] Jie, M.S.; Pasha, M.K.; Alam, M.S. Oxidation reactions of acetylenic fatty esters with selenium dioxide/tert-butyl hydroperoxide. Lipids, 1997, 32, 1119-1123.

[176] Li, Y.; Huang, C.; Li, W.; Li, Y. A facile total synthesis of (3R,7RS)-3,7,11-Trimethyl-10-oxododecanoic acid. Synth. Commun., 1997, 27, 4341-4348.

[177] Warpehoski, M.A.; Chabaud, B.; Sharpless, K.B. Selenium dioxide oxidation olefins. Evidence for a dissociation-recombination pathway. J. Org. Chem., 1982, 47, 2897-2900.

[178] Cecherelli, P.; Curini, M.; Marcotullio, M.C.; Rosati, O. Trans 1,2functionalization of cycloalkanes using selenium intermediates. Tetrahedron Lett., 1989, 30, 3175-3178.

[179] Chabaud, B.; Sharpless, K.B. Oxidation of acetylenes with tertbutyl hydroperoxide catalyzed by selenium dioxide. J. Org. Chem., 1979, 44, 4202-4204.

[180] Mateos, A.F.; Barrueco, O.F.; Gonzales, R.R. Synthesis of pinguisanes through furan-terminated cationic cyclization. Tetrahedron Lett., 1990, 31, 4343-4346.

[181] Bock, I.; Bornowski, H.; Rant, A.; Theis, H. New aspects in the synthesis of mono- and dialkylfurans. Tetrahedron, 1990, 46, 11991210.

[182] Desai, R.S.; Gore, V.K.; Bhat, S.V. Highly stereoselective syntheses of $a$-sinesal and trans-b-ocimenal. Synth. Commun., 1990, 20, 523-533.

[183] Schreiber, S.L.; Myers, H.V.; Wiberg, K.B. Stereochemistry of intramolecular enamine/enal (enone) cycloaddition reaction and subsequent transformations. J. Am. Chem. Soc., 1986, 108, 82748277.

[184] Singh, J.; Sharma, M.; Kadr, G.L.; Chhabra, B.R. Selective oxidation of allylic methyl groups over a solid support under microwave irradiation. J. Chem. Res., (S) 1997, 7, 264-265.

[185] Taherpour, A.; Karnal, S.B. 1,2,3-Trione compounds synthesis by oxidation of 1,3-diketone. Asian J. Chem., 2007, 19, 4107-4109.

[186] Manktala, R.; Dhillon, R.S.; Chhabra, B.R. Urea-hydrogen peroxide and microwave: An eco-friendly blend for allylic oxidationof alkenes with catalytic selenium dioxide. Indian $J$. Chem., Sect .B, 2006, 45B, 1591-1594.

[187] Tagawa, Y.; Yamashita, K.; Higuchi, Y.; Goto, Y. Improved oxidation of active methyl group of $n$-heteroaromatic compounds by selenium dioxide in the presence of tert-butyl hydroperoxide. Heterocycles, 2003, 60, 953-957.

[188] Tranel, F.; Haute, G. Claisen rearrangements based on vinyl fluorides. J. Fluor. Chem., 2004, 125, 1593-1608.

[189] Gogoi, P.; Sharma, S.D.; Konwar, D. $\mathrm{SeO}_{2} / \mathrm{H}_{2} \mathrm{O}_{2} / \mathrm{H}_{2} \mathrm{O}$-Dioxane: A new catalytic system for trans dihydroxylation of olefins. Lett. Org. Chem., 2007, 4, 249-252.

[190] Chang, M.-Y.; Lin, C.-H.; Chen, Y.-L. Selenium dioxide-mediated methoxyhydroxylation of cyclic arylolefin. Tetrahedron Lett., 2010, 51, 1430-1433.

[191] Chang, M.-Y.; Hsu, R.-T.; Cheng, H.-P.; Lin, P.-J. Concise synthesis of 3-arylpiperidines. Heterocycles, 2006, 68, 1173-1183.

[192] Knothe, G.; Glass, R.S.; Schroeder, T.B.; Bagby, M.O.; Weisleder, D. Reaction of isolated double bonds with selenium dioxide/hydrogen peroxide: formation of novel selenite esters. Synthesis, 1997, 57-60.

[193] Payne, G.B.; Smith, C.W. Reactions of Hydrogen Peroxide. II. A novel use of selenium dioxide as catalyst for the ring contraction of cycloalkanones to cycloalkane carboxylic acids. J. Org. Chem., 1957, 22, 1680-1682.
[194] Ishii, Y.; Adach, A.; Imai, R.; Ogawa, M. Hydrogen peroxide oxidation of cyclohexanone and cyclohexanone oxide in the presence of some metal oxides. Chem. Lett., 1978, 7, 611-614.

[195] Hellman, H.M.; Rosegay, A. The oxidative rearrangement of ketones to carboxylic acids. Tetrahedron Lett., 1959, (13), 1-3.

[196] Sonoda, N.; Tsutsumi, T. Hydrogen Peroxide Oxidation. I. A new selenium dioxide - catalyzed synthesis of carboxylic acids from aliphatic ketones accompanied by rearrangement of alkyl groups. Bull. Chem. Soc. Jpn., 1959, 32, 505-510.

[197] Sonoda, N.; Tsutsumi, T. Hydrogen Peroxide Oxidation. IV. A new rearrangement reaction of phenyl alkyl ketones by selenium dioxide catalyst. Bull. Chem. Soc. Jpn., 1960, 33, 1440-1443.

[198] Caspi, E.; Shimizu, Y.; Balasubrahmanyam, S.N. Oxidation of steroidal ketones. IV. Reinvestigation of selenium dioxidehydrogen peroxide oxidation of ring a saturated 3-ketones. Tetrahedron, 1964, 20, 1271-1277.

[199] Hellmann, H.M.; Jerussi, R.A. The oxidative rearrangement of $5 \alpha-$ cholestan-3-one. Tetrahedron, 1964, 20, 741-745.

[200] Guzman, J.A.; Mendoga, V.; Garcia, E.; Garibay, C.F; Olivares, L.Z.; Maldonaldo, L.A. Baeyer-Villiger Oxidation of $\tilde{b}$ aryl substituted unsaturated carbonyl compounds with hydrogen peroxide and catalytic selenium dioxide. Synth. Commun., 1995, 25, 2121-2133.

[201] Naota, T.; Sasao, S.; Tanaka, K.; Yamamoto, H.; Murahashi, S-I. Selenium and palladium-catalyzed oxidative cleavage of enelactams with hydrogen peroxide. Tetrahedron Lett., 1993, 34, 4843-4846.

[202] Nishioka, H.; Katsuno, K.; Fujii, M.; Nishita, Y.; Koshiba, N.; Harayama, T. Baeyer-Villiger reaction of benzaldehydes possessing oxygen functions with $\mathrm{SeO}_{2}-\mathrm{H}_{2} \mathrm{O}_{2}$. Yakugaku Zasshi, 1999, 119, 519-528, Chem. Abstr., 1999, 131, 144481d.

[203] Brząszcz, M.; Maposah, M.; Kloc, K.; Młochowski, J. Selenium(IV) oxide catalyzed oxidation of aldehydes to carboxylic acids with hydrogen peroxide. Synth. Commun., 2000, 30, 44254434

[204] Murahashi, S-I. and Shiota, T. Synthetic aspects of metal-catalyzed oxidations of amines and related reactions. Agnew. Chem., Int. Ed. 1995, 34, 2447-2465.

[205] Murahashi, S-I. Selenium dioxide catalyzed oxidation of secondary amines with hydrogen peroxide. Simple synthesis of nitrones from secondary amines. Tetrahedron. Lett., 1987, 28, 2383-2386.

[206] Marcantoni, E.; Petrini, M.; Polimanti, O. Oxidation of secondary amines to nitrones using urea-hydrogen peroxide complex (UHP) and metal catalyst. Tetrahedron Lett., 1995, 36, 3561-3562.

[207] Priewisch, B.; Rück-Braun, K. Efficient Preparation of nitrosoarenes for the synthesis of azobenzenes. J. Org. Chem. 2005, 70, 2350-2352.

[208] Gebhard, C.; Previsch, B.; Irran, B.; Rück-Braun, K. Oxidation of anilines with hydrogen peroxide and selenium doxide as catalyst Synthesis, 2008, 1889-1894.

[209] Kim, K.S. Hydrogen peroxide-Tellurium dioxide. In e-EROS Encyclopedia of Reagents for Organic Synthesis, Ed.; Wiley\&Sons, 2001 .

[210] Młochowski J.; Lisiak, R.; Wójtowicz-Młochowska H. In The Chemistry of Organic Selenium and Tellurium Compounds Rappaport, Z. Ed.; Wiley\&Sons: Chichester, 2011, Vol. 3, Chap. 38

[211] Kim, K.S.; Hwang, H.J.; Cheong, C.S.; Hahn, C.S. Tellurium dioxide catalyzed selective oxidation of sulfides to sulfoxides with hydrogen peroxide. Tetrahedron Lett., 1990, 31, 2893-2894.

[212] Młochowski, J.; Kloc, K.; Kubicz, E. Oxidative conversion of $N, N$ dimethylhydrazones derived from aliphatic and heteroaromatic aldehydes into nitriles with hydrogen peroxide and 3chloroperoxybenzoic acid. J. Prakt. Chem./Chem.-Ztg., 1994, 336, 467-469.

[213] Drabowicz, J.; Łyżwa, P.; Łuczak, J.; Mikołajczyk, M.; Laur, P. New procedures for the oxidation of sulfides to sulfoxides and sulfones. Phosphorus Sulfur Silicon Relat. Elem., 1997, 120-121, 425-426.

[214] Goodman, M.A.; Detty, M.R. Selenoxides as catalysts for epoxidation and baeyer-villiger oxidation with hydrogen peroxide Synlett, 2006, 1100-1104.

[215] Betzemeier, B.; Lhermitte, F.; Knochel, P. A selenium catalyzed epoxidation in perfluorinated solvents with hydrogen peroxide Synlett, 1999, 489-491. 
[216] ten Brink, G.-J.; Vis, J.M.; Arends, I.W.C.E.; Sheldon, R.A. Selenium catalyzed oxidations with aqueous hydrogen peroxide. Part 3. Oxidation of carbonyl compounds under mono/bi/triphasic conditions. Tetrahedron, 2002, 58, 3977-3983.

[217] Santoro, S.; Santi, C.; Sabatini, M.; Testaferi L.; Tiecco, M. EcoFriendly olefin dihydroxylation catalyzed by diphenyl diselenide. Adv. Synth. Catal., 2008, 350, 2881-2884.

[218] Back, T.G.; Moussa, Z. Diselenides and allyl selenides as glutathione peroxidase mimetics. J. Am. Chem. Soc., 2003, 125, 13455-13460.

[219] Back, T.G.; Kuzma, D.; Parvez, M. Aromatic derivatives and tellurium analogues of cyclic seleninate esters and spirodioxyselenuranes that act as glutathione peroxidase mimetics. J. Org. Chem., 2005, 70, 9230-9236.

[220] Press, D.J.; Mercier, E.A.; Kuzma, D.; Back, T.G. Substituent effects upon the catalytic activity of aromatic cyclic seleninate esters and spirodioxyselenuranes that act as glutathione peroxidase mimetics. J. Org. Chem., 2008, 73, 4252-4255.

[221] Francavilla, G.; Drake, M.D.; Bright, F.V.; Detty, M.R. Dendrimeric organochalcogen catalysts for the activation of hydrogen peroxide: improved catalytic activity through statistical effects and cooperativity in succesive generation. J. Am. Chem. Soc., 2001, 123, 57-67.

[222] Drake, M.D.; Bright, F.V.; Detty, M.R. Dendrimeric organochalcogen catalysts for the activation of hydrogen peroxide: origins of the "dendrimeric effect" with catalysts terminating phenylseleno groups. J. Am. Chem. Soc., 2003, 125, 12558-12566.

[223] Bennett, S.M.; Tang, Y.; McMaster, D.; Bright, F.V.; Detty, M.R. A xerogel-sequestered selenoxide catalyst for bromination with hydrogen peroxide and sodium bromide in an aqueous environment. J. Org. Chem., 2008, 73, 6849-6852.

[224] Reichel, L.; Kirschbaum, E. Über aromatische tellurverbindungen. i. mitteilung über organometallverbindungen. Liebigs, Ann. Chem., 1936, 523, 211-223.

[225] Brill, W.F. A site isolated tellurium oxidation catalyst having no soluble analog. J. Org. Chem., 1986, 51, 1149-1150.

[226] Engman, L.; Stern, D.; Cotgreave, I.A.; Anderson, C.M. Thiol peroxidase activity of diaryl ditellurides as determined by a proton NMR. J. Am. Chem. Soc., 1992, 114, 9737-9743.

[227] Freudendahl, D.M.; Shahzad, S.A.; Wirth, T. Recent advances in oragnoselenium chemistry. Eur. J. Org. Chem., 2009, 1649-1664.

[228] Młochowski, J.; Brząszcz, B.; Giurg, M.; Palus, J.; Wójtowicz, H. Selenium-promoted oxidation of organic compounds: reactions and mechanisms. Eur. J. Org. Chem., 2003, 4329-4339.

[229] Młochowski, J.; Brząszcz, B.; Chojnacka, M.; Giurg, M.; Wójtowicz, H. Diaryl diselenides and bezisoselenazol-3(2H)-ones as oxygen-transfer agents. Arkivoc, 2004, (iii), 226-248.

[230] van der Toorn, J.C.; Kemperman, G.; Scheldon, R.A.; Arends, I.W.C.E. Diphenyl diselenide-catalyzed selective oxidation of activated alcohols with tert-butyl hydroperoxide: new mechanistic insights. J. Org. Chem., 2009, 74, 3085-3089.

[231] Zhao, D.; Johansson, M.; Bäckvall, J.E. In situ generation of nitroso compounds from cartalytic hydrogen peroxide oxidation of primary aromatic amines and their one-pot use in hetero-diels-alder reactions. Eur. J. Org. Chem., 2007, 4431-4436.

[232] Kalsi, P.S.; Chhabra, B.R.; Singh, J.; Vig, R. Selective oxidation of primary allylic alcohols to $a, b$-unsaturated aldehydes. Synlett, 1992, 1992, 425-426.

[233] Reich, H.J.; Chow, F.; Peake, S.L. Seleninic acids as catalysts for oxidation of olefins and sulfides using hydrogen peroxide. Synthesis, 1978, 299-300.

[234] Kubicz, E.; Młochowski, J.; Syper, L. Oxidation of styrene and its analogues with hydrogen peroxide activated by organoselenium compounds. J. Prakt. Chem., 1991, 333, 243-247.

[235] Syper, L. The baeyer-villiger oxidation of aromatic aldehydes and ketones with hydrogen peroxide catalyzed by selenium compounds. A convenient method for the preparation of phenols. Synthesis, 1989, 167-171.

[236] Syper, L. Reaction of $a, b$-unsaturated aldehydes with hydrogen peroxide catalyzed by benzeneseleninic acids and their precursors. Tetrahedron, 1987, 43, 2853-2871.

[237] Ichikawa, H.; Usami, Y.; Arimoto, M. Synthesis of novel organoselenium compounds as catalysts for Baeyer-Villiger oxidation with $30 \% \mathrm{H}_{2} \mathrm{O}_{2}$. Tetrahedron Lett., 2005, 46, 8665-8668.
[238] Said, S.B.; Skarżewski, J.; Młochowski, J. conversion of aldehydes into nitriles via oxidation of their dimethylhydrazones. Synthesis, 1989, 223-224.

[239] Syper, L.; Młochowski, J. Benzeneperoxyseleninic acids synthesis and properties. Tetrahedron, 1987, 43, 207-213.

[240] Syper, L.; Młochowski, J. Lithum diselenide in aprotic medium - a convenient reagent for synthesis of organic diselenides. Tetrahedron, 1988, 44, 6119-6130.

[241] Giurg, M.; Syper, L. Diaryl diselenides and related compounds as oxygen-transfer agents. Phosphorus Sulfur Silicon Relat. Elem., 2008, 183, 970-985.

[242] Giurg, M.; Syper, L.; Młochowski, J. Hydrogen peroxide oxidation of naphtalene derivatives catalyzed by poly(bis-1,2-diphenylene) diselenide. Polish J. Chem., 2004, 78, 231-238.

[243] Młochowski, J.; Giurg, M.; Kubicz, E.; Said, S.B. Benzisoselenazol-3(2H)-ones and bis(2-Carbamoyl)phenyl diselenides as new catalysts for hydrogen peroxide oxidation of organic compounds. Synth. Commun., 1996, 26, 291-300.

[244] Palus, J.; Młochowski, J.; Juchniewicz, L. 2,2'Diselenobisbenzoates and 2,2'-diselenobissulfonates, new chiral aryldiselenides. Polish J. Chem., 1998, 72, 1931-1936.

[245] Giurg, M.; Said, S.B.; Syper, L.; Młochowski, J. One-pot oxidation of azomethine compounds into arene carboxylic acids. Synth. Commun., 2001, 31, 3151-3159.

[246] Giurg, M.; Młochowski, J. Oxidative ring contraction of cycloalkanones: a facile method for synthesis of medium ring cycloalkanecarboxylic acids. Synth. Commun., 1999, 29, 22812291.

[247] Giurg, M.; Kowal, E.; Muchalski, H.; Syper, L.; Młochowski, J. Catalytic oxidative domino degradation of alkyl phenols towards 2and 3-substituted muconolactones. Synth. Commun., 2009, 39, 251 256.

[248] ten Brink, G.-J.; Martijn, J.-M.; Vis, J.-H.; Arends, I.W.C.E.; Sheldon, R.A. Selenium-catalyzed oxidations with aqueous hydrogen peroxide. 2 . baeyer-villiger reactions in homogenous solution. J. Org. Chem., 2001, 66, 2429-2433.

[249] ten Brink, G.-J.; Fernandes, B.C.M.; van Vliet, M.C.A.; Arends, I.W.C.E.; Sheldon, R.A. Selenium catalyzed oxidations with aqueous hydrogen peroxide. Part I. Epoxidation reactions in homogenous solution. J. Chem. Soc., Perkin Trans. 1, 2001, 224228.

[250] Drake, M.D.; Bateman, M.A.; Detty, M.R. Substituent effects in arylseleninic acid-catalyzed bromination of organic substrates with śodium bromide and hydrogen peroxide. Organometallics, 2003, $22,4158-4162$.

[251] Goodmanm, M.A.; Detty, M.R. Selenoxides as catalysts for the activation of hydrogen peroxide. Bromination of organic substrates with sodium bromide and hydrogen peroxide. Organometallics, 2004, 23, 3016-3020.

[252] Młochowski, J. Developments in the chemistry of selenoheterocyclic compounds of practical importance. Phosphorus Sulfur Silicon Relat. Elem., 2008, 183, 931-938.

[253] Młochowski, J.; Giurg, M. In Topics in Heterocyclic Chemistry; Gupta, R.R., Ed.; Springer-Verlag: Berlin Heilderberg, 2009, Vol. 19, pp. 287-340.

[254] Młochowski, J. In Comprehensive Heterocyclic Chemistry III; Katritzky, A.; Ramsden, C.; Scriven, E.F.V. and Taylor R.J.K., Eds.; Elsevier: Oxford, 2008, Vol. 4, Chap. 4.07, pp. 755-789.

[255] Wójtowicz, H.; Brząszcz, M.; Kloc, K.; Młochowski, J. Selective oxidation of aromatic aldehydes to arenecarboxylic acids using ebselen-tert-butyl hydroperoxide catalytic system. Tetrahedron, 2001, 57, 9743-9748.

[256] Said, S.B.; Skarżewski, J.; Młochowski, J. Oxidative conversion of aldoximes into carboxylic acid esters. Synth. Commun., 1992, 22, 1851-1862.

[257] Giurg, M.; Wójtowicz, H.; Młochowski, J. Hydroperoxide oxidation of azomethines and alkylarenes catalyzed by ebselen. Polish J. Chem., 2002, 76, 537-542.

[258] Brząszcz, M.; Kloc, K.; Młochowski, J. Hydroperoxide oxidation of benzylamines catalyzed by selenium compounds. Polish J. Chem. 2003, 77, 1579-1586.

[259] Wójtowicz, H.; Młochowski, J. Oxidation of hydrocarbons with tert-butyl hydroperoxide promoted by organoselenium compounds. Ann. Polish Chem. Soc., 2001, 74-78.

[260] Brząszcz, M. PhD Thesis, Wrocław University of Technology, 2004. 
[261] Wójtowicz, H.; Młochowski, J.; Syper, L.; Yadav, H.S. $t$-Butyl Hydroperoxide oxidative dealkylation of hydroquinone ethers to 1,4-Quinones. Synth. Commun., 2006, 36, 1991-2000.

[262] Giurg, M.; Wiech, E.; Piekielska, K.; Gębala, M.; Młochowski, J.; Wolański, M.; Ditkowski, B.; Peczyńska-Czoch, W. A new approach to synthesis of questiomycin a: oxidative cyclocondensation of ortho-aminophenol. Polish J. Chem., 2006, 80, 297-306.

[263] Wójtowicz-Młochowska, H.; Soroko, G.; Młochowski, J. New recoverable organoselenium catalyst for hydroperoxide oxidation of organic substrates. Synth. Commun., 2008, 38, 2000-2010.

[264] Giurg, M.; Brząszcz, M.; Młochowski, J. Hdroperoxide oxidation of different organic compounds catalyzed by silica-supported selenenamide. Polish J. Chem., 2006, 80, 417-428.

[265] Młochowski, J.; Kloc, K.; Syper, L.; Inglot, A.D.; Piasecki, E. Aromatic and azaaromatic diselenides, benzisoselenazolones and related compounds active in humans: Synthesis and properties. Liebigs Ann. Chem., 1993, 1239-1244.

[266] Pfeiffer, W.D. Annulated selenazole compounds. Sci. Synth., 2001, 11,931-940.

[267] Reddy K.R., Maheswari C.U.; Venkateshwar M.; Kantam M.L. Oxidative amidation of aldehydes and alcohols with primary amines catalyzed by KI-TBHP. Eur. J. Org. Chem., 2008, 36193622.

[268] Reddy, K.R.; Maheswari, C.U.; Venkateshwar, M.; Prashanti, S.; Kantam, M.L. Catalytic oxidative conversion of alcohols, aldehydes and amines into nitriles using $\mathrm{KI} / \mathrm{I}_{2}$-TBHP system. Tetrahedron Lett., 2009, 50, 2050-2053.

[269] Reddy, K.R.; Maheswari, C.U.; Venkateshwar, M.; Kantam, M.L. Selective oxidation of aromatic amines to nitro derivatives using potassium iodide-tert-butyl hydroperoxide catalytic system. $A d v$. Synth. Catal., 2009, 351, 93-96.

[270] Barluenga, J.; Marco-Arias, M.; Gonzalez-Bobes, F.; Ballesteros, A.; Gonzalez, J.M. New reactions in water: metal-free conversion of alcohols and ketones into $a$-iodoketones. Chem. Commun., 2004, 2616-2617.

[271] Kropp, P.J.; Breton, G.W.; Fields, J.D.; Tung, J.C.; Loomis, B.R. Surface-mediated reactions. 8. Oxidation of sulfides to sulfoxides with tert-butyl hydroperoxide and OXONE. J. Am. Chem. Soc., 2000, $122,4280-4285$.

[272] Sato, K.; Hyodo, M.; Takagi, J.; Aoki, M.; Noyori, R. Hydrogen peroxide oxidation of aldehydes to carboxylic acids: an organic solvent-, halide- and metal-free procedure. Tetrahedron Lett., $\mathbf{2 0 0 0 ,}$ 41, 1439-1442.

[273] Jang, N.; Ragauskas, A.J. TEMPO-catalyzed oxidation of benzylic alcohols to aldehydes with the $\mathrm{H}_{2} \mathrm{O}_{2} / \mathrm{HBr}$ /ionic liquid [bmim] $\mathrm{PF}_{6}$ system. Tetrahedron Lett., 2005, 46, 3323-3326.

[274] Faber, K. Biotransformation in organic chemistry. Springer: Heidelberg, 2004.

[275] Buchholtz, K; Kasche, V.; Bomscheuer, M. Biocatalysis and Enzyme Technology; Wiley-VCH: Veinheim, 2005.

[276] Pollard, D.J.; Woodley, J.M. Biocatalysis for pharmaceutical intermediates: the future is now. Trends Biotechnol., 2007, 25, 6673.

[277] Faber, K.; Kroutil, W. New enzymes for biotransformation. Curr. Opin. Chem. Biol., 2005, 9, 181-187.

[278] Ayala, M; Pickard, A.M.; Vasquez-Duhalt, R. Fungal enzymes for environmental purposes, a molecular biology challenge. J. Mol. Microbiol. Biotechnol., 2008, 15, 172-180.

[279] Torres, E.; Ayala, M. Biocatalysis Based on Heme Peroxidases, Peroxidases as Potential Industrial Biocatalysts, Springer: Heidelberg, 2010.

[280] Adam, W.; Lazarus, M.; Saha-Moller, C.R.; Weichold, U.; Haring, D.; Schreier, P. Biotransformations with peroxidases. Adv. Biotech. Eng./Biotechnol., 1999, 63, 73-108.

[281] Ryjan, B.J.; Carolan, N.; O'Fagalin, C. Horseradish and soy bean peroxidases: comparable tools for alternative niches. Trends Biotechnol., 2006, 24, 355-363.

[282] Colonna, S.; Gaggero, N.; Richelmini, C.; Pasta, P. Recent biotechnological development in the use of peroxidases. TIBITECH, 1999, 17, 163-138.

[283] Veith, N.C. Horseradish peroxidase: a modern view of classic enzyme. Phytochemistry, 2004, 65, 249-259.

[284] Eerseles, J.L.H.; Travis, M.; Herscheid, M. Manufacturing I-123labelled radiopharmaceuticals. pitfalls and solutions. J. Label. Compd. Radiopharm., 2005, 48, 241-243.
[285] Azevedo, A.M; Martins, V.C.; Prazeres, D.M.; Voijnovic, V.; Cabral, J.M; Fonseca, L.P. Horseradish peroxidase, a valuable tool in biochemistry. Biotechnol. Ann. Rev., 2003, 9, 199-247.

[286] Conesa, A.; van de Velde, F.; van Rantwijk, F.; Sheldon, R.A.; Cees, A.M.; van den Hondel, J.J.; Punt, P.J. Expression of the Caldariomyces fumago chloroperoxidase in Aspergillus niger and characterization of the recombinant enzyme. J. Biol. Chem., 2001, 276, 17635-17640.

[287] Messerschmidt, L.; Prade, L.; Wever, R. Implications for the catalytic mechanism of the vanadium - containing chloroperoxidase from the fungus Curvularia inequalis by X-ray structures of the native and peroxide form. Biol. Chem., 1997, 378, 309-315.

[288] ten Brink, H.B.; Schoemaker H.; Wever, R. Sulfoxidation mechanism of vanadium bromoperoxidase from Ascophyllium nodosum: Evidence for the direct oxygen transfer catalysis. Eur. J. Biochem., 2001, 68, 132-138.

[289] Flohe, L.; Gunzler, W.A.; Schock H.H. Glutathione peroxidase: a selenoenzyme. FEBS Lett., 1973, 32, 132-134.

[290] Hofrichrer, M.; Ulrich, R.; Pecyna, M.J.; Liers, C.; Lundell, T. New and classic families of secreted fungal heme peroxidases. Appl. Microbiol. Biotechnol., 2010, 87, 871-897.

[291] Hammel K.E.; Cullen, D. Role of fungal peroxidases in biological ligninolysis. Curr. Opin. Plan. Biol., 2008, 11, 349-355.

[292] van Deurzen, M.P.J.; van Rantvijk, F.; Sheldon, R.A. Selective oxidations catalysed by peroxidases. Tetrahedron, 1997, 53, 13183-13220.

[293] Dembitsky, V.M. Oxidation, epoxidation and sulfoxidation reactions catalysed by haloperoxidases. Tetrahedron, 2003, 59, 4701-4720.

[294] Morgenstern, I.; Klopman, S.; Hibbett, D.S. Molecular evolution and diversity of lignin degrading heme peroxidases in the Agaricomycetes. J. Mol. Evol., 2008, 66, 243-257.

[295] Butler, A.; Carter-Franklin, J.N. The role of vanadium bromoperoxidase in the biosynthesis of halogenated marine products. Nat. Prod. Rep., 2004, 21,180-188.

[296] Casella, L.; Poli, S.; Gullotti, M.; Sevalgini, C.; Beringhelli, T.; Marchesini, A. The chloroperoxidase - catalysed oxidation of phenols. Mechanism, selectivity and characterization of enzymesubstrate complex. Biochemistry, 1994, 33, 6377-6381.

[297] Conesa, A.; Punt, P.J.; van den Hondel, C.A. Fungal peroxidases: molecular aspects and application. J. Biotechnol., 2002, 93, 143158.

[298] Nazari, K.; Esmaeili, N.; Mahmoudi A.; Rahimi, H.; MoosaviMovahedi A.A. Peroxidative phenol removal from aqueous solutions using activated peroxidase biocatalyst. Enzyme Microb. Technol., 2007, 41, 226-233.

[299] Reichman, M.; Ritter, H. Synthesis of phenol polymers using peroxidases. Adv. Polym. Sci., 2006, 194, 1-49.

[300] Ujama, K.; Kobayashi, S. Enzyme-catalyzed polymerization to functional polymers. J. Mol. Catal. B: Enzym., 2002, 19-20, 117127.

[301] An, E.S.; Cho, D.H.; Choi, J.W.; Kim, Y.H.; Song, B.K. Peroxidase-catalysed copolymerisation of syringaldehyde and bisphenol A. Enzyme Microb. Technol., 2010, 46, 287-291.

[302] Donelly, M.X.; Murphy, F.G.; Polonsky, J.; Prange T. Enzymemediated $\mathrm{H}_{2} \mathrm{O}_{2}$ oxidation of $(E)$ - stilbene-3,4-diol. J. Chem. Soc. Perkin Trans. 1, 1987, 2719-2722.

[303] Goodbody, A.E.; Endo, T.; Vukovic, J.; Kutney, J.P.; Choi, L.S.K.; Misawa, M. Enzymic coupling of catharanthine and vindoline to form 3', 4'-anhydrovinblastine by horseradish peroxidase. Planta Med., 1988, 136-139.

[304] Schen, Y.P.; Sun, J.Z.; Wu, J.G.; Zhou, Q.Y.J. Synthesis and characterization of water-soluble conducting polyanilines by enzyme catalysis. Appl. Polym. Sci., 2005, 96, 814-817.

[305] Giurg, M.; Piekielska, K.; Gębala, M.; Ditkowski, B.; Wolański, M.; Peczyńska-Czoch, W.; Młochowski, J. Catalytic oxidative cyclocondensation of $\mathrm{o}$-aminophenols to 3 -amino- $3 \mathrm{H}$ phenoxazinones. Synth. Commun., 2007, 37, 1779-1789.

[306] Graf, E.; Schneider, K.; Nicholson, G.; Strobel, M.; Jones, A.L.; Goodfellow, M.; Beil, W.; Fiedler, H.P. Elloxazinones A and B, new aminophenoxazinones from Streptomyces griseus Acta 2871. J. Antibiotics, 2007, 60, 277-284.

[307] Chen, H; Liu, X.; Patel, D.J. DNA bending and unwinding associated with actinomycin D antibiotics bound to partially overlapping sites on DNA. J. Mol. Biol. , 1966, 258, 457-479. 
[308] Kim, B.B.; Pisarev, V.; Egorov, A.M. A comparative study of peroxidases from horse radish and Arthromyces ramosus as labelles in luminol-mediated chemiluminescent assays. Anal. Biochem., 1991, 199, 1-6.

[309] Hammel, K.E.; Cullen, D. Role of fungal peroxidases in biological ligninolysis. Curr. Opin. Plant Biol., 2008, 11, 349-355.

[310] Meunier, G.; Meunier, B. Evidence for an efficient demethylation of methoxyellipticine derivatives catalyzed by peroxidase. $\mathrm{J}$. Am. Chem. Soc., 1985, 107, 2558-2560.

[311] Baciocchi, E.; Gerini, M.F.; Lanzalunga, A.; Lappi, L.A.; Mancinelli, S.; Mencarelli, P. Oxidative $N$-demethylation of $N, N$ dimethylanilines catalyzed by lignin peroxidase: a mechanistic insight by kinetic deuterium isotope effet study. Chem. Commun., 2000, 393-395.

[312] Bodalo, A.; Gomez, J. L.; Gomez, E.; Bastyda, J.; Malimo, M.F. Comparison of commercial peroxidases for removing phenol from water solutions. Chemosphere, 2006, 63, 626-632.

[313] Cheng, X.; Jia, R.; Li, P.; Tu, S.; Zhu, Q.; Tang, W.; Li, X. Purification of a new manganese peroxidase of the white-rot fungus Schizophyllum sp.F17, and decolorization of azo dyes by the enzyme. Enzyme Microb. Technol., 2007, 41, 258-264.

[314] Zhou, M.; Diwi, Z.; Panhuk-Voloshina, N.; Haugland, R.A. Stable nonfluorescent derivative of resorufin for the fluorometric determination of trace hydrogen peroxide: applications in detecting the activity of phagocyte NADP oxidase and other oxidases. Anal. Biochem., 1997, 253, 162-168.

[315] Fiamegos, Y.; Stalikas, C.; Pilidis, G. 4-Aminoantipyrine spectrophotometric method of phenol analysis: study of the reaction products via liquid chromatography with diode arrays and mass spectrometric detection. Anal. Chem. Acta, 2002, 467, 105114.

[316] Winter, J.M.; Moore, B.S. Exploring the chemistry and biology of vanadium-dependent haloperoxidases. J. Biol. Chem., 2009, 284, 18577-18581.

[317] Bailey, G. The Protein Protocols Handbook; Walker, J.W., Ed.; Hatfield, Humana Press Inc.: Totowa, New Jersey, 2002, p. 967.

[318] Gładek, A.; Mordarski, M. Enzymatic method of incorporation of I-125 into DNA. Arch. Immunol. Ther. Exp., 1983, 31, 541-550.

[319] Kevin, K.; Liu, C.; Wong, C.H. Enzymatic halohydration of glycals. J .Org. Chem., 1992, 57, 3748-3750.

[320] Zaks, A.; Dodds, D.R. Chloroperoxidase-catalysed asymmetric: substrate specificity and mechanistic study. J. Am. Chem. Soc., 1995, 177, 10419.

[321] Wojaczyńska, E.; Wojaczyński, J. Enantioselective synthesis of sulfoxides: 2000-2009. Chem. Rev., 2010, 110, 4303-4356.

[322] Allenmark, S.G.; Andersson, M.A. Chloroperoxidase-induced asymmetric sulfoxidation of some conformationally restricted sulfides. Chirality, 1998, 10, 246.

[323] Valderrama, B.; Ayala, M.; Vazquez-Duhalt, R. Suicide inactivation of peroxidases and the chalenge of engineering more robust enzyme. Chem. Biol., 2002, 9, 555-560.

[324] Lutz, S.; Steckhan, E.; Liese, A. First asymmetric electroenzymatic oxidation catalyzed by a peroxidase. Electrochem. Commun., 2004, $6,583-587$.

[325] van der Velde, F.; Lourenco, N.D.; Bakker, M.; van Rantwijk, F.; Sheldon, R.A. Improved operational stability of peroxidases by immobilization with glucose oxidase. Biotech. Bioeng., 2000, 69, 286-290.

(C) Młochowski et al.; Licensee Bentham Open.

This is an open access article licensed under the terms of the Creative Commons Attribution Non-Commercial License (http://creativecommons.org/licenses/by-nc/ 3.0/) which permits unrestricted, non-commercial use, distribution and reproduction in any medium, provided the work is properly cited. 